AD

\title{
AN EVALUATION OF THE ENVIRONMENTAL FATE AND BEHAVIOR OF MUNITIONS MATERIEL (TNT, RDX) IN SOIL AND PLANT SYSTEMS
}

\section{Environmental Fate and Behavior of TNT}

\author{
Final Report \\ Dominic A. Cataldo \\ Scott D. Harvey \\ Robert J. Fellows \\ Roger M. Bean \\ Bruce D. McVeety
}

\section{August 1989}

\section{Supported by:}

U.S. Army Medical Research and Development Command

Fort Detrick, Frederick, MD 21701-5012

Project Order No. 88PP8853

\author{
Pacific Northwest Laboratory \\ Richland, Washington 99352 \\ Operated for the U.S. Department of Energy \\ by Battelle Memorial Institute
}

Approved for public release;

distribution unlimited

\footnotetext{
The findings of this report are not to be construed as official Department of the Army positions unless so designated by other authorized documents
} 


\title{
DISCLAIMER
}

This report was prepared as an account of work sponsored by an agency of the United States Government. Neither the United States Government nor any agency thereof, nor Battelle Memorial Institute, nor any of their employees, makes any warranty, expressed or implied, or assumes any legal itability or responsibility for the accuracy, completeness, or usefulness of any information, apparatus, product, or process disclosed, or represents that its use would not infringe privately owned rights. Reference herein to any specific commercial product, process, or service by trade name, trademark, manufacturer, or otherwise, does not necessarily constitute or imply its endorsement, recommendation, or favoring by the United States Government of any agency thereof, or Battelie Memorial Institute. The views and opinions of authors expressed herein do not necessarily state or reflect those of the United States Government or any agency thereof.

\author{
PACIFIC NORTHWEST LABORATORY \\ operated by \\ BATTELLE MEMORIAL INSTITUTE \\ for the \\ UNITED STATES DEPARTMENT OF ENERGY \\ under Contract DE-ACO6-76RLO 1830
}

Printed in the United States of America

Available to DOE and DOE contractors from the

Office of Scientific and Technical Information, P.O. Box 62, Oak Ridge, TN 37831;

prices available from (615) 576-8401. FTS 626-8401.

Available to the public from the National Technical Information Service,

U.S. Department of Commerce, 5285 Port Royal Rd., Springfield, VA 22161.

NTIS Price Codes, Microfiche A01

Printed Copy

\begin{tabular}{cr}
\hline Price Code & Page Range \\
\hline A02 & $1-10$ \\
A03 & $11-50$ \\
A04 & $51-75$ \\
A05 & $76-100$ \\
A06 & $101-725$ \\
A07 & $126-150$ \\
A06 & $151-175$ \\
A09 & $176-200$ \\
A10 & $201-225$ \\
A11 & $226-250$ \\
A12 & $251-275$ \\
A13 & $276-300$ \\
A14 & $301-325$
\end{tabular}

\begin{tabular}{cc}
\hline Price Code & Page Range \\
\hline A15 & $326-350$ \\
A16 & $351-375$ \\
A17 & $376-400$ \\
A18 & $401-425$ \\
A19 & $426-450$ \\
A20 & $451-475$ \\
A21 & $476-500$ \\
A22 & $501-525$ \\
A23 & $526-550$ \\
A24 & $551-575$ \\
A25 & $576-600$ \\
A99 & $601-\mathrm{Up}$
\end{tabular}




\section{AN EVALUATION OF THE ENVIRONMENTAL FATE AND BEHAVIOR OF MUNITIONS MATERIEL (TNT, RDX) IN SOIL AND PLANT SYSTEMS \\ Environmental Fate And Behavior of TNT}

\section{Final Report}

Dominic A. Cataldo, Ph. D.

Scott Harvey, Ph. D.

Robert J. Fellows, Ph. D.

Roger M. Bean, Ph. D.

Bruce D. McVeety, Ph. D.

\section{AUGUST 1, 1989}

Supported by:

U.S. Army Medical Research and Development Command

Fort Detrick, Frederick, MD 21701-5012

Project Order No. 88PP8853

Pacific Northwest Laboratory

Richland, Washington 99352

Operated for the U.S. Department of Energy by Battelle Memorial Institute

Project Officer: Wayne R. Mitchell

U.S. Army Biomedical Research and Development Laboratory

Fort Detrick, Frederick, MD 921701-5010

Approved for public release; distribution unlimited

\footnotetext{
The findings of this report are not to be construed as official Department of the ArrTy position uniess so designated by other authorized documents
} 

REPORT DOCUMENTATION PAGE

\begin{tabular}{|c|c|c|c|c|}
\hline $\begin{array}{l}\text { 14. REPOAT SECURITY CLASSIFICATION } \\
\text { Unclass ified }\end{array}$ & & Ib. RESTRICTIVE MARKINGS & & \\
\hline $\begin{array}{l}\text { 20. SECURITY CLASSIFICATION AUTHORITY } \\
\text { 2b. DECLASSIFICATION/DOWNGRADING SCHEDU }\end{array}$ & & $\begin{array}{l}\text { 3. OISTRIBUTION I AVALABEI } \\
\text { Approved for pul } \\
\text { distribution un }\end{array}$ & $\begin{array}{l}\text { REPO } \\
\text { rele } \\
\text { ed }\end{array}$ & \\
\hline $\begin{array}{l}\text { 4. PERFORMING ORGANIZATION REPORT NUMBE } \\
\text { Pacific Northwest Laboratories }\end{array}$ & R(S) & 5. MONITORING ORGANIZA & PORT & \\
\hline $\begin{array}{l}\text { 6a. NAME OF PERFORMING ORGANIZATION } \\
\text { Pacific Northwest Laboratories }\end{array}$ & $\begin{array}{l}\text { 6b. OFFICE SYMBOL } \\
\text { (If dppolicabie) }\end{array}$ & 7a. NAME OF MONITORING & VIZATIC & \\
\hline $\begin{array}{l}\text { 5c. ADORESS (City, State, and Zil Code) } \\
\text { Richland, WA } 99352\end{array}$ & & 7b. ADORESS (City, State, di & .ode) & \\
\hline $\begin{array}{l}\text { 8a. NAME OF FUNDING / SPONSORING } \\
\text { ORGANIZATION U.S. Army Medica } 1 \\
\text { Research \& Development Comunand }\end{array}$ & $\begin{array}{l}\text { 8b. OFFICE SYMBOL } \\
\text { (If applicable) }\end{array}$ & $\begin{array}{l}\text { 9. PROCUREMENT INSTRUM } \\
\text { Amy Project ord }\end{array}$ & $\begin{array}{l}\text { INTIFIC } \\
88\end{array}$ & UBER \\
\hline 8C AODRESS (City, State, and ZIP Code) & & 10. SOURCE OF FUNDING $\mathrm{N}$ & & \\
\hline $\begin{array}{l}\text { Fort Detrick } \\
\text { Frederick, MD 21701-5012 }\end{array}$ & & \begin{tabular}{l|l} 
PROGRAM & PROJECT \\
ELEMENT NO. & NO.
\end{tabular} & $\begin{array}{l}\text { TASK } \\
\text { NO. }\end{array}$ & $\begin{array}{l}\text { WORK UNIT } \\
\text { ACCESSION NO. }\end{array}$ \\
\hline
\end{tabular}

1i. IITLE (Include Security Classification) in Soil and Plant Systems

12. PERSONAL AUTHOR(S)

Dominic A. Cataido, Scott D. Harvey, Robert J. Fellows, Roger M. Bean, and Bruce D. McVeety

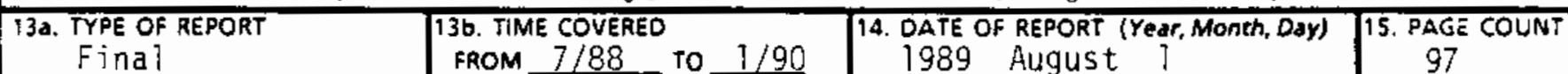

16. SUPPLEMENTARY NOTATION

Subtitle: Environmental Fate and Behavior of TNT

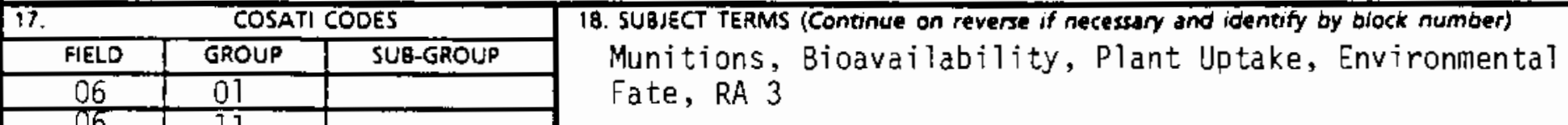

19. ABSTAACT (Continue on reverse if necessary and identify by block number)

The objective of these investigations was to elucidate the environmental behavior and fate of trinitrotoluene (TNT). Emphasis was placed on those chemical transformations occurring in soils and in plant tissues following uptake and on the probable impact of these chemical transformations on the food chain. Analytical methodology was developed to fractionate and characterize both TNT and TNT-derived residues in soil and plant matrices. The procedures developed in this program extend prior art, through the use of matrix-specific extraction and fractionation schemes followed by classical HPLC separations. Methods showed good recovery and reproducibility.

Soil-sorbed TNT, or that fraction not readily removed by exhaustive extraction, increases from less than $6 \%$ at 0 time, to $50 \%$ after 60 days of incubation. Experiments with sterile soil systems indicate that the sorption process is nonbiotic in origin. Mass balance deficits in non sterile soils can be accounted for (Continued on reverse side)

20. DISTRIBUTION/AVALABILITY OF ABSTRACT $\square$ UNCLASSIFFEDNNLIMITED CO SAME AS RPT.

22a. NAME OF RESPONSIBTE INOIVIDUAL Mary Frances Bostian

DD Form 1473, JUN 86
21. ABSTRACI SECURITY CLASSIFICATION Unclassified

22b. TELEPHONE (Inciude Ared Code) 22C. OFFICE SYMBOL $301-663-7325$ SGRD-RMI - S
SECURITY CLASSIFICATION OF THIS PAGE

UNCLASSIFIED 


\section{Abstract (Cont.)}

by microbial oxidation of TNT to $\mathrm{CO}^{2}$. Estimates of soil half-life for TNT-residues, based on $\mathrm{CO}^{2}$ evolution rates, range from 4 to 10 years for the soils studied. Of the extractable TNT-derived residues, the content of 2,4,6-trinitrotoluene decreases to $30 \%$ after 60 days incubation, depending on soil type. Five additional TNT-derived residues isolated from soil following 60 days' incubation make up the balance of the extractable material amended to soil. Mass spectrometry showed TNT-derived transformation products to include two aminodinitrotoluene (AMDNT) isomers (2-amino-4,6-dinitrotoluene and 4-amino-2,6dinitrotoluene), nitroazotoluene, and two unidentified products unique to individual soils. After 60 days of incubation, the two AMDNT compounds account for $>80 \%$ of the TNT-derived activity. Similar transformation patterns were observed for the sterile soils, indicating that these chemical transformations are nonbiotic in origin.

Experiments with hydroponic systems showed that the absorption capacity for plants is high. Total uptake into plant tissues is directly related to the concentration of TNT to which roots are exposed. Results indicate that both TNT and AMDNT are root absorbed. Following root absorption, greater than $75 \%$ of the accumulated residues are retained within the root. Of the total TNT residues recovered from plant tissues, less than $20 \%$ are recovered within the nonpolar TNT and TNT-residue fraction, and consist primarily of AMDNTs. The remainder represent highly polar or nonextractable components. Analysis of acidhydrolyzed and nonhydrolyzed tissue extracts indicates that TNT-derived plant-accumulated products are stored and transported as polar conjugates.

Studies on TNT-amended soils with plants grown to maturity show TNT-derived metabolites to accumulate in all tissues. The relative order of concentration is root $>$ stem $>$ leaves $>>$ seed and pod. Total plant concentration is highly dependent on soil type or soil-available-TNT concentrations. In all cases, plant uptake was inversely proportional to soil organic-matter content as reflected in Burbank, Palouse, and Cinebar soils. The chemistry of accumulated residues shows patterns similar to the hydroponic studies, with principal components identified as TNT and AMDNT isomers. 


\section{FOREWARD}

Opinions, interpretations, conclusions and recommendations are those of the author and are not necessarily endorsed by the U.S. Army.

$\frac{X}{\text { Where copyrighted materiat is quoted, permission has been }}$
obtained to use such material.

$x$ Where material from documents designated for limited distribution is quoted, permission has been obtained to use the material.

X Citations of commercial organizations and trade names in this report do not constitute an official Department of the Army endorsement or approval of the products or services of these organizations.

$\underline{X}$ In conducting research using animals, the investigator (s) adhered to the "Guide for the Care and Use of Laboratory Animals," prepared by the Committee on Care and Use of Laboratory Animals of the Institute of Laboratory Animal Resources, National research Council (NIH Publication No. 86-23. Revised 1985.)

$X$ For the protection of human subjects, the investigator (s) have adhered to policies of applicable Federal law 45CFR46.

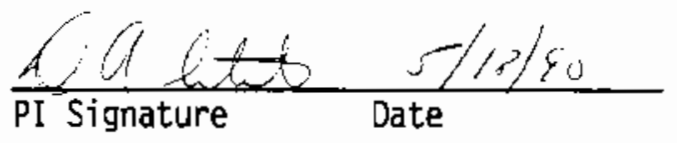



The objective of these investigations was to elucidate the environmental behavior and fate of trinitrotoluene (TNT). Emphasis was placed on those chemical transformations occurring in soils and in plant tissues following uptake and on the probable impact of these chemical transformations on the food chain. Analytical methodology was developed to fractionate and characterize both TNT and TNT-derived residues in soil and plant matrices. The procedures developed in this program extend prior art, through the use of matrix-specific extraction and fractionation schemes followed by classical high-pressure liquid chromatography (HPLC) separations. For soil matrices, soxhlet extraction methods and HPLC provided a good basis for mass balance of soil TNT and identification of nonpolar decomposition and/or degradation products. With plant-tissue matrices, extraction and analysis are severely complicated by endogenous metabolites and pigments. This problem was alleviated by using selective solvent extraction and subsequent adsorption and elution chromatography from Florisil. This resolved interference problems and permitted separation of the less-polar TNT and metabolites from more-polar fractions. Both methods showed good recovery and reproducibility.

Soil-sorbed TNT, or that fraction not readily removed by exhaustive extraction, increases from less than $6 \%$ at 0 time to 30 to $50 \%$ after 60 days of incubation. Experiments with sterile soil systems indicate that the sorption process is nonbiotic in origin. Mass balance deficits in nonsterile soils can be accounted for by microbial oxidation of TNT to $\mathrm{CO} 2$. Estimates of soil half-life for TNT-residues, based on $\mathrm{CO} 2$ evolution rates, range from 4 to 10 years for the soils studied. Of the extractable TNT-derived fraction, the content of 2,4,6trinitrotoluene decreases to $30 \%$ after 60 days' incubation, depending on soil type. Five additional TNT-derived residues isolated from soil following 60 days of incubation make up the balance of the extractable material amended to soil. Mass spectrometry showed TNT. derived transformation products to include two aminodinitrotoluene (AMDNT) isomers (2amino-4,6-dinitrotoluene and 4-amino-2,6-dinitrotoluene), nitroazotoluene, and two unidentified products unique to individual soils. After 60 days of incubation, the two AMDNT compounds account for $>80 \%$ of the TNT-derived activity. Similar transformation patterns were observed for the sterile soils, indicating that these chemical transformations are nonbiotic in origin.

Experiments with hydroponic systems showed that the absorption capacity for plants is high. Plant absorption is concentration dependent, and the total uptake into plant tissues is directly related to the concentration of TNT to which roots are exposed. Thus, soil sorption will control the concentration of soil-solution TNT and/or TNT-derived residues available for root uptake. Results indicate that both TNT and AMDNT are root absorbed. Following root absorption, greater than $75 \%$ of the accumulated residues are retained within the root. Of the total TNT residues recovered from the root, less than $20 \%$ are recovered within the TNT and TNT-residue fraction. The remainder represent highly polar or nonextractable components. A similar trend is seen for shoot tissues, although their total TNT-derived activity is substantially lower. The principal components identified were the AMDNT isomers, with substantially less TNT. Analysis of stem residues indicated that nearly all TNT-derived activity transported from the root to shoot of bush bean was as an unidentified highly polar component, which on acid hydrolysis releases principally AMDNT, and an unidentified polar metabolite. Similar studies with root-tissue extracts, containing similar but substantially more of the high molecular-weight metabolite/conjugate, showed acid hydrolysis to yield substantial amounts of AMDNT isomers. These results indicate that TNT-derived and plant-accumulated products are stored and transported as conjugates. 
Studies with plants grown to maturity on TNT-amended soils show TNT-derived metabolites to accumulate in all tissues. The relative order of concentration is root $>$ stem >leaves $>$ seed and pod. Total plant concentration is highly dependent on soil type or on soil available-TNT concentrations. In all cases, plant uptake was inversely proportional to soil organic-matter content, as reflected in Burbank, Palouse, and Cinebar soils. The chemistry of accumulated residues shows patterns similar to hydroponic studies, with principal components identified as TNT and AMDNT isomers.

The results strongly indicate that greater than $80 \%$ of the activity derived from TNT is either conjugated and/or chemically modified in plant tissues. Future research should focus on identifying the unknown metabolite isolated in fraction F2. Further structural elucidation of the unique transformation product isolated from Burbank soil also seems to be warranted, since this might lead to a better understanding of catalytic alteration of TNT in soils. Of primary importance however, is the further characterization of the polar metabolites occurring in the Aq-base and F4 fractions. Current analytical methods, including those described in this report, are inadequate to characterize these metabolites. Further elucidation will require the development and implementation of new methods using preparative-scale Gel Permeation Chromatography (GPC) separations followed by analytical fractionation and extensive characterization using high-pressure liquid chromatography/mass spectroscopy. 


\section{TABLE OF CONTENTS}

REPORT DOCUMENT PAGE...........................................................................................

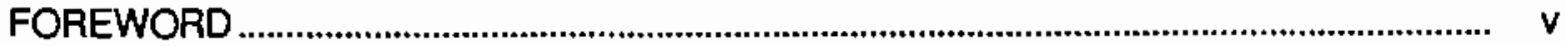

EXECUTIVE SUMMARY............................................................................................ vii

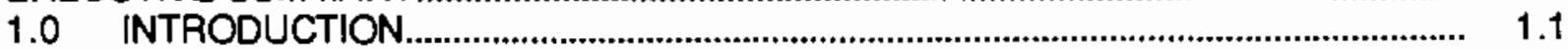

$1.1 \quad$ Review of Related Literature .................................................................... 1.1

1.1.1 Chemistry and Analytic Methods..................................................... 1.2

1.1.2 Soil Fate and Microbial Decomposition............................................ 1.2

1.1.3 Plant Uptake and Metabolism............................................................. 1.3

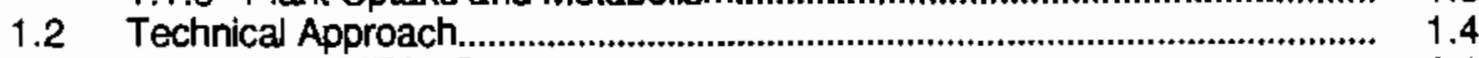

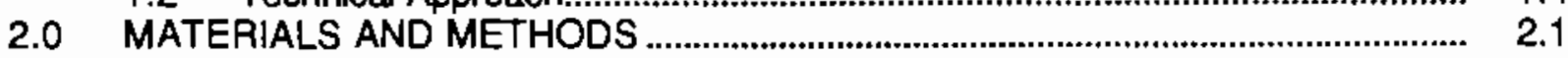

2.1 Chemicals and Standards......................................................................... 2.1

2.2 Soil Characterization and Sampling.............................................................. 2.1

$2.3 \quad$ Plant Cultivation Sampling............................................................................. 2.2

2.3.1 Hydroponic Studies ........................................................................ 2.2

2.3.2 Soil/Plant Studies ............................................................................ 2.3

2.4 Chemical/Analytical Procedures .................................................................. 2.3

2.4 .1 Soil Extraction.................................................................................... 2.3

2.4.2 Tissue Extraction and Fractionation ................................................. 2.3

2.4.3 Residue Analysis........................................................................... $\quad 2.4$

2.4.4 Radioanalyses.......................................................................... 2.6

3.0 RESULTS AND DISCUSSION ........................................................................ 3.1

3.1 Analytical Methods Development ............................................................... 3.1

3.1.1 Soil Extraction and Analysis ............................................................ 3.1

3.1.2 Plant-Tissue Extraction and Analysis .............................................. 3.4

3.2 Behavior and Chemical Fate of TNT in Soils.............................................. 3.6

3.2.1 Recovery and Mass Balance for TNT in Soils ................................ 3.6

3.2.2 Chemical Fate of TNT in Soils ...................................................... $\quad 3.10$

3.2.3 Oxidative Decomposition in Soils .................................................. 3.30

3.3 Short-Term Plant Availability from Hydroponics, and Chemical Fate of TNT ............................................................................................ 3.33

3.3.1 Plant Availability of TNT from Solution Culture ................................ 3.34

3.3.2 Short-Term Partitioning of TNT Within the Plant ............................... 3.37

3.3.3 Chemical Fate of TNT in Hydroponically Grown Plants................ 3.38

3.3.4 Transport Forms of TNT in Hydroponically Grown Bush Bean...... $\quad 3.49$

3.3.5 Respiration and/or Volatilization of TNT by Plants Grown in Solution Culture

3.4 Absorption and Chemical Fate of TNT in Mature Plants Grown in

Soil.....

3.4.1 Short-Term Soil/Plant Toxicity Studies.

3.4.2 Long-Term Partitioning of TNT Within the Plant............................... 3.55

3.4.3 Chemistry of TNT in Mature Plants ..................................................... 3.61

4.0 SUMMARY AND CONCLUSIONS ………............................................................. 4.1

4.1 Summary of Results............................................................................

4.1.1 Analytical Methods........................................................................ 4.1

4.1.2 TNT Fate in Soils............................................................................ 4.1

4.1.3 Plant Availability and Chemical Fate of TNT.................................. 4.2

4.2 Research Needs....................................................................................... 4.3

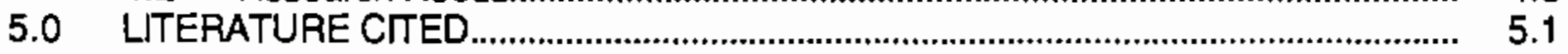




\section{LIST OF FIGURES}

FIGURE 2.1 Plant-Tissue Extraction Flow Chart.

FIGURE 2.2 Trapping System Used to Evaluate Potential Loss of ${ }^{14} \mathrm{C}-\mathrm{TNT}$ or Metabolites as ${ }^{14} \mathrm{CO}$

FIGURE 3.1 Representative TNT Standard Curve

FIGURE 3.2 Chromatograms of TNT and Residues in Burbank Soil.......................... 3.3

FIGURE 3.3 Chromatograms of TNT and Residues in Palouse Soil........................... 3.3

FIGURE 3.4 Chromatograms of TNT and Residues in Cinebar Soil ........................... 3.4

FIGURE 3.5 Methanol (Top) and Methanol: Chloroform: Water (Bottom) Extractions and Chromatographic Separations of TNT From Plant Tissue Spiked with Radiolabeled TNT.

FIGURE 3.6 Methylene Chloride Extraction and Chromatographic Separation of TNT From Plant Tissue Blank and Tissue Spiked with Radiolabeled TNT....

FIGURE 3.7 Reproducibility of Methylene Chioride Extraction and Chromatographic Separation of TNT From Fraction \#2 of Plant Tissues Spiked with Radiolabeled TNT

FIGURE 3.8 TNT Transformation Products in Burbank Soil at Time 0 and 7 Days....

FIGURE 3.9 TNT Transformation Products in Palouse Soil at Time 0 and 11 Days..

FIGURE 3.10 TNT Transformation Products in Cinebar Soil at Time 0 and 18 Days..

FIGURE 3.11 Photodiode Array Spectra of Peak $t$

FIGURE 3.12 Comparison of UV-Absorbing (Upper) and Radiocarbon (Lower) Constituents From Cinebar Soil

FIGURE 3.13 Comparison of UV-Absorbing (Upper) and Radiocarbon (Lower) Constituents From Palouse Soil.

FIGURE 3.14 Comparison of UV-Absorbing (Upper) and Radiocarbon (Lower) Constituents From Burbank Soil

FIGURE 3.15 Radiochromatogram of HPLC Separations of Extracts From Burbank Soil Aged for 10 Days.

FIGURE 3.16 HPLC Chromatogram TNT Residues in Cinebar Soils Incubated for 18-Days (Upper), and Cochromatography of Added 2-Amino-4,6Dinitrotoleuene (Lower)

FIGURE 3.17 Chromatograms and Mass Spectra of TNT and 2-Amino- 4,6-Dinitrotoluene Standards 


\section{LUST OF FIGURES (Cont.)}

FIGURE 3.18 Total lon-Current Chromatogram and Mass Spectra of TNT Residues Extracted From Burbank Soil

FIGURE 3.19 Peak Areas of TNT, Aminodinitrotoluene Isomers, and the Unique Transformation Product During the 61-Day Study in Burbank Soil

FIGURE 3.20 Mass Spectra of the Unique Transformation Product Isolated From Burbank Soil Containing TNT

FIGURE 3.21 Mass Spectrum of an Additional Isomer of the Unique Transformation Product Which Co-Elutes in the Same HPLC Peak as the Compound in Figure 3.20 .

FIGURE 3.22 Chromatograms of Sterile Burbank, Palouse and Cinebar Soils

FIGURE 3.23 Comparison of the Methanol-Extractable Components From Sterile Burbank Soil at $T=O(A)$ and $T=10$-Day $(B)$.

FIGURE 3.24 Uptake Rates of Radiolabeled-TNT by Roots of Bush Bean, Wheat, and Blando Brome From 1, 5, 10 and 25 ppm TNT-Amended Nutrient Solutions.

FIGURE 3.25 Double Reciprocal Plots of $1 N$ Versus $1 / \mathrm{S}$ for Bush Bean (A), Wheat $(\mathrm{B})$ and Blando Brome (C)

FIGURE 3.26 Chromatographic Profiles of Hydroponic Solutions Prior to the Uptake Study (Top), After 1 Day (Center) and After 7 Days (Bottom) of Supporting Growth of Bush Bean

FIGURE 3.27 Chromatographic Profile of Components Concentrated From a Bush Bean Hydroponic Solution

FIGURE 3.28 Representative Chromatograms of the F2 Fraction of Bush Bean Leaves (Top), Stems (Center), and Roots (Bottom).

FIGURE 3.29 Chromatograms of the F2 Fractions of Blando Brome Shoot (Top) and Roots (Bottom)

FIGURE 3.30 Radiochromatogram of Bush Bean Exudate.

FIGURE 3.31 Radiochromatogram of Acid-Hydrolyzed Bush Bean Exudate.

FIGURE 3.32 Radiochromatogram of the F2 Fraction of Acid-Hydrolyzed Bush Bean Root Tissue.

FIGURE 3.33 UV Spectrum of the Unknown TNT Metabolite (Retention Time in $22 \mathrm{~min}$ ) 


\section{LIST OF TABLES}

TABLE 2.1 Selected Properties of Test Soils.

TABLE 3.1 Amount of Radiolabel in Various Florisil Eluate Fractions From Spiked Plant Tissues.

TABLE 3.2 Mass Balance of Soil Systems Containing TNT (n=3).

TABLE 3.3 Average Retention Time \pm 1 Standard Deviation (min) of Compounds Present in Soils Aged With TNT $(n=3)$

TABLE 3.4 Average Peak Areas (in Arbitrary Units) and Relative Standard Deviations for Compounds Present in Soil Aged with TNT $(n=3) \ldots \ldots \ldots . . . \quad 3.15$

TABLE 3.5 Mass Balance of Sterile Soil Systems Containing TNT

TABLE 3.6 Volatility and Respiration of Soil Amended With Radiolabeled TNT......

TABLE 3.7 Calculated $K_{s}$ and $V_{\max }$ Values from Apparent Isotherms From Figure 3.25.

TABLE 3.8 Distribution of Radiocarbon in Plants Following 2-h Exposure in Solution Culture at Various TNT Concentrations.

TABLE 3.9 Quantity of TNT and Radiolabel in Hydroponic Solutions at the Beginning of the Study and at the Two Harvest Times

TABLE 3.10 Radiolabel Contained in Tissues of Bush Bean, Wheat, and Blando Brome

TABLE 3.11 Percentage of Total Radioactivity, Based on Oxidation, in Chemical Fractions of Bush Bean

TABLE 3.12 Percentage of Total Radioactivity, Based on Oxidation, in Chemical Fractions of Blando Brome.

TABLE 3.13 Percentage of Total Radioactivity, Based on Oxidation, in Chemical Fractions of Wheat

TABLE 3.14 Concentrations of TNT, AMDNT Isomers, and Unidentified Polar and Non Polar Components in Plant Tissues Following 1 and 7 Days of Adsorption From Hydroponic Solutions.

TABLE 3.15 Distribution of Radio-Labeled TNT in a Hydroponically Grown Bush Bean Following 72-h Exposure to a 20-ppm Solution

TABLE 3.16 Concentration of Tissue TNT-Derived Residues From Radiolabeled TNT in Tissues of Bush Bean Grown in Soils Containing 10-ppm TNT or in Control Soils 


\section{LIST OF TABLES (Cont)}

TABLE 3.17 Distribution of Radiocarbon in Bush Bean Plants Grown for 60 Days in TNT-Amended or Control Soils.

TABLE 3.18 Concentration of Tissue TNT-Derived Radiocarbon and Distribution of Radiocarbon in Wheat and Blando Brome Tissues From Plants Grown on TNT-Amended or Control Soils

TABLE 3.19 Average Fresh Weight (g) of Bush Bean Plants Grown for 60 Days in Soils Amended with Radiolabeled-TNT or Control Soils.

TABLE 3.20 Average Fresh Weights of Wheat and Blando Brome Plants Grown for 60 Days on 10-ppm TNT Amended or Control Soils.

TABLE 3.21 Percentage of Total Radioactivity, Based on Oxidations, in the Various Chemical Fractions of Mature Bush Bean Plants Grown in Burbank Soil

TABLE 3.22 Percentage of Total Radioactivity, Based on Oxidations, in the Various Chemical Fractions of Mature Bush Bean Plants Grown in Palouse Soil

TABLE 3.23 Percentage of Total Radioactivity, Based on Oxidations, in the Various Chemical Fractions of Mature Bush Bean Plants Grown in Cinebar Soil

TABLE 3.24 Percentage of Total Radioactivity, Based on Oxidations, in the Various Chemical Fractions of Mature Bush Bean Plants Grown in Burbank Soil

TABLE 3.25 Percentage of Total Radioactivity, Based on Oxidations, in the Various Chemical Fractions of Mature Wheat and Blando Brome Plants Grown in Palouse Soil

TABLE 3.26 Percentage of Total Radioactivity, Based on Oxidations, in the Various Chemical Fractions of Mature Wheat and Blando Brome Plants Grown in Cinebar Soil. 



\subsection{INTRODUCTION}

Munitions materiel currently used as propellants or as explosive charges include 2,4,6trinitrotoluene (TNT) and hexahydro-1,3,5-trinitro-1,3,5-triazine (RDX). The latter contains some level of octahydro-1,3,5,7-tetranitro-1,3,5,7-tetrazocine (HMX). These materiel and their combustion or decomposition products can accumulate or cycle in terrestrial environments. An understanding of the persistence, bioavailability, and chemical fate of these contaminants is necessary to avoid unwarranted environmental impacts and to establish decision points with respect to remedial need and approaches.

Munitions materiel can enter the environment through production/manufacturing activities and through field usage/disposal (Small and Rosenblatt 1974; Kitchens et al. 1978; Spanggord et al. 1983b; Ryon et al. 1984). The production of munitions materiel and their use for training purposes can both lead to localized accumulations of parent munition compounds and stable decomposition products in terrestrial and aquatic environments. The presence of specific munitions-related components in the environment is not in itself, however, indicative of the presence or severity of impact. Organic contaminants or xenobiotics entering terrestrial or aquatic environments undergo chemical partitioning related to sorptive processes and water solubility. While these factors influence short-term accumulation and mobility, respectively, chemical stability and biologically mediated degradative processes greatly influence persistence and, therefore, accumulation.

Three biotic processes are important for assessing the relative long-term importance of munitions materiel released to the environment: 1) the extent to which soil microbes degrade and/or modify the contaminant; 2) the extent to which the parent compounds and their major decomposition products are accumulated by food chain plants; and 3) the extent to which plant-accumulated contaminants are metabolized. Studies of non-munitions-related organic xenobiotics clearly indicate that biotic systems are effective in degrading and/or detoxifying a variety of compound classes.

\subsection{REVIEW OF RELATED LITERATURE}

Studies have been conducted on numerous munitions-based chemicals. The vast majority of these deal with development of analytical methods and characterization of parent compounds and decomposition products associated with waste streams and impoundments and with releases from production sites. Fewer deal with environmental persistence, bioavailability, and metabolic detoxification. Of these, only a smail number address chemical 
fate and behavior at environmental concentrations within the solubility constraints of the munitions components.

\subsubsection{Chemistry and Analytical Methods}

Effluent waste streams associated with TNT production processes have been carefully characterized and shown to contain over 30 isomeric nitroaromatics and associated byproducts ranging in concentration from 0.001 to $48 \mathrm{mg} / \mathrm{L}$ of ether-extracted effluent (Spanggord et al. 1982). No evidence of significant ring opening is available for TNT.

Because federal National Polutant Discharge Elimination System (NPDES) permits limit discharges of munitions components at the point of discharge to surface streams, analyses are performed for TNT, RDX, HMX--a common impurity in RDX-and 2,4dinitrotoluene (Jenkins et al. 1986; Bauer et al. 1986). This and requirements to monitor drinking-water sources for TNT, 2,4-DNT, and 2,6-DNT (Belkin et al. 1985) establish the range of chemical species which would be of initial concern in understanding the environmental fate and behavior of munitions-based contaminants in soil and plant systems.

A number of gas chromatography (GC) and gas chromatography/mass spectrometry (GC/MS) methods are available for identifying and quantifying parent compounds, byproducts, and decomposition products (Spanggord et al. 1982, t983a; Belkin et al. 1985). These methods are required to establish both chemically and biologically based transformations. More recent applications involving high-pressure liquid chromatography (HPLC) are suitable only for resolving and quantifying major constituents (Jenkins et al. 1986; Bauer et al. 1986). Soil-extraction methods are available for the three parent munitions compounds (Jenkins and Grant 1987), but only one study (Palazzo and Leggett 1986) addresses planttissue-extraction methods.

\subsubsection{Soil Fate and Microbjal Decomposition}

Although substantial research into the fate of nitroguanidine in soil has been performed (Spanggord et al. 1985), relatively few data are available for TNT. We are aware of no data relating soil characteristics (i.e., cation exchange capacity [CEC], $\mathrm{pH}$, organicmatter content) to the extent of sorption/solubility. An understanding of this relationship is necessary to define limits of environmental mobility and plant availability. 
Soil microbial studies, both in vivo and in vitro, indicate that TNT is subject to metabolic modification (McCormick et al. 1976). Kearney et al. (1983), using ${ }^{14} \mathrm{C}$ TNT, preUV-irradiated and amended to soil, found respiratory losses of ${ }^{14} \mathrm{CO}_{2}$ to increase with time. The addition of microorganisms able to metabolize nitroaromatics resulted in a sharp increase in respiratory losses. Yang et al. (1983), using soil-isolated organisms, demonstrated a $90 \%$ reduction in extractable RDX over 3 days, with indications that the organisms were able to use the nitro groups as an alternate $\mathrm{N}$ source. RDX has been shown to be degraded with a half-life of 7 days in a water/sediment system, but only after a several week lag period (Sikka et al. 1980). The latter results indicated that ring opening occurred. In vitro anaerobic transformations have been reported for RDX and HMX and their acylated byproducts 1-acetyloctahydro-3,5,7-trinitro-1,3,5,7-tetrazocine (SEX) and 1-acetyloctrahydro3,5-dinitro-1,3,5-triazine (TAX) (Spanggord et al. 1982, 1983b), but rates of decomposition were substantially lower than for sediment systems. Nitro reductions, ring opening, and further reduction to methanol, formaldehyde, and hydrazines were the metabolic pathways implicated by these studies. Although few soil studies have been performed, indications are that both anaerobic and aerobic biotransformations may occur in soils.

\subsubsection{Plant Uptake and Metabolism}

The literature contains few data related to soil/plant fate and bioavailability of TNT. In the 1970 s a substantial amount of research was performed on aquatic organisms, including algae and aquatic plants. TNT has been found to be toxic to duckweed at levels in excess of $1 \mathrm{ppm}$ (Schott and Worthley 1974), to inhibit freshwater algae growth at 2 to $15 \mathrm{ppm}$ (Smock et al. 1976), and to inhibit the growth and metabolism of microorganisms (Klausmeier et al. 1973; Nay et al. 1974). With the exception of Smock et al. (1976) and Schott and Worthley (1974), none of the investigators performed chemistry on either culture solutions or materials accumulated. The latter authors noted a conversion of TNT to 2,4-dinitrotoluene and 4amino-2-nitrotoluene in their culture medium.

One higher-plant study was performed using hydroponically grown yellow nutsedge to assess the uptake, toxicity, and metabolic transformations of TNT (Palazzo and Leggett 1986). This study showed shoot and, particularly, root growth to be inhibited at $5 \mathrm{ppm}$. Although not noted by the authors, the toxicity symptoms were characteristic of dinitroaniline herbicide damage. This toxicity would be expected based on the chemical structure of TNT, particularly the dinitrotoluenes. Chemical analysis showed $>90 \%$ of all tissue-extractable material to be 2-and 4-aminodinitrotoluene, with only a small amount of TNT being recovered. 
Since these species were not observed in the nutrient solutions, it is assumed that they are metabolic detoxification products. No data were found for either RDX or HMX.

\subsection{TECHNICALAPPROACH}

It is clear that the major route of entry to the environment for nitro-substituted munitions materiels such as TNT is through discharge from production facilities and decommissioning activities. Based on the limited data available, it is conceivable that these parent materials and many of their by-products may be mobile in the environment. The present study addresses several aspects of the fate and behavior of TNT in the environment, including the following

- Methods for analysis of TNT and its decomposition products in soils and plant tissues

- Rates of microbial decomposition or chemical degradation in soil, particularly by the near-surface rhizosphere-colonizing microorganisms

- Characterization of principal transformation products produced in the rhizosphere, and their respective bioavailability and fate

- Evaluation of the rates of plant uptake, TNT and metabolite distributions in edible tissues, and the chemical fate and persistence of accumulated xenobiotics

- The relationship between soil characteristics ( $\mathrm{pH}, \mathrm{OM}, \mathrm{CEC}$, mineralogy) that control soil sorption/solubility and plant availability.

Soils used were Burbank silt sand, Palouse silt loam, and Cinebar, a clay-based high organic-matter forest soil. Plant species included wheat, bush bean, and a grass, blando brome. Wheat and bush bean were used to represent monocotyledon and dicot seed sources, respectively. Blando brome was used as a typical browse species for evaluating food chain pathways. Studies were designed to provide an integrated understanding of TNT behavior and fate in the soil/plant system. 


\subsection{MATERIALS AND METHODS}

\subsection{CHEMICALS AND STANDARDS}

A series of standards containing 2,4,6-trinitrotoluene, 2-amino-4,6-dinitrotoluene, and 4-hydroxylamine-2,6-dinitrotoluene were obtained from Chem Service (West Chester, Pennsylvania), U.S. Army Toxic and Hazardous Materials Agency SARM Repository, and Oak Ridge National Laboratory, respectively. Purity was $>98 \%$ for each compound. Uniformly ring-labeled ${ }^{14} \mathrm{C}$-TNT (specific activity of $5.3 \mathrm{mCl} / \mathrm{mM}$ ) was obtained from E.I. du Pont de Nemours \& Co. (Boston, Massachusetts). Radiopurity, based on HPLC radiochromatography, was $99.86 \%$. All solvents used for extractions or analyses were either HPLC- or GC-grade.

\subsection{SOIL CHARACTERIZATION AND SAMPLING}

The chemical and physical characteristics of the soils used in these studies are shown in Table 2.1. Palouse is a silt-loam, mixed-mesic Pachic Ultic Haploxeroll. The sample, collected at Pullman, Washington, consisted of the Ap horizon. This soil is $78 \%$ silt, and $21 \%$ clay, contains $1.7 \%$ organic matter, and has a CEC of $23.8 \mathrm{meq} / 100 \mathrm{~g}$ and a pH of 5.4 . Burbank, a sandy loam (sandy, skeletal, mixed xeric Torriorthent), is representative of the desert areas of Washington, Oregon, and Idaho. The sample, collected on the Hanford Site near Richland, Washington, consisted of the Ap horizon. This soil is $51 \%$ silt, $4 \%$ clay, and $45 \%$ sand, contains $0.5 \%$ organic matter, and has a CEC of $5.5 \mathrm{meq} / 100 \mathrm{~g}$ and a pH of 7.4 . Cinebar, a silt loam, has $51 \%$ silt, and $13 \%$ clay, contains $7.2 \%$ organic matter, and has a CEC of $38.2 \mathrm{meq} / 100 \mathrm{~g}$ and a pH of 5.6. Cinebar is a forest soil from the Cascade Mountain Range of Washington.

For soil experiments, a solution containing appropriate proportions of labeled and/or vacuum-desiccated unlabeled TNT was prepared in $2.0 \mathrm{~mL}$ of methanol and amended with $400 \mathrm{~g}$ of air-dried soil to give a final concentration of $60 \mathrm{ppm}$ TNT containing 10 or $20 \mu \mathrm{Ci}$ of labeled TNT. Amended soils were immediately brought to and maintained at 0.66 of field capacity. Initial sampling was performed to assure both mixing efficiency and adequate activity levels. Soils were maintained in a growth-chamber environment that simulated the luminous intensity and spectral dispersion of sunlight $\left(500 \mu \mathrm{E} / \mathrm{m}^{-2} \mathrm{sec}^{-1}\right)$ during the $16-\mathrm{h}$ daily light cycle. 
IABLE2.1. SELECTED PROPERTIES OF TEST SOILS

\begin{tabular}{llll}
\hline Soil Property & $\begin{array}{c}\text { Burbank } \\
\text { Sandy Loam }\end{array}$ & $\begin{array}{c}\text { Palouse } \\
\text { Silt Loam }\end{array}$ & $\begin{array}{l}\text { Cinebar } \\
\text { Silt Loam }\end{array}$ \\
\hline \% Sand & 45.1 & 1.1 & 35.2 \\
$\%$ Silt & 51.4 & 77.5 & 51.4 \\
$\%$ Clay & 4.0 & 21.4 & 13.4 \\
$\%$ Ash & 98.0 & 93.8 & nd (a) \\
pH $(100 \%$ field capacity) & 7.4 & 5.4 & 5.6 \\
Organic carbon (\%) & 0.5 & 1.7 & 7.2 \\
Sulfur $(\%)$ & 0.053 & 0.043 & nd \\
Nitrogen $(\%)$ & 0.061 & 0.16 & 0.44 \\
Total P $(\mu \mathrm{g} / \mathrm{g})$ & 2400 & 3770 & 3400 \\
Phosphate-P $(\mu \mathrm{g} / \mathrm{g})$ & 4.8 & 5.8 & 26 \\
Carbonate/Bicarbonate $(\%)$ & $<0.1$ & $<0.1$ & $<0.1$ \\
Ammonium- $\mathrm{N}(\mu \mathrm{g} / \mathrm{g})$ & 6.1 & 18.3 & 15 \\
CEC (meq/100 g) & 5.5 & 23.8 & 38.2 \\
& & & \\
\hline
\end{tabular}

(a) nd = not determined

In studies with sterile soils, the soils were irradiated for $4 \mathrm{~h}$ with ${ }^{60} \mathrm{Co}$, which provided a total gamma-radiation dose of $60 \mathrm{Krad}$.

\subsection{PLANT CULTIVATION SAMPLING}

The chemical fate of TNT in plants was evaluated using bush beans (Phaseolus vulgaris), wheat (Triticum aestivum), and blando brome (Bromus mollis). All plants used for either hydroponic or soil studies were grown from seed. All plants were maintained in controlled-environment chambers with a 16/8-h light cycle $\left(500 \mu \mathrm{E} / \mathrm{m}^{-2} \mathrm{sec}^{-1}, \mathrm{PAR}\right.$, at leaf surface), a day/night temperature of $26 / 22^{\circ} \mathrm{C}$, and $50 \%$ relative humidity.

\subsubsection{Hydroponic Studies}

Plants were grown for 18 to 26 days on hydroponic nutrient solutions as described previously (Cataldo et al. 1978), at which time solutions were amended with 1 to $25 \mathrm{ppm}$ TNT containing $5 \mu \mathrm{Ci}$ of radiolabeled TNT per $500 \mathrm{~mL}$. These solutions were filter sterilized and placed in autoclaved $500-\mathrm{mL}$ beakers to minimize bacterial contamination, which could promote transformation of TNT. Plants were placed in these solutions and maintained in a 
growth chamber until harvested. The beakers were jacketed in an opaque sheath to protect the roots from light and to minimize the photolysis of TNT. Solutions were analyzed by HPLC and liquid scintillation spectrometry at specified intervals. At harvest, plants were removed from the hydroponic solutions and the roots rinsed with $0.1 \mathrm{M} \mathrm{CaCl}_{2}$ followed by a rinse in a methanol.water solution ( $80 \%: 20 \%$ ). Plants were then separated into component tissues (roots, stems, leaves) as described; each of the tissues was minced, thoroughly mixed, analyzed for radiocarbon, and stored at $-80^{\circ} \mathrm{C}$ until chemical analysis.

\subsubsection{Soil/Plant Studies}

Soil studies were conducted both with unlabeled and radiolabeled TNT. Soils were uniformly mixed to the concentration noted, and plants were grown to maturity. Shoot tissues were harvested, and roots were washed free of adhering soil. All tissues were assayed for radioactivity and analyzed for TNT and residues.

\subsection{CHEMICAL/ANALYTICALPROCEDURES}

\subsubsection{Soil Extraction}

Soils were subjected to exhaustive soxhlet extraction with $200 \mathrm{~mL}$ of methanol (J. T. Baker HPLC Grade) for $48 \mathrm{~h}$. The soil extracts were filtered through a $0.22-\mu \mathrm{m}$ Nylon 66 filter (Altech Associates, Deerfield, Illinois), and the volume was then reduced to approximately 20 $\mathrm{mL}$ by rotary evaporation. After the concentrated extract was again filtered through a 0.22 $\mu \mathrm{m}$ filter, the final volume was adjusted to a total of $25.0 \mathrm{~mL}$. Extracted soils were dried at $105^{\circ} \mathrm{C}$ overnight, cooled in a desiccator, and weighed to obtain an accurate oven-dry weight. Portions of the extracted soils were further analyzed by total combustion in a Packard Model 306 oxidizer (Packard Instrument Company, Downers Grove, Ilinois) to determine the amount of irreversibly bound TNT residues not removed by Soxhlet extraction. The extraction efficiency of the procedure was determined by comparing the amount of radiolabel contained in the final metharol extract with the amount originally added to the soil (both values were determined by liquid scintillation spectrometry). The methanol extract was subsequently analyzed for TNT and transformation products by HPLC as described below.

\subsubsection{Tissue Extraction and Fractionation}

The extraction and fractionation scheme for plant tissues is outlined in Figure 2.1. A 1.0-g sample of fresh-weight tissue was homogenized for $2.5 \mathrm{~min}$ in a Sorvall Omni-Mixer ${ }^{\mathrm{TM}}$ 
(Newtown, Connecticutt) with $10.0 \mathrm{~mL}$ of $1 \mathrm{M} \mathrm{HCl}$ and approximately $0.5 \mathrm{~g}$ of dry ice. After transfer to a 25-mL Corex ${ }^{\circledR}$ (Corning Glass Works, Corning, New York) centrifuge tube, the tissue was subjected to acid hydrolysis by immersing the tube into a boiling-water bath for 1 h. After cooling to room temperature, the hydrolyzed material was extracted with $10.0 \mathrm{~mL}$ of diethyl ether. The phases were separated by centrifugation for $10 \mathrm{~min}$ with a centrifugal force of $3000 \times \mathrm{g}$. The volume of each layer was recorded and $100-\mu \mathrm{L}$ aliquots were removed for liquid scintillation spectrometry. The radioactivity remaining in the pellet was determined by oxidation followed by liquid scintillation spectrometry. To obtain an extract of the basic organics, the $\mathrm{HCl}$ layer was made basic by the addition of $4.0 \mathrm{~mL}$ of $4 \mathrm{M} \mathrm{NH}_{4} \mathrm{OH}$ and extracted with a second $10.0-\mathrm{mL}$ portion of diethyl ether. The layers were separated by centrifugation, the volumes recorded, and subsamples taken for liquid scintillation spectrometry. The two ether extracts were combined, evaporated to dryness with a stream of dry nitrogen, and reconstituted with $2.0 \mathrm{~mL}$ of methylene chloride.

The methylene chloride sample was applied to a Sep-Pak ${ }^{\mathrm{TM}}$ (Waters Associates, Milford, Massachusetts) florisil column which had previously been equilibrated with methylene chloride. An additional $2.0 \mathrm{~mL}$ of methylene chloride was used to rinse the remaining residue from the sample vial to the Florisil column. The column eluate collected during the application of the sample composed fraction 1. Fractions 2 and 3 were eluted from the column with successive 5.0-mL portions of a mixture of methylene chloride:ethyl acetate (95\%:5\%). The final fraction (fraction 4) was eluted from the Florisil column by $5.0 \mathrm{~mL}$ of methanol. This strong solvent was chosen to strip the column of the maximal amount of adsorbed material. Volumes of the Florisil fractions were recorded and $100-\mu \mathrm{L}$ aliquots were taken for liquid scintillation spectrometry. Prior to HPLC analysis, fraction 2 was evaporated to dryness and the residue was dissolved in $1.0 \mathrm{~mL}$ of methanol.

\subsubsection{Residue Analysis}

The HPLC system consisted of a Waters pump and system controller (Model 600E, Milford, Massachusetts). The methanol extract $(20 \mu \mathrm{L})$ of soil or plant-tissue extracts was injected by a Waters WISP 710 automatic injector onto a Beckman Ultrasphere ${ }^{\mathrm{TM}}$ (Bechman Ultrasphere, San Ramon, California) $5-\mu \mathrm{m}$ octadecyl silica column and the components were separated by a linear solvent program at a flow rate of $1.0 \mathrm{~mL} / \mathrm{min}$. The solvent system was water/acetonitrile, with a 20 -min gradient from $40 \%$ to $100 \%$ acetonitrile. Components were 


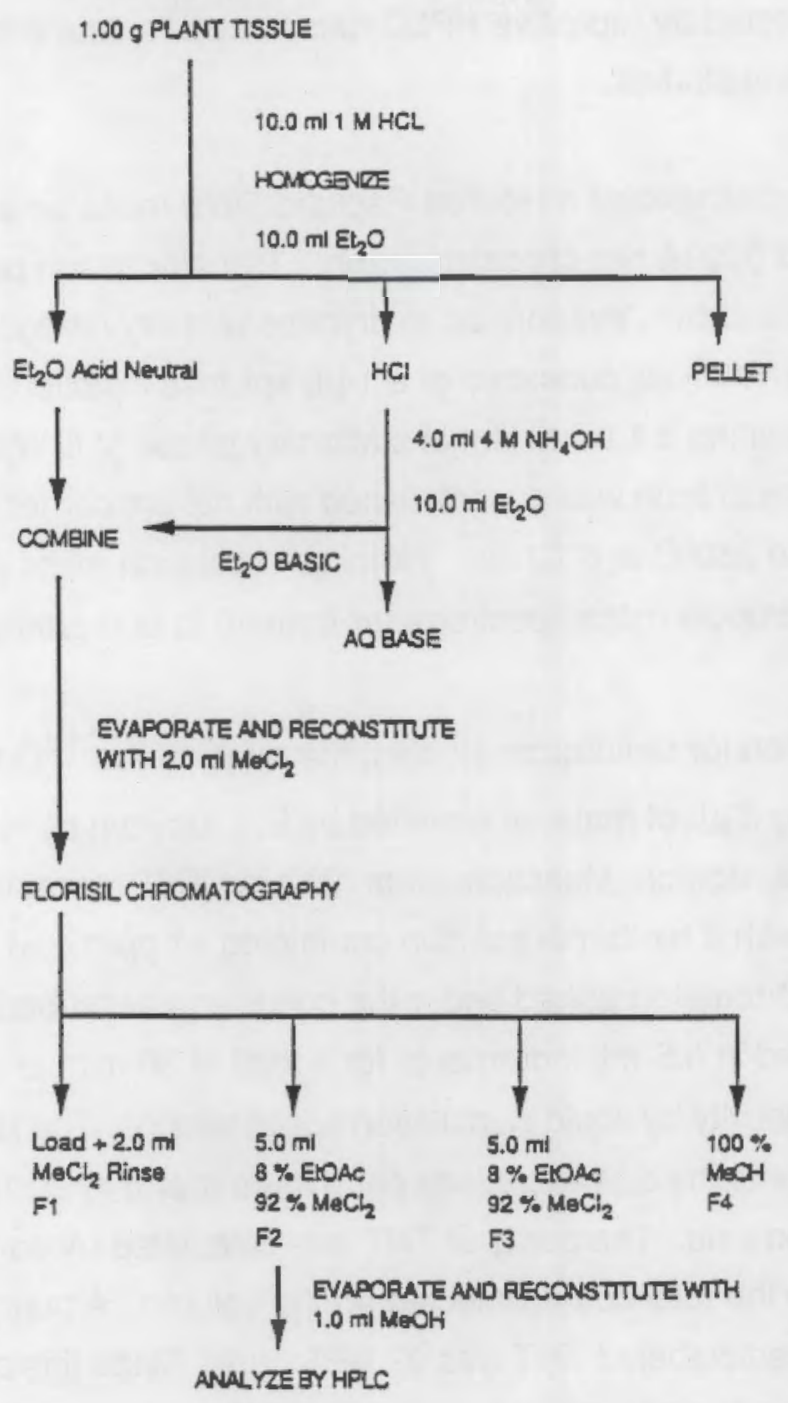

\section{FIGURE 2.1. PLANT-TISSUE EXTRACTION FLOW CHART}

detected by UV absorption at $254 \mathrm{~nm}$ (Waters Model 490E detector), with a detector sensitivity of 0.008 AUFS. Peak areas obtained from a Hewlett-Packard (Hewlett-Packard, Avondale, Pennsyivania) 3390 integrator were used for quantitative measurements.

Radiochromatographic detection was used extensively for unambiguous identification of transformation products arising from TNT. During selected chromatographic runs, the column eluate was collected in $0.5-\mathrm{mL}$ increments for a total of $30 \mathrm{~min}$. Each fraction was assayed for radioactivity by liquid scintillation spectrometry. Radiochromatograms were generated by plotting the disintegrations per minute (dpm) in each successive aliquot as a 
function of retention time. Transformation products and/or metabolites identified in this manner were collected by repetitive HPLC runs to accumulate enough material for subsequent mass-spectral studies.

GC/MS studies utilized a Hewlett-Packard 5970 mass-selective detector interfaced to a Hewlett-Packard 5990A gas chromatograph. Transformation products were purified by HPLC as described above, evaporated to dryness with dry nitrogen, and dissolved in a small aliquot of hexane. Analysis consisted of a $1-\mu \mathrm{L}$ splitless injection onto a $30 \mathrm{~m} \times 250 \mu \mathrm{m}$ ID DB-5 column containing a 1.0- $\mu \mathrm{m}$ film of stationary phase ( $\mathrm{J} \& \mathrm{~W}$ Scientific, Folsom, California). The separation was accomplished with helium carrier gas and a temperature program from 40 to $280^{\circ} \mathrm{C}$ at $6^{\circ} \mathrm{C} / \mathrm{min}$. Nominal resolution mass spectra were obtained by scanning the quadrupole mass spectrometer from 40 to 600 amu at a rate of $200 \mathrm{amu} / \mathrm{sec}$.

In preparation for radiotracer studies, the purity of the ${ }^{14} \mathrm{C}$ ring-labeled TNT was checked by diluting $2 \mu \mathrm{L}$ of material provided by E. I. DuPont de Nemours \& Company, NEN Research Products, Boston, Massachusetts (223 mg TNT containing $5.3 \mathrm{mCi}$ in $4.3 \mathrm{~mL}$ acetone) to $5 \mathrm{~mL}$ with a methanol solution containing $11 \mathrm{ppm}$ cold TNT. Ten microliters of this solution was chromatographed under the conditions described above. The column eluate was collected in $0.5-\mathrm{mL}$ increments for a total of $30 \mathrm{~min}$, and each fraction was assayed for radioactivity by liquid scintillation spectrometry. The radiochromatogram shown in Figure 6 represents the disintegrations per minute (dpm) in each successive aliquot as a function of retention time. The purity of TNT was calculated by comparing the dpm contained in the TNT peak to the total counts injected on the column. A purity calculated in this manner indicated that the radiolabeled TNT was $99.86 \%$ pure. Since this purity was sufficient, the material provided was used without further chromatographic purification.

\subsubsection{Radioanalyses}

Soils and plant tissues were oxidized by total combustion in a Packard Model 306 oxidizer (Packard Instrument Co., Downers Grove, Illinois) to determine the amount of radiocarbon associated with each sample. Combusted samples and liquid samples were counted using a Beckman 9800 Liquid Scintillation Spectrometer (Beckman Instruments, Downers Grove, Illinois) with appropriate quench correction.

To assess the potential of TNT to be oxidatively decomposed in plant tissues and soils and/or its potential to be released essentially unchanged to the atmosphere, experiments were conducted using a gas-trapping system diagramed in Figure 2.2. For the plant 
experiment, because the construction of the chamber and the anatomy of the plants themselves prohibited the use of both the wheat and the grass, a 28-day-old bean plant was placed in the chamber, with the roots immersed in EDTA-free nutrient solutioncontaining 20 $\mathrm{ppm}{ }^{14} \mathrm{C}$-TNT $(9 \mu \mathrm{Ci})$. The shoot was carefully sealed off from the root with mastic to prevent exchange of gas between the two chambers and to prevent damage to the stem.

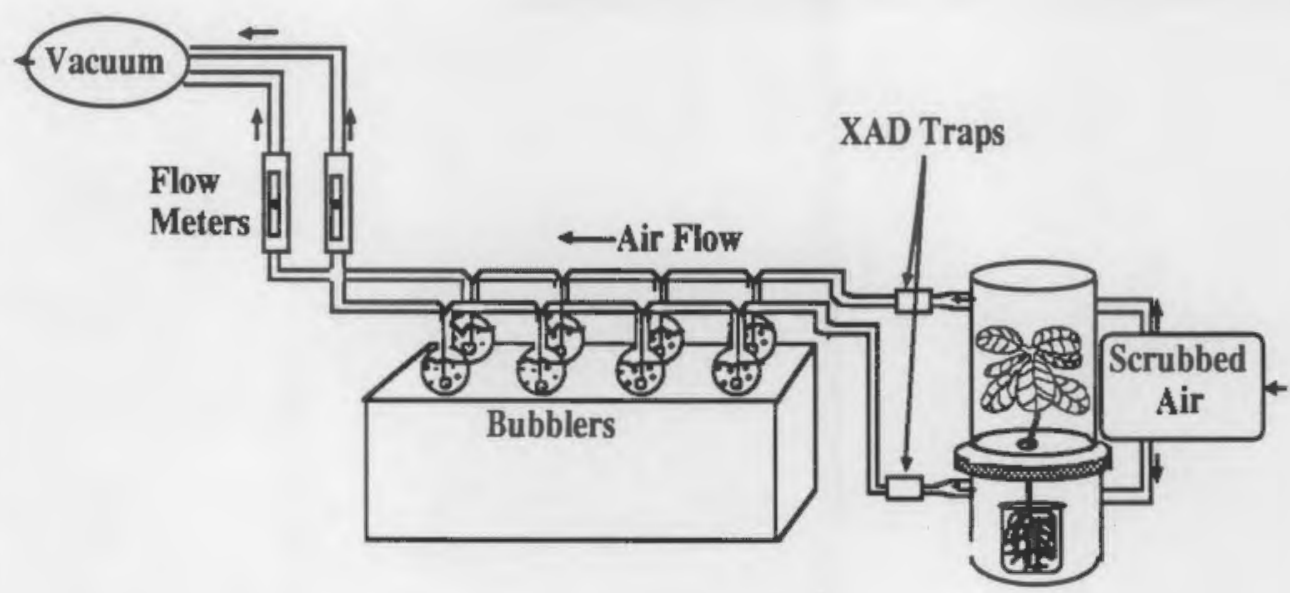

\section{FIGURE, 22. TRAPPING SYSTEM USED TO EVALUATE POTENTIAL LOSS OF ${ }^{14} \mathrm{C}$-TNT or METABOLITES AS ${ }^{14} \mathrm{CO}_{2}$}

The plant was illuminated at $450 \mu \mathrm{E} / \mathrm{m}^{2} / \mathrm{sec}$ for a 12 -h photoperiod with a chamber temperature of $28^{\circ} \mathrm{C}$. Filtered air was pulled through both chambers at the rate of 500 $\mathrm{mL} / \mathrm{min}$. Air from the shoot chamber then passed through two XAD resin traps $(1.0 \times 15.0 \mathrm{~cm}$ and $1.0 \times 5.0 \mathrm{~cm}$ columns) followed by four bubbler traps each containing $10 \mathrm{~mL}$ of $3 \mathrm{~N}$ $\mathrm{NaOH}$. The XAD traps were washed and dried prior to placement in the gas train and both the $\mathrm{NaOH}$ traps and the XAD resin traps were changed daily. Volumes were taken from the 
$\mathrm{NaOH}$ traps and aliquots counted by liquid scintillation. The XAD traps were eluted with four times the void volume using absolute $\mathrm{MeOH}$, and volumes and aliquots were taken and counted. After 3 days the plant was removed from the system, the roots washed with $\mathrm{CaCl}_{2}$ and $\mathrm{MeOH}$ and blotted dry, and the plant separated into roots, stem, and leaves. The tissues were weighed, diced, and quickly frozen. Subsequent aliquots were oxidized and counted. Water from transpiration that had condensed on the inside of the chamber was also collected and counted, as was the remaining nutrient solution. For soil analyses the plant chamber was replaced with a single closed chamber large enough for a single $400-\mathrm{g}$ pot. The soil was brought to 0.66 of field capacity with distilled water and sealed in the chamber.

Measurements were taken for 3 days for each soil type plus sterile controls. Amendment and activity levels for each soil type are given in the text. 


\subsection{RESULTS AND DISCUSSION}

The purpose of this study was to provide an understanding of the environmental fate and behavior of 2,4,6-trinitrotoluene (TNT). A series of experiments were performed, based on previous studies with TNT, to elucidate the extent of sorption in soils, the chemical transformations of TNT in soils, the relative availability of TNT to plants, and the chemical forms of TNT-related residues in plant tissues. In support of these activities, a principal activity involved developing suitable analytical methods to separate and characterize transformation products in soils and plant tissues.

\subsection{ANALYTICAL METHODS DEVELOPMENT}

\subsubsection{Soil Extraction and Analysis}

The methodology adopted for examining soil samples was based on exhaustive Soxhlet extraction followed by high-performance liquid-chromatographic analysis. Ten grams of soil (wet weight) placed in an extraction thimble were extracted for $48 \mathrm{~h}$ with $200 \mathrm{~mL}$ methanol. After extraction, the methanol solution was filtered through a $0.22-\mu \mathrm{m}$ nylon membrane filter prior to reducing the volume to approximately $15 \mathrm{~mL}$ using a rotary evaporator. The extract was subsequently filtered through a second $0.2-\mu \mathrm{m}$ nylon filter before the final volume was adjusted to $25.0 \mathrm{~mL}$ with methanol. These samples were subjected to chromatographic analysis, and residue content was determined based on the soil dry weight.

High-performance liquid chromatography (HPLC) involved injecting the methanol extract $(20 \mu \mathrm{L})$ onto a Beckman Ultrashpere $5-\mu \mathrm{m}$ octadecyl silica column and separating the components by a linear solvent gradient of water/acetonitrile, with a 20 -min gradient from $40 \%$ to $100 \%$ acetonitrile. Components were detected by UV absorption at $254 \mathrm{~nm}$. Retention time for TNT under these conditions was $13.4 \mathrm{~min}$. Figure 3.1 shows a representative standard curve used for quantitative calculations. The estimated detection limit for a 20- $\mu \mathrm{L}$ Injection of TNT on this system was $0.1 \mathrm{ppm}$.

The chromatograms in Figures 3.2 through 3.4 are profiles of the Soxhlet extracts of the three different soils used in these studies. The figures show HPLC chromatograms of soilblank extracts (upper) and of soils amended with $20 \mathrm{ppm}$ TNT and extracted immediately after amendment (lower). The soil blanks are from a soil low in organic content (Figure 3.2, Burbank soil), a soil intermediate in organic matter (Figure 3.3, Palouse soil), and a soil with a high total- 
organic-carbon content (Figure 3.4, Cinebar soil). The only peak observed in these soil blanks was a component in the extract from Cinebar soil that elutes with a retention time of approximately $19.21 \mathrm{~min}$. These blanks evidently are relatively clean, demonstrating that the procedure does not extract and concentrate compounds that are likely to interfere with the analysis of TNT or any aromatic TNT transformation products. Extracts of TNT-amended soils show a peak due to TNT, eluting at $13.4 \mathrm{~min}$. The chemical transformations of TNT in soils, based on incubation time, are discussed further in Section 3.2.

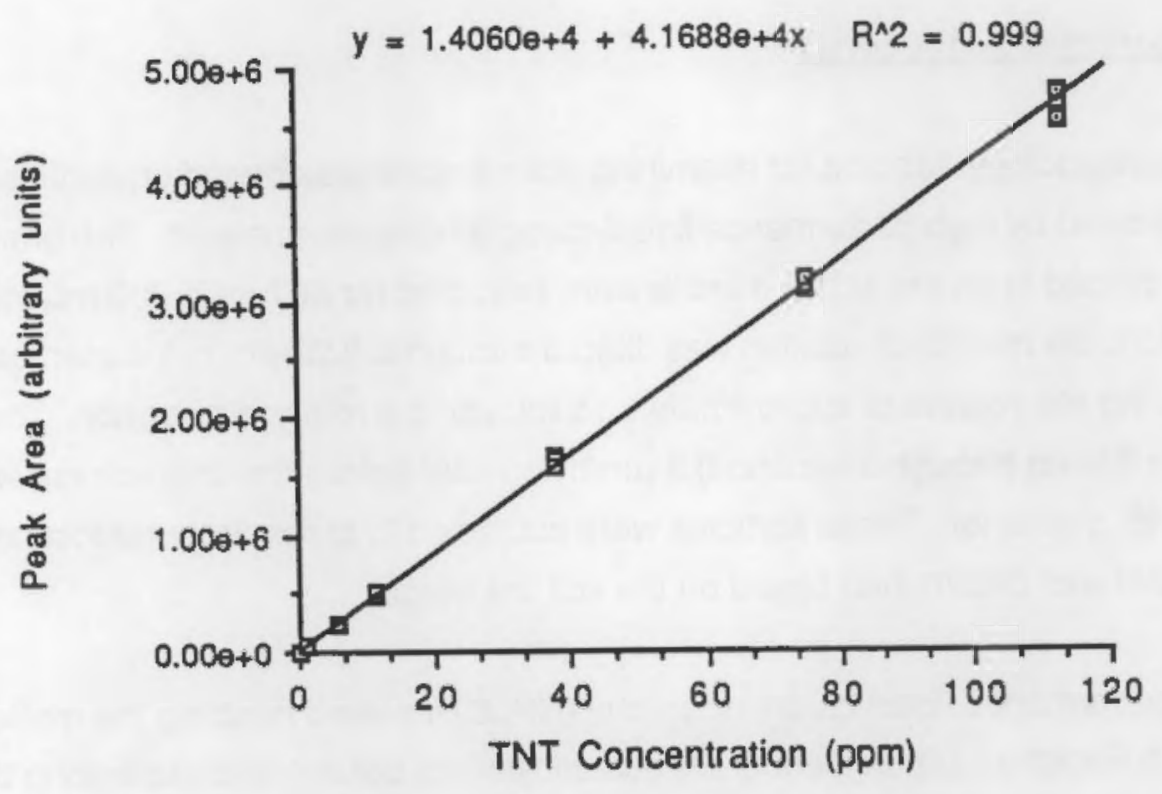

EIGURE 3.1. REPRESENTATIVE TNT STANDARD CURVE

3. 2 

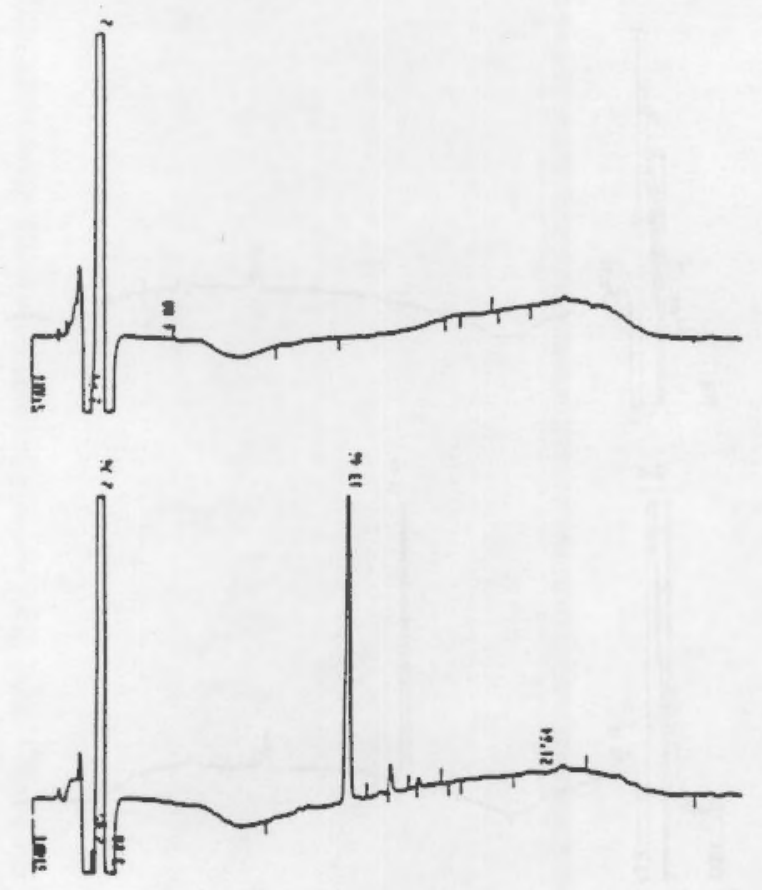

FIGURE 3.2. CHROMATOGRAMS OF TNT AND RESIDUES IN BURBANK SOIL
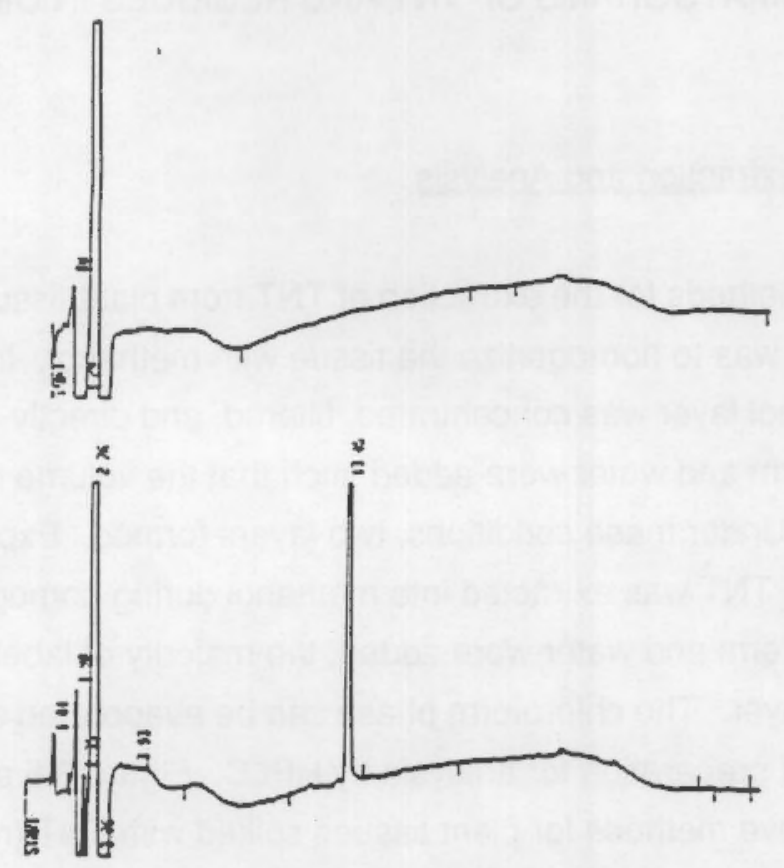

FIGURE 3.3. CHROMATOGRAMS OF TNT AND RESIDUES IN PALOUSE SOIL

3. 3 


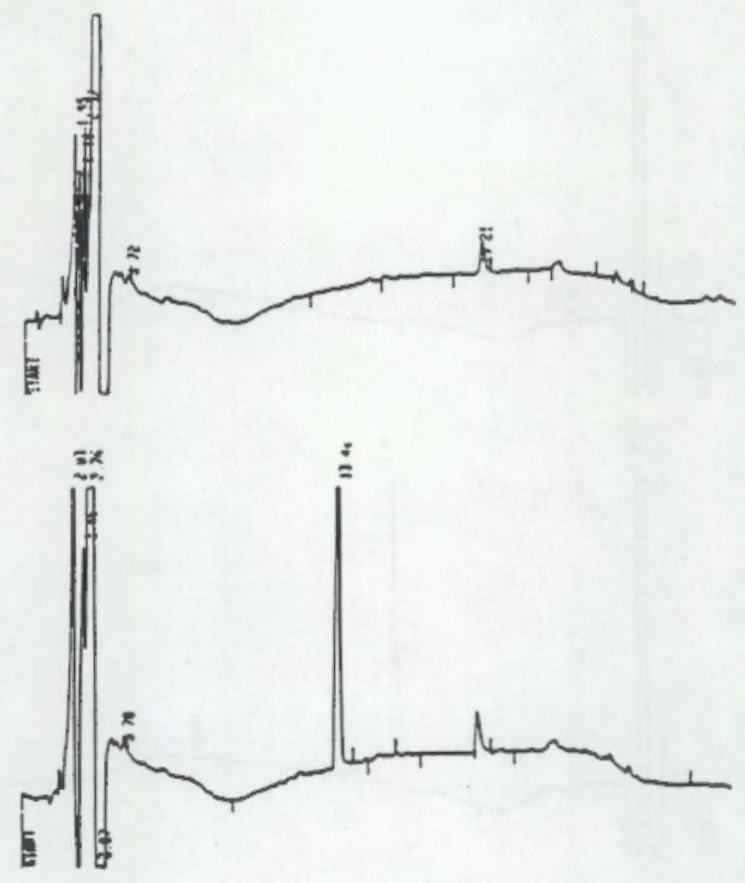

FIGURE 3.4. CHROMATOGRAMS OF TNT AND RESIDUES IN CINEBAR SOIL

\subsubsection{Plant-Tissue Extraction and Analysis}

Initially, two methods for the extraction of TNT from plant tissues were investigated. In both, the first step was to homogenize the tissue with methanol. In the first of these methods, the methanol layer was concentrated, filtered, and directly analyzed by HPLC. In the second, chloroform and water were added such that the volume ratio of $\mathrm{MeOH}$ to $\mathrm{CHCl}_{3}$ to $\mathrm{H}_{2} \mathrm{O}$ was 12:5:3. Under these conditions, two layers formed. Experiments with labeled TNT showed that the TNT was extracted into methanol during homogenization of the plant tissue. When chloroform and water were added, the majority of label was found to partition into the chloroform layer. The chloroform phase can be evaporated and the residue dissolved in methanol in preparation for analysis by HPLC. Figure 3.5 shows chromatograms generated by the above methods for plant tissues spiked with TNT (retention time of $13.04 \mathrm{~min}$ ). Although both methods are potentially valuable because of their abilities to extract a wide variety of organic compounds, they suffer from the disadvantage of 

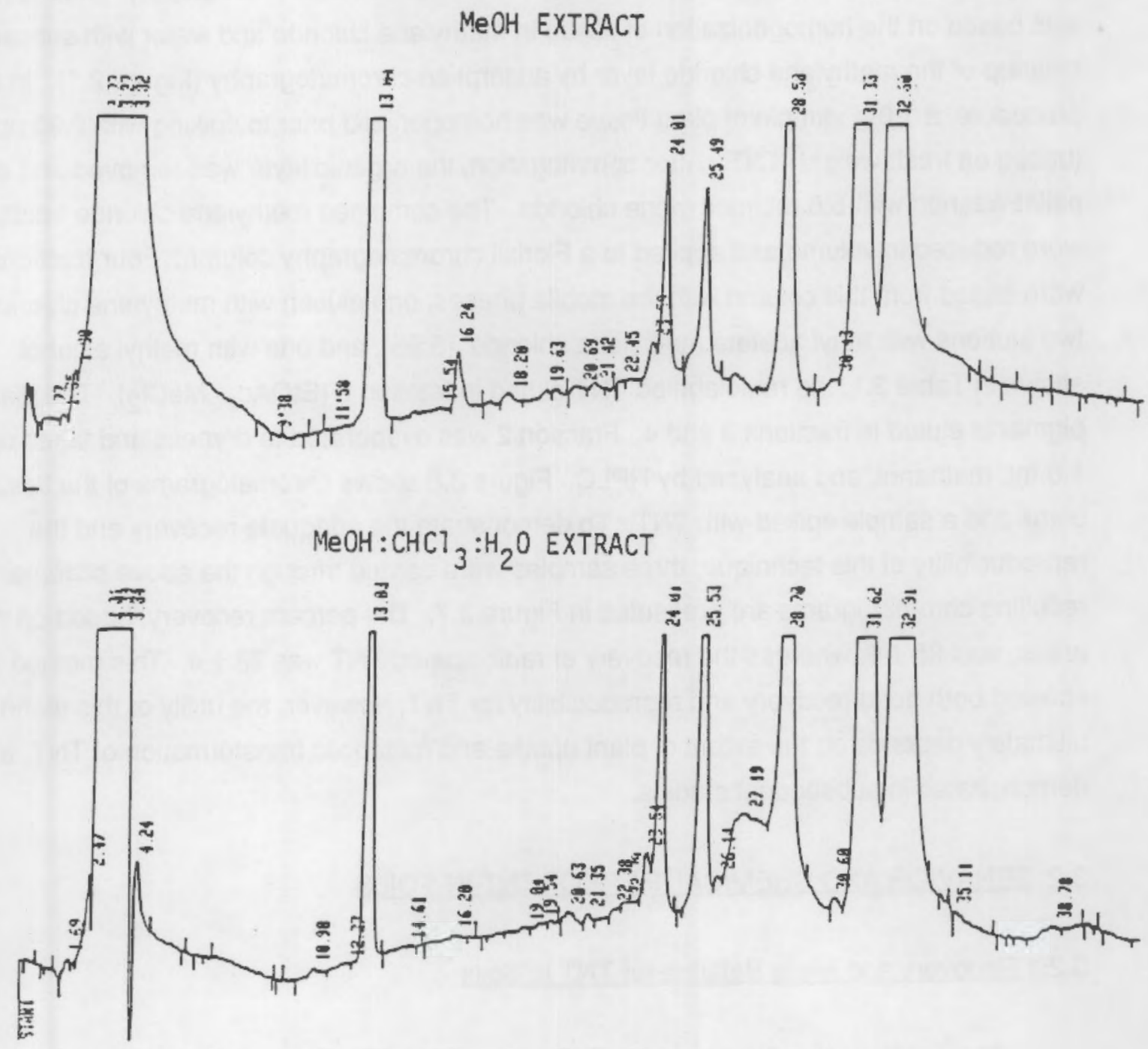

FIGURE 3.5. METHANOL (TOP) AND METHANOL:CHLOROFORM:WATER (BOTTOM) EXTRACTIONS AND CHROMATOGRAPHIC SEPARATIONS OF TNT FROM PLANT TISSUE SPIKED WITH RADIOLABELED TNT 
co-extracting the plant pigments (retention times from 21.04 to $33.0 \mathrm{~min}$ ). Such a large concentration of plant pigments may obscure TNT metabolites and may lead to column fouling.

A third method was developed to obviate problems associated with analyzing fractions containing plant pigments while maintaining a reasonable amount of flexibility. This method - was based on the homogenization of tissue in methylene chloride and water with subsequent cleanup of the methylene chloride layer by adsorption chromatography (Figure 2.1). In this procedure, a 1.0-g sample of plant tissue was homogenized prior to spiking with $2.93 \mathrm{ppm}$ (based on fresh weight) TNT. After centrifugation, the organic layer was removed and the pellet washed with $5.0 \mathrm{~mL}$ methylene chloride. The combined methylene chloride fractions were reduced in volume and applied to a Florisil chromatography column. Four fractions were eluted from this column with the mobile phases; one elution with methylene chloride, two elutions with ethyl acetate:methylene chloride (5:95), and one with methyl alcohol. As shown in Table 3.1, the radiolabeled TNT eluted in fraction $2\left(\mathrm{EtOAC}+\mathrm{MeCl}_{2}\right)$. The plant pigments eluted in fractions 3 and 4 . Fraction 2 was evaporated to dryness and taken up in $1.0 \mathrm{~mL}$ methanol, and analyzed by HPLC. Figure 3.6 shows chromatograms of the tissue blank and a sample spiked with TNT. To demonstrate the adequate recovery and the reproducibility of this technique, three samples were carried through the above scheme. The resulting chromatograms are presented in Figure 3.7. The percent recovery, based on peak areas, was $85 \pm 6$, whereas the recovery of radiolabeled TNT was $83 \pm 4$. This method showed both good recovery and reproducibility for TNT; however, the utility of this technique ultimately depends on the extent of plant uptake and metabolic transformation of TNT, as demonstrated in subsequent studies.

\subsection{BEHAVIOR AND CHEMICALFATE OF TNT IN SOILS}

\subsubsection{Recovery and Mass Balance for TNT in Soils}

The analysis of soil systems for TNT recovery and TNT transformation products was studied over a 61-day period. Results are presented in Table 3.2. Soil studies incorporating radiolabeled TNT allow not only identification of transformation products but also calculation of a mass balance. The first column represents the percentage of total radioactivity added to the soil that can be extracted by methanol during the Soxhlet extraction procedure. The second column represents the percentage TNT recovered in an unaltered form (these values 


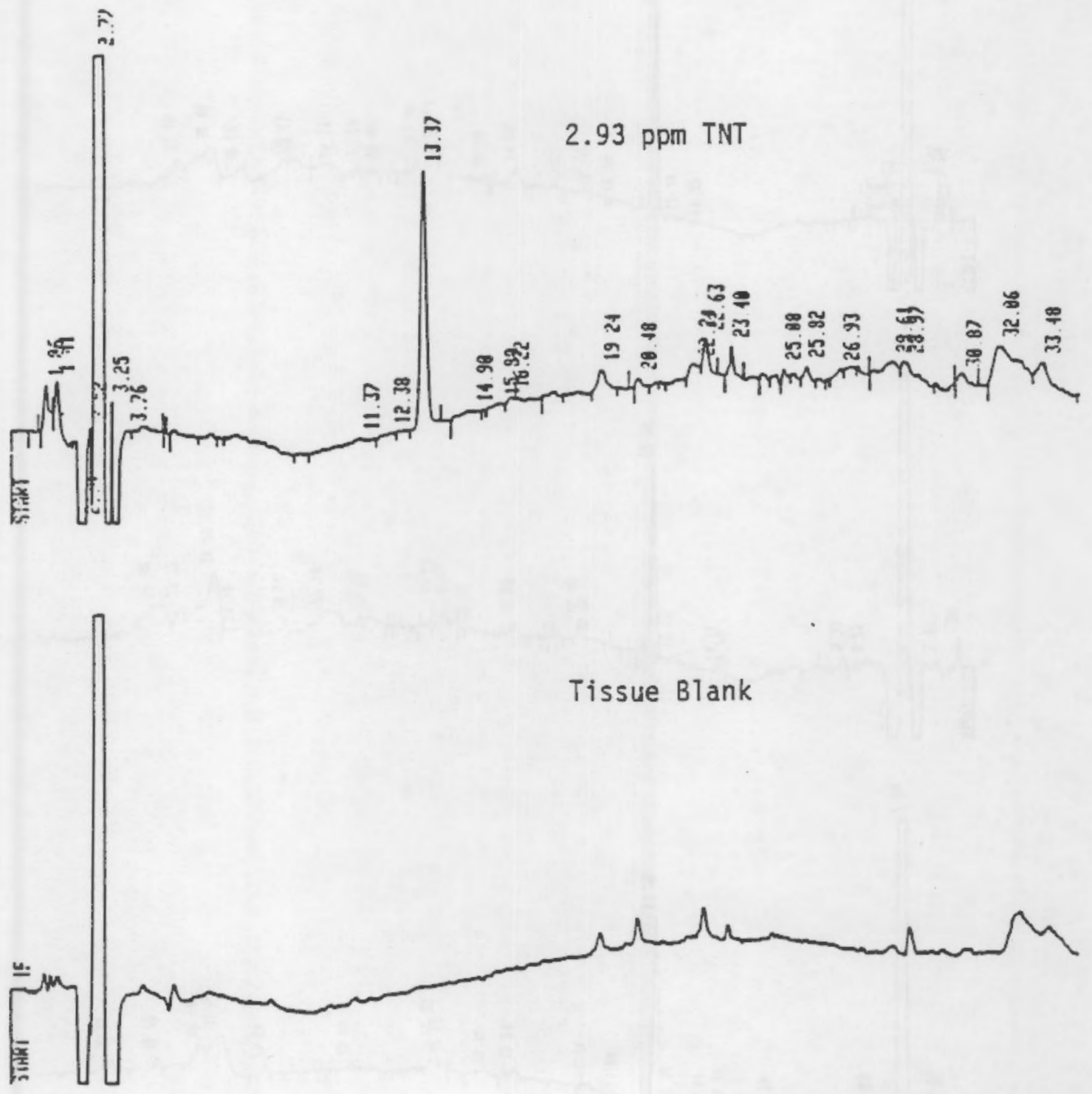

FIGURE 3.6. METHYLENE CHLORIDE EXTRACTION AND CHROMATOGRAPHIC SEPARATION OF TNT FROM PLANT TISSUE BLANK AND FROM TISSUE SPIKED WITH RADIOLABELED TNT 

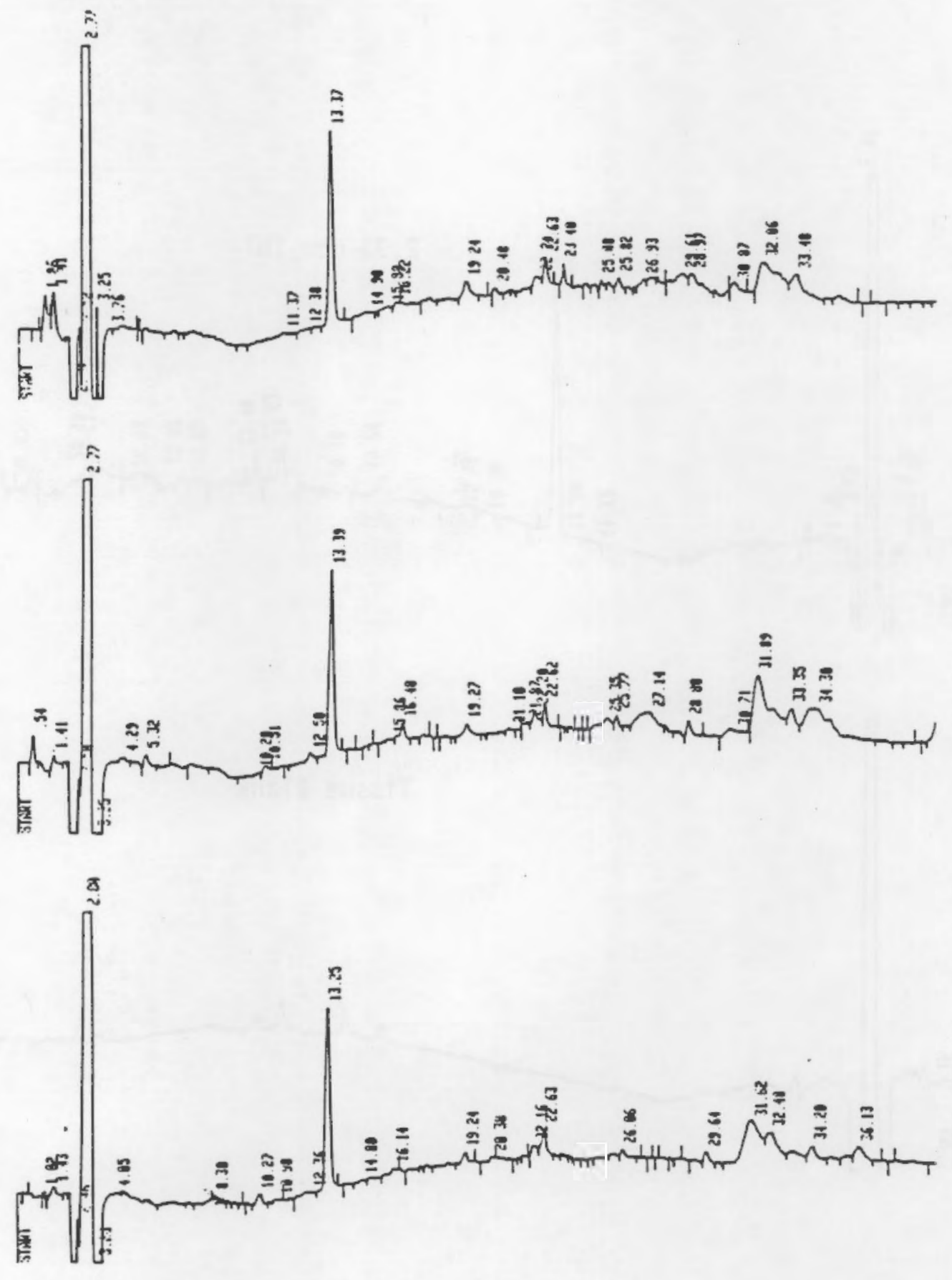

FIGURE 3.7. REPRODUCIBILITY OF METHYLENE CHLORIDE EXTRACTION AND CHROMATOGRAPHIC SEPARATION OF TNT FROM FRACTION 2 (F2) OF PLANT TISSUES SPIKED WITH RADIOLABELED TNT 
IABLE 3.1. AMOUNT OF RADIOLABEL IN VARIOUS FLORISIL ELUATE FRACTIONS FROM SPIKED PLANT TISSUES

\begin{tabular}{llcccc}
\hline $\begin{array}{l}\text { Sample } \\
\text { Replicate }\end{array}$ & \multicolumn{5}{c}{ Eluent Fraction (Activity in DPM) } \\
\cline { 2 - 6 } & $\mathrm{MeCl}_{2}$ & EtOAC $+\mathrm{MeCl}_{2}$ & EtOAC $+\mathrm{MeCl}_{2}$ & $\mathrm{MeOH}$ & Aqueous Layer \\
& 29 & 13,350 & 196 & 0 & 0 \\
\hline 1 & 0 & 11,775 & 15 & 0 & 166 \\
2 & 0 & 14,710 & 0 & 0 & 0 \\
\hline
\end{tabular}

TABLE 3.2. MASS BALANCE OF SOIL SYSTEMS CONTAINING TNT $(n=3)$

\begin{tabular}{lccccc}
\hline Soil & $\begin{array}{c}\text { Time } \\
\text { (days) }\end{array}$ & $\begin{array}{c}\text { \% Radiolabel } \\
\text { in Methanol } \\
\text { Extract }\end{array}$ & $\begin{array}{c}\% \text { Unaltered } \\
\text { TNT }\end{array}$ & $\begin{array}{c}\text { \% Radiolabel } \\
\text { in Soil After } \\
\text { Extraction }\end{array}$ & $\begin{array}{c}\text { Mass-Balance } \\
\text { Deficit } \\
(\%)\end{array}$ \\
\hline Burbank & 0 & $89 \pm 3$ & $74 \pm 4$ & $0.7 \pm .05$ & 10 \\
& 10 & $66 \pm 3$ & $2.3 \pm 3$ & $19 \pm 3$ & 15 \\
& 61 & $37 \pm 3$ & $2.3 \pm 0.4$ & $31 \pm 2$ & 32 \\
Palouse & 0 & $94 \pm 1$ & $88 \pm 1$ & $0.7 \pm 0.1$ & 5 \\
& 10 & $71 \pm 2$ & $57 \pm 4$ & $17 \pm 3$ & 12 \\
& 61 & $60 \pm 2$ & $36 \pm 3$ & $30 \pm 1$ & 10 \\
Cinebar & 0 & $101 \pm 1$ & $93 \pm 3$ & $6.2 \pm 0.5$ & -7 \\
& 10 & $48 \pm 1$ & $16 \pm 2$ & $50 \pm 3$ & 2 \\
& 61 & $40 \pm 2$ & $7.6 \pm 0.7$ & $54 \pm 3$ & 6 \\
\hline
\end{tabular}

were determined by chromatographic studies). The third column is the percentage of total TNT left in the soil after Soxhlet extraction, as determined by oxidation of the extracted soil and quantitation of the resulting ${ }^{14} \mathrm{CO}_{2}$ by liquid scintillation spectrometry. The last column represents the percentage of TNT that cannot be accounted for in either the methanol extract or the extracted soil [100 - (column $1+$ column 3)]. Two trends in these data are worthy of comment. First, at time 0 , the extraction efficiencies are quite high, but after 10 days the efficiency drops dramatically. This suggests that the TNT has undergone transformation into a nonextractable form. This trend is especially pronounced for the Cinebar soil, where 
approximately $50 \%$ of the TNT is present in the soil in a nonextractable form after only 10 days. Discrepancies between the percentage of recoverable radiolabel and of TNT at time 0 reflect the amount of transformation the TNT has undergone. For instance, the radiochromatogram of Burbank soil at 0 time shows that fifteen percent of the initial TNT is present as a unique transformation product (retention time of $15.24 \mathrm{~min}$, Table 3.2). Second, as soils are aged with TNT, the amount of radiolabel that cannot be accounted for increases. This may indicate that a small amount of TNT undergoes transformation to volatile products as the soils are aged.

After the soils had aged with TNT for 61 days, the percentage of radiolabel recoverable in the methanol extract continued to decrease. This decrease in extractable radiolabel with time corresponds to an increase in nonextractable radiolabel in the soils. The nonextractable radiolabel (as determined by oxidation of the extracted soils) corresponds to irreversible sorption of TNT or TNT transformation products to mineral surfaces and/or organic matter. This phenomenon has been described for chemically related compounds by several authors (Bollag et al. 1978; Hsu and Bartha 1974; Bartha and Pramer 1967). Cinebar soil had a greater ability to sequester radiolabel in nonextractable forms than the other two soil types, as might be expected from a soil with a high organic-carbon content. This trend was established within 10 days of aging, and continued through the analysis period. The mass balance throughout the 61 -day period was greater than $85 \%$ with the exception of a $32 \%$ mass deficit for Burbank soil observed during analysis at 61 days. In general, the mass-balance deficit seems to increase as the soils were aged, indicating that loss of radiolabel may occur through volatilization of a TNT transformation product or, more likely, through ${ }^{14} \mathrm{CO}_{2}$ evolution, either of which may explain the large mass deficit observed for Burbank soil at 61 days. The percentage of unaltered TNT recovered in the methanol extracts drops to very low levels $(2.3$ to $36 \%$ ) in all three soil types. This trend was least pronounced for Palouse soil, which showed $36 \%$ recovery of unaltered TNT after 61 days. This soil also displayed the highest recovery of unaltered TNT at 10 days post-amendment.

\subsubsection{Chemical Fate of TNT in Soils}

\section{Experiments with Nonsterile Soils}

Experiments were performed to evaluate the extraction procedure for its ability to recover and characterize TNT and its residues from the three soils. Pots containing $400 \mathrm{~g}$ of Burbank, Palouse, and Cinebar soils were amended with 20 ppm unlabeled TNT, and 10-g quantities of soil were immediately extracted $(\mathrm{t}=0)$ by the previously described method. The chromatograms of these samples are shown in the upper portions of Figures 3.8 to 3.10 . 
Interestingly, the chromatogram of the spiked Burbank soil shows a minor component eluting after the TNT peak with a retention time of about $15.14 \mathrm{~min}$ (peak 3). This is interesting since no more than $2 \mathrm{~h}$ elapsed between the soil amendment and the beginning of Soxhlet extraction. Peak 3 seems to be unique to Burbank soil containing TNT, not being observed in the other two soils. Recoveries of TNT (peak 2) from Burbank, Palouse, and Cinebar soils were $63.2,85.9$, and $95.8 \%$, respectively. The low recovery from Burbank soil was somewhat perplexing.

Further experiments examined triplicate extractions of each soil at times of up to 18 days after amendment. The chromatograms shown in the bottoms of Figures 3.8 to 3.10 are representative of the chromatographic profiles of Burbank ( $t=7$ days), Palouse ( $t=11$ days), and Cinebar ( $t=18$ days) soils. Given the short residence time of TNT in these soils, the extent of the chemical alteration was striking. The recovery of TNT (peak 2) from Burbank soil was $26.7 \pm 7.5 \%$ (after 7 days) from Palouse soil $31.6 \pm 1.6 \%$ (after 11 days), and from Cinebar soil $9.4 \pm 1.3 \%$ (after 18 days). These results strongly suggest that the
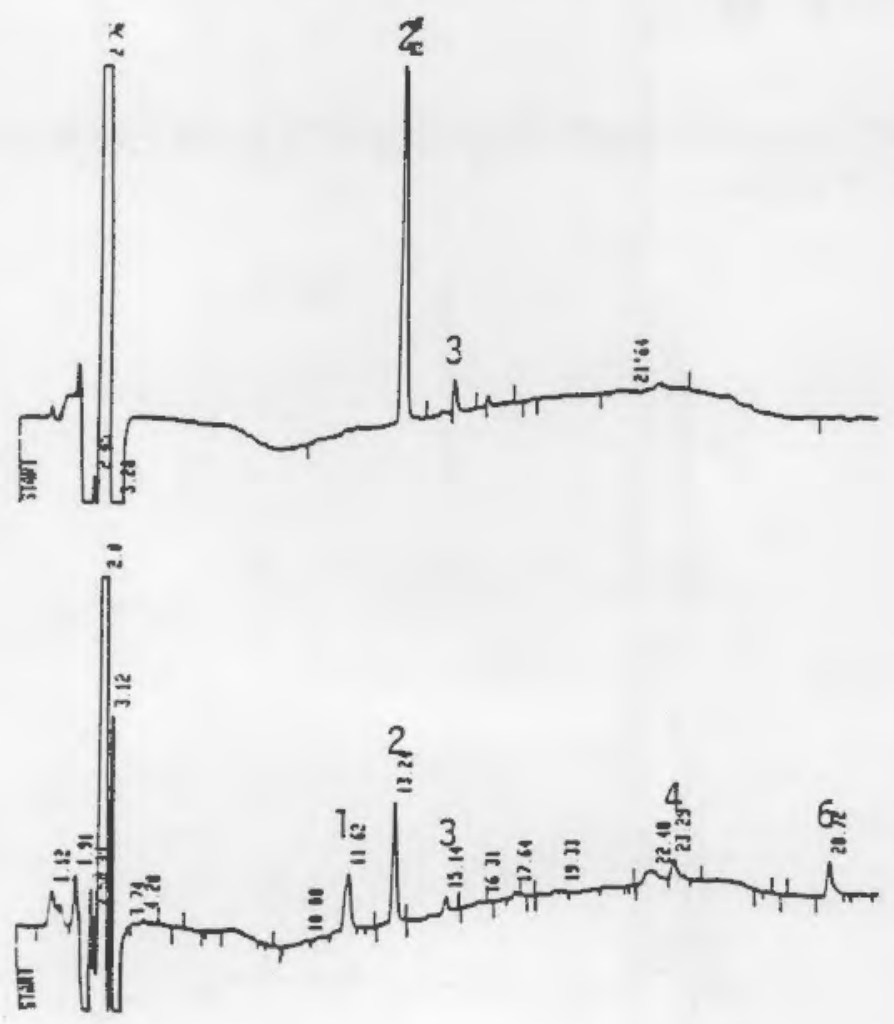

EIGURE 3.8. TNT TRANSFORMATION PRODUCTS IN BURBANK SOIL AT TIME 0 AND AT 7 DAYS 


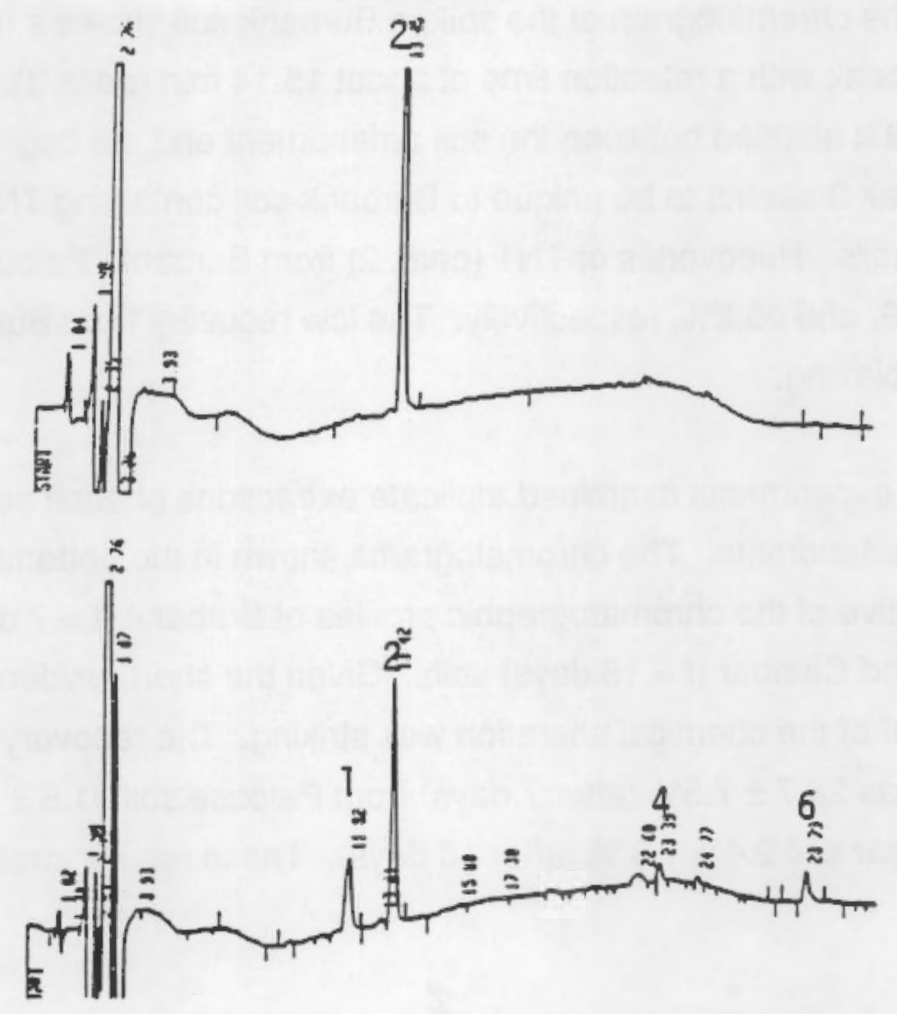

FIGURE 3.9. TNT TRANSFORMATION PRODUCTS IN PALOUSE SOIL AT TIME O AND AT 11 DAYS

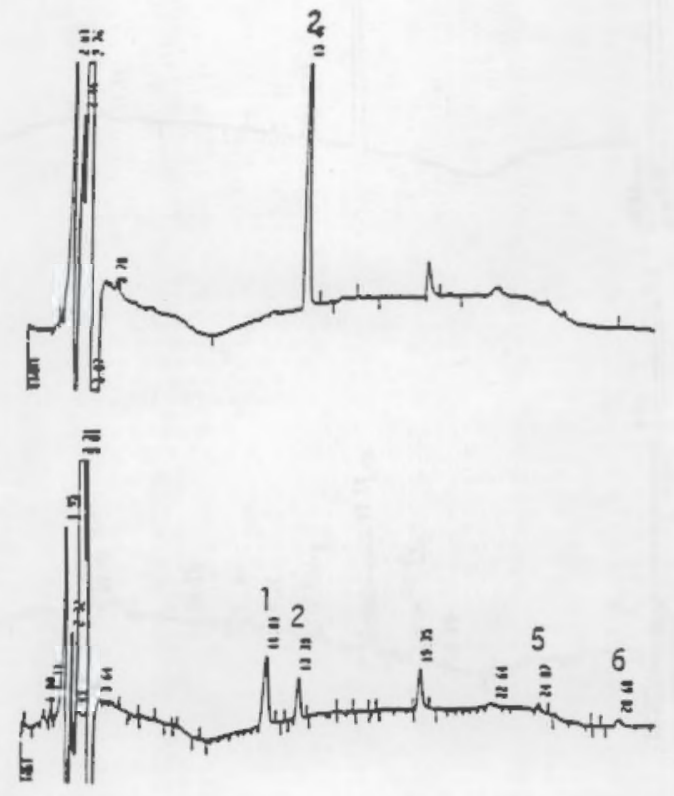

FIGURE 3.10. TNT TRANSFORMATION PRODUCTS IN CINEBAR SOIL AT TIME O AND AT 18 DAYS 
TNT undergoes extensive and rapid transformation within the soil. Well over $50 \%$ of the original TNT in the Burbank soil has undergone transformation within 7 days, and by 18 days only $10 \%$ of the original TNT remains in the Cinebar soil.

The chromatograms in the bottoms of Figures 3.8 to 3.10 all show additional peaks not present in the soil blanks. These compounds may represent transformation products of TNT. Of these compounds, the peak eluting prior to TNT (peak 1) seems consistently to be a major constituent of soils aged with TNT. Peak 1 is asymmetrical, which suggests that this peak represents the co-elution of at least two components. Provided that the co-eluting compounds have sufficiently different UV spectra, it should be possible to resolve the components by using a photodiode array (PDA) detector. Figure 3.11 shows a threedimensional plot of peak 1 as detected by the PDA detector. The lack of resolution of peak-1 components suggests that the co-eluting compounds have very similar UV spectra. In an independent experiment, a Cinebar ( $\mathrm{t}=18$ day) soil-extract sample was co-injected with a standard solution containing both TNT and 2-amino-4,6-dinitrotoluene. Peak 1 was tentatively identified as 2-amino-4,6-dinitrotoluene, based on the co-elution of this standard with peak 1. The second component in peak 1 may have been 4-amino-2,6-dinitrotoluene, since this compound and 2-amino-4,6-dinitrotoluene would be expected to have nearly identical retention times. Both compounds have been identified as transformation products of TNT by previous investigators (Spanggord et al. 1980; Pallazzo and Leggett 1986; Pennington 1987; Folsom et al. 1986). Since 2-amino-4,6-dinitrotoluene and 4-amino-2,6-dinitrotoluene are isomers, their UV spectra would be expected to be similar.

Minor components were observed in all three soil types aged with TNT. These compounds are labeled peaks 3 to 6 in Figures 3.8 to 3.10. Compound 3, which persists 7 days after amendment in the Burbank soil, seems to represent a TNT transformation product unique to this soil. Compounds present in lower abundance (peaks 4 to 6) were also observed in the chromatographic profiles. Compound 4 seems to be present in the TNTaged Burbank and Palouse soils, whereas Cinebar soil seems to contain a unique component (peak 5) and no detectable peak 4 . The intriguing possibility remains that unique microbial populations present in each soil type are responsible for the differences observed in the chromatographic profiles. The last component (Table 3.3, peak 6) was observed in all three soil types. The later-eluting compounds (peaks 4 to 6 ) could be nitroazotoluene isomers observed by previous investigators (Spanggord et al. 1980). A summary of retention times and areas of peaks found in TNT-aged soil is given in Tables 3.3 and 3.4. As can be seen from the relative peak areas (Figures 3.7-3.9 and Table 3.4), the compound represented by peaks 4 to 6 are present only in trace quantities. 


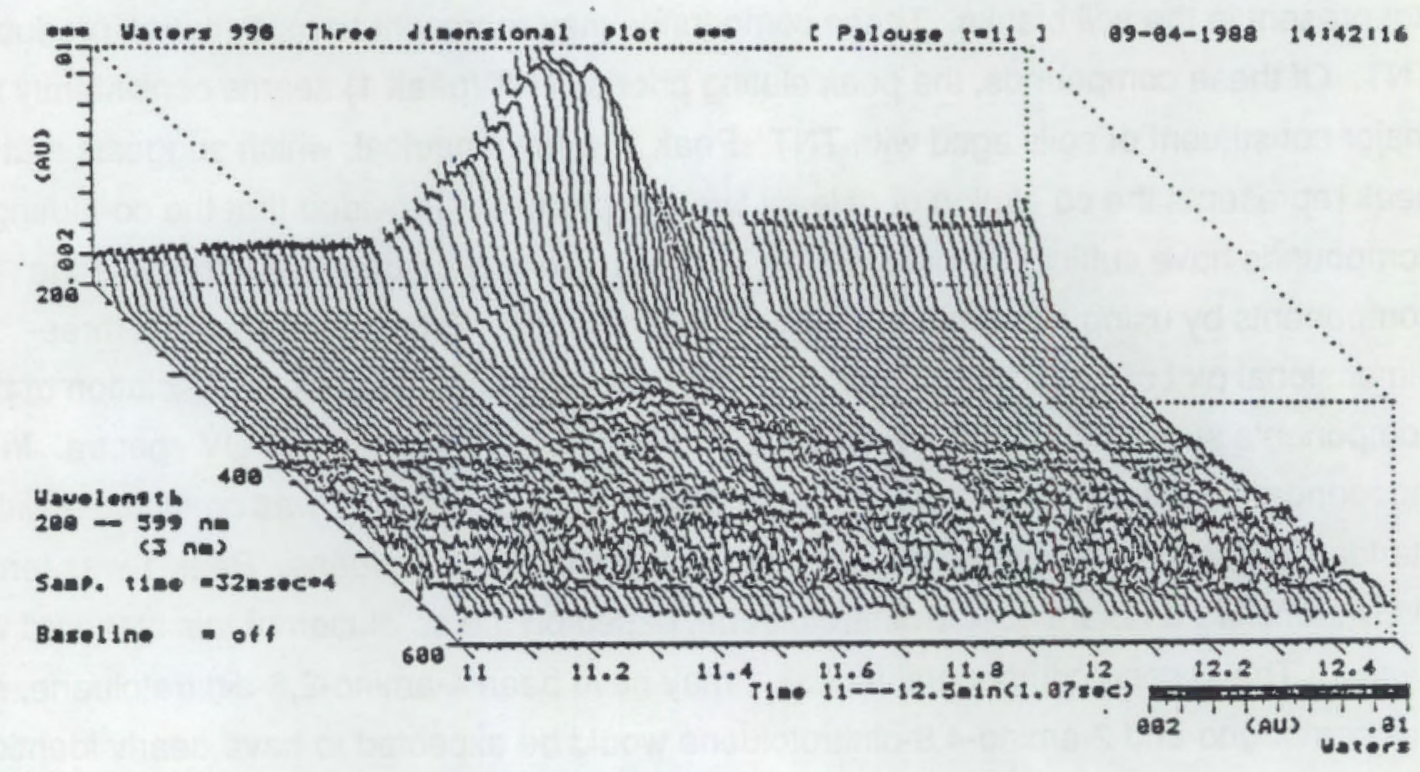

EIGURE 3.11. PHOTODIODE-ARRAY SPECTRA OF PEAK 1

TABLE 3.3. AVERAGE RETENTION TIME \pm 1 STANDARD DEVIATION (min) OF COMPOUNDS PRESENT IN SOILS AGED WITH TNT $(n=3)$

\begin{tabular}{lllll}
\hline Peak \# & Burbank Soil & Palouse Soil & Cinebar Soil & $\begin{array}{l}\text { Tentative } \\
\text { ldentity }\end{array}$ \\
\hline & & & & \\
1 & $11.66 \pm 0.04$ & $11.80 \pm 0.02$ & $11.83 \pm 0.03$ & AMDNT isomers \\
2 & $13.27 \pm 0.03$ & $13.40 \pm 0.02$ & $13.4 \pm 0.02$ & TNT \\
3 & $15.15 \pm 0.01$ & nd(a) & nd & Unique Burbank \\
4 & $23.33 \pm 0.05$ & $23.37 \pm 0.02$ & nd & UNK \\
5 & nd & nd & $24.85 \pm 0.03$ & UNK \\
6 & $28.66 \pm 0.06$ & $28.76 \pm 0.07$ & $28.69 \pm 0.03$ & UNK \\
\hline
\end{tabular}

(a) not detected 
TABLE 3.4. AVERAGE PEAK AREAS (IN ARBITRARY UNITS) AND RELATIVE STANDARD DEVIATIONS FOR COMPOUNDS PRESENT IN SOIL AGED WITH TNT $(n=3)$

\begin{tabular}{llll}
\hline Peak \# & Burbank Soil & Palouse Soil & Cinebar Soil \\
\hline 1 & $41416 \pm 14 \%$ & $55880 \pm 10 \%$ & $55173 \pm 5 \%$ \\
2 & $76787 \pm 28 \%$ & $103577 \pm 2 \%$ & $25120 \pm 4 \%$ \\
3 & $6046 \pm 79 \%$ & nd (a) & nd \\
4 & $17649 \pm 7 \%$ & $11385 \pm 7 \%$ & nd \\
5 & nd & nd & $13784 \pm 65 \%$ \\
6 & $12827 \pm 87 \%$ & $16638 \pm 18 \%$ & $6104 \pm 36 \%$
\end{tabular}

(a) not detected

Further studies, designed to confirm the presence of transformation products, differ from the above studies in two ways: 1) radiolabeled TNT was amended in the soil at the level of $10 \mu \mathrm{Ci}$ per $400 \mathrm{~g}$ soil (dry weight basis) and 2) the concentration of TNT was increased from 20 to $60 \mathrm{ppm}$. Since several tentative transformation products were observed in soils aged with cold TNT, the incorporation of radiolabeled TNT should allow for unambiguous identification of transformation products. The concentration of TNT in amended soils was increased threefold to allow for a more intense representation of possible transformation products in the chromatographic profiles.

The upper portions of Figures $3.12,3.13$, and 3.14 show chromatograms obtained from Soxhlet extracts of Cinebar, Palouse, and Burbank soils. These chromatograms represent the extractable components in the amended soils at time 0 . (No more than $3 \mathrm{~h}$ elapsed between the end of soil amendment and the start of Soxhlet extraction.) All three chromatograms show recovery of 2,4,6-trinitrotoluene (retention time of $13.39 \mathrm{~min}$ ). The component eluting at $19.35 \mathrm{~min}$ in Cinebar soil, found in the soil blank, was not formed as a result of TNT transformation (Figure 3.12). The soil blanks of both Burbank and Palouse 


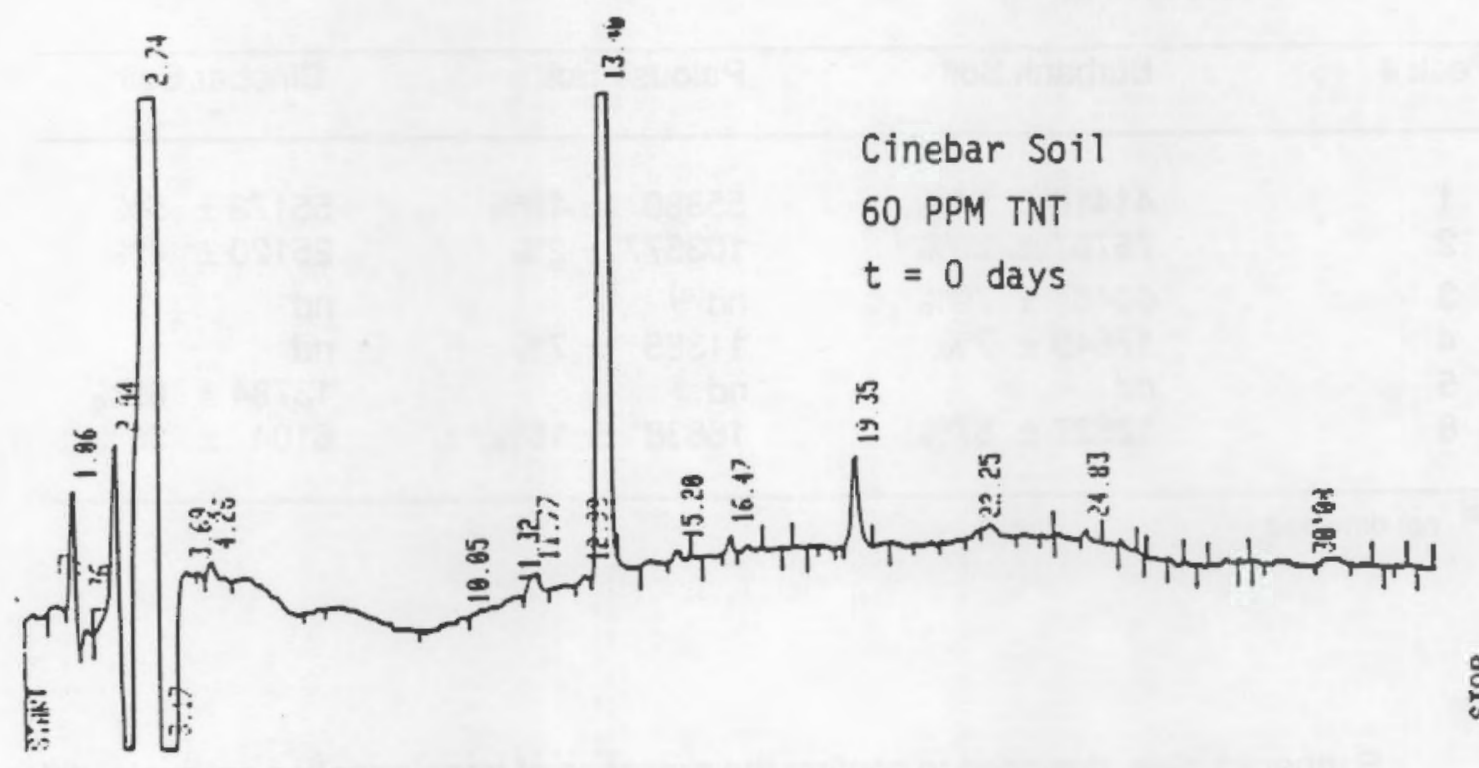

응

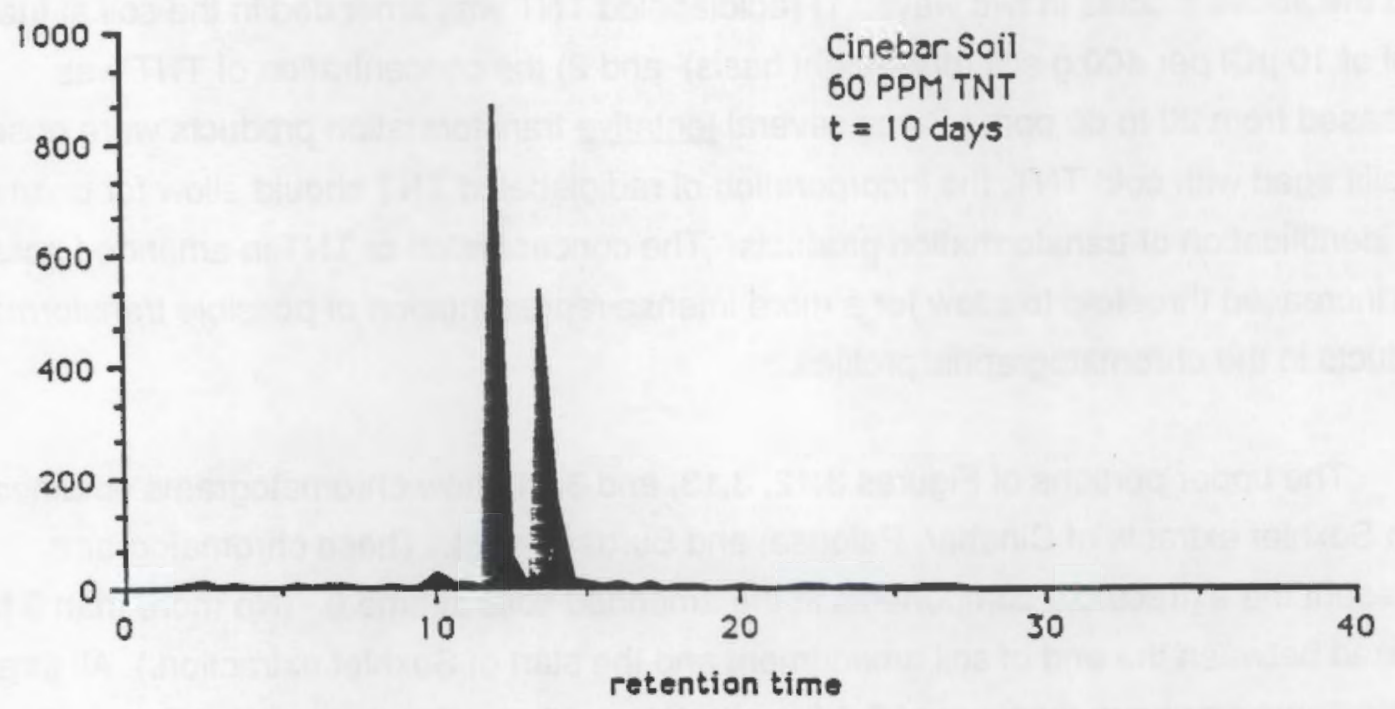

FIGURE 3.12. COMPARISON OF UV-ABSORBING (UPPER) AND RADIOCARBON (LOWER) CONSTITUENTS FROM CINEBAR SOIL 


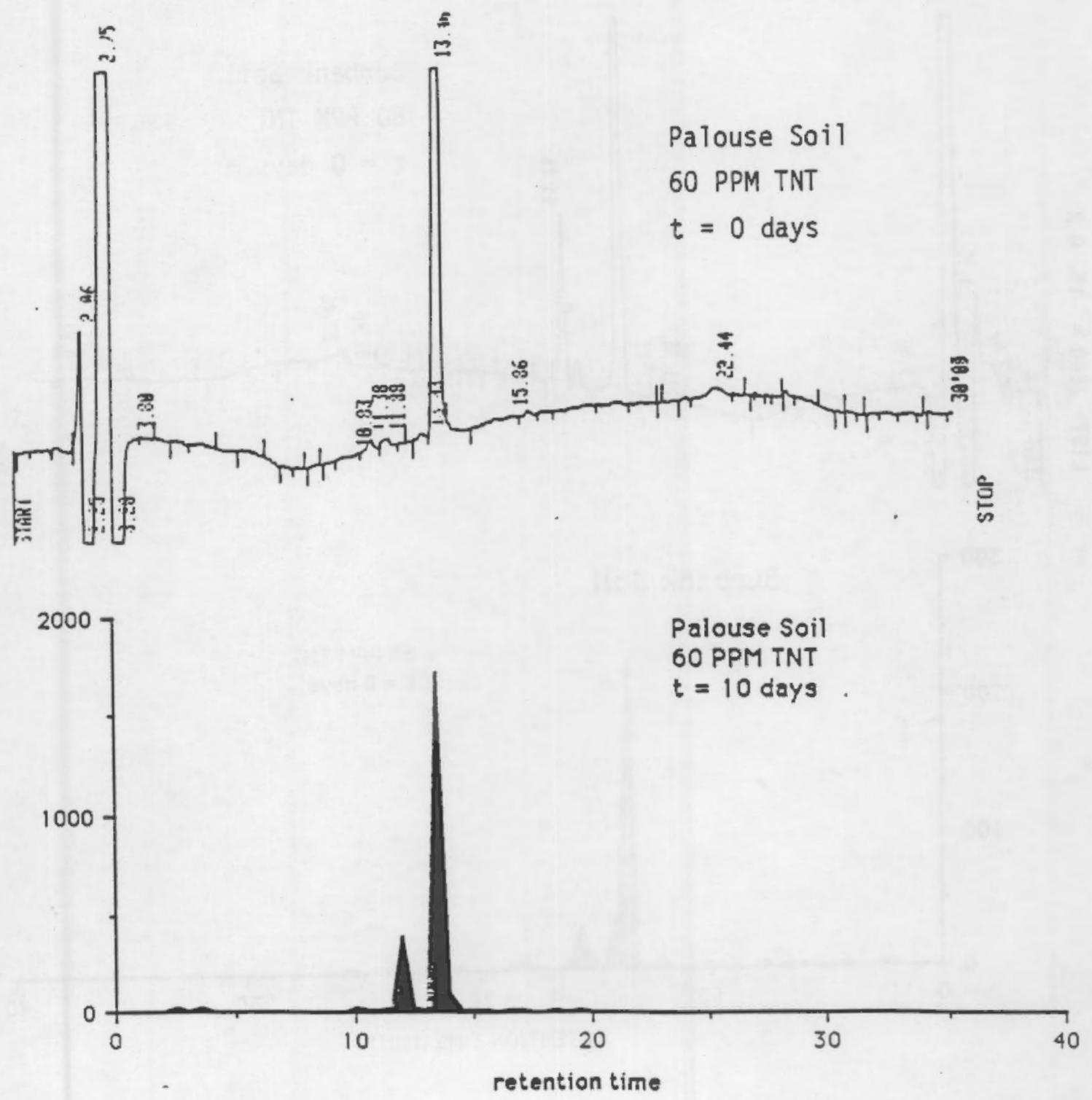

EIGURE 3.13. COMPARISON OF UV-ABSORBING (UPPER) AND RADIOCARBON (LOWER) CONSTITUENTS FROM PALOUSE SOIL 

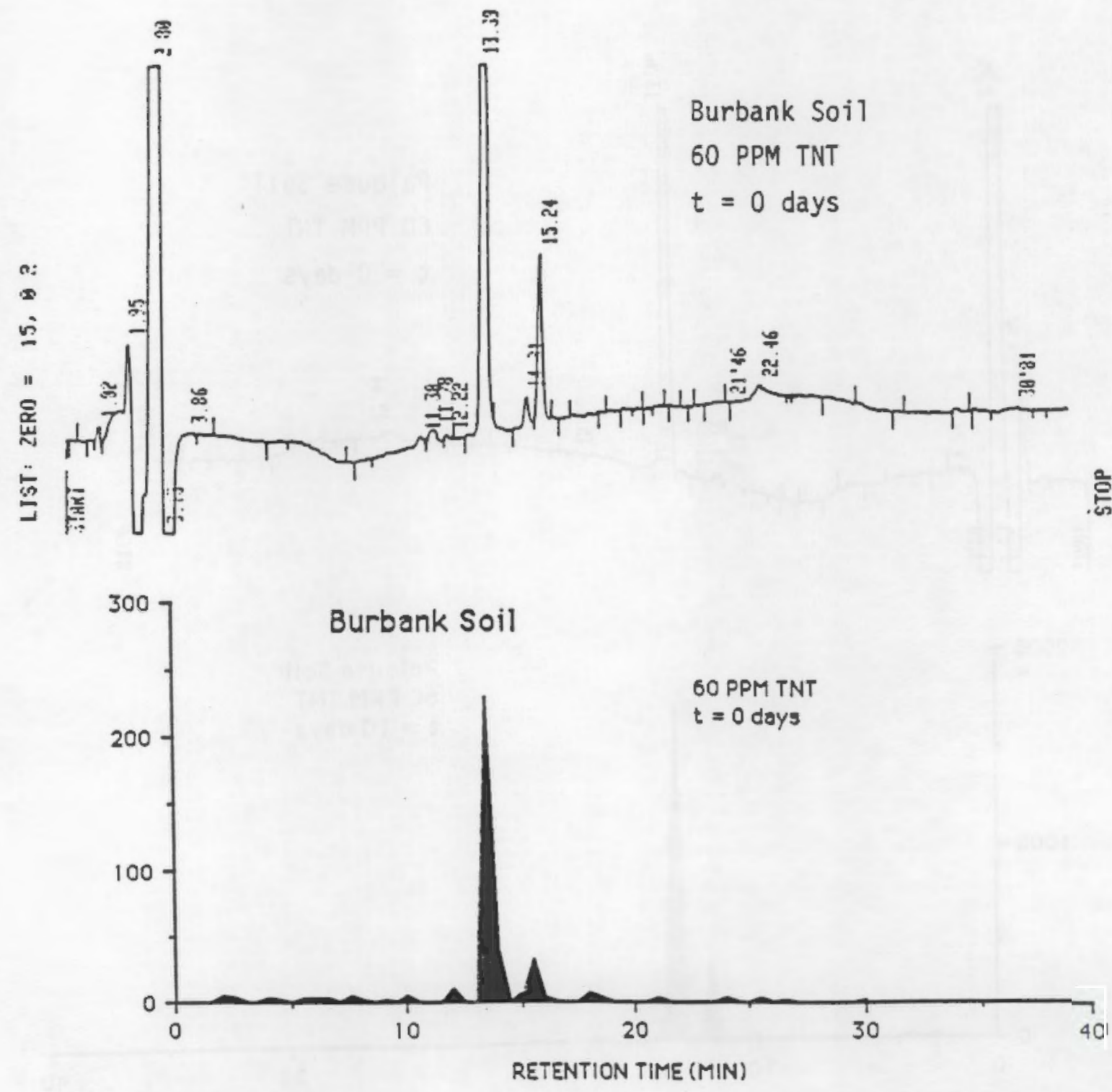

FIGURE 3.14. COMPARISON OF UV-ABSORBING (UPPER) AND RADIOCARBON (LOWER) CONSTITUENTS FROM BURBANK SOIL 
soils did not contain any indigenous compounds absorbing at $254 \mathrm{~nm}$. No major constituents other than TNT were observed in Palouse soil (Figure 3.13), although a component eluting with a retention time of 15.24 min was observed in the Burbank soil (Figure 3.14). The compound observed in Burbank soil was identified as a transformation product of TNT, because of the presence of radiolabel, as discussed below.

Radiochromatography was used to examine the methanol extracts of soils that seemed to contain TNT transformation products. Radiochromatograms of Cinebar and Palouse soils aged with TNT for a 10-day period are shown in the bottoms of Figures 3.12 and 3.13. It is apparent that both soils contain the same TNT transformation product, which elutes with a retention time of about $12 \mathrm{~min}$. To determine whether the compound that appears in Burbank soil a few hours after amendment is derived from TNT, radiochromatography was performed on this extract. The chromatogram is presented in the bottom of Figure 3.14. As can be seen in this figure, the compound eluting with a retention time of 15.24 min contains radiolabel from the parent TNT. Apparently, TNT is rapidly altered in this particular soil to yield a unique transformation product. The chromatographic profiles of Burbank soil become even more interesting when the TNT is allowed to age in this soil. The radiochromatogram presented in Figure 3.15 shows the extract of Burbank soil aged with TNT for 10 days. This profile shows not only the persistent presence of the unique

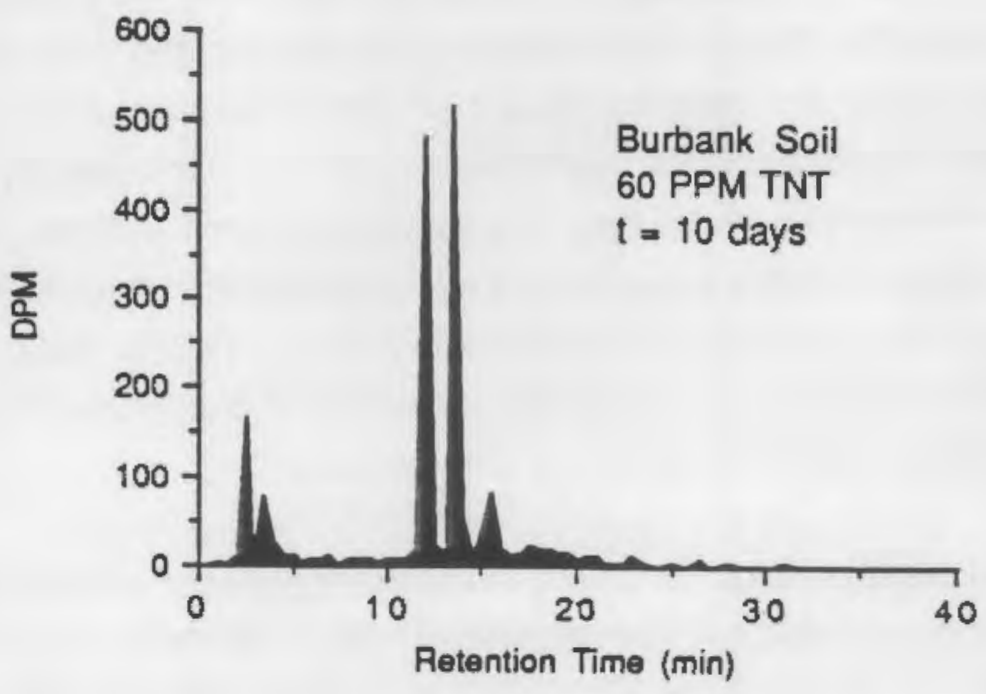

\section{FIGURE 3.15 . RADIOCHROMATOGRAM OF HPLC SEPARATIONS OF EXTRACTS FROM BURBANK SOIL AGED FOR 10 DAYS}


transformation product (retention time of $15.24 \mathrm{~min}$ ) but also the presence of the same transformation product found in both Cinebar and Palouse soils (retention time of $12 \mathrm{~min}$ ). Two additional unique transformation products, which elute shortly after the column dead volume, were observed.

An attempt to identify the ubiquitous TNT transformation product found in all three soils was undertaken. Careful inspection of the chromatographic profiles at time 0 (tops of Figures $3.12,3.13$, and 3.14 ) revealed small peaks (retention time of 11.3 to $11.9 \mathrm{~min}$ ) in the vicinity of where this transformation product was ultimately detected. This suggested that transformation of TNT to this product begins immediately on amendment in all three soil types. Since this component elutes with an asymmetrical peak shape, it was suspected that this peak contained at least two compounds. Attempts to spectrally resolve these components by using a photodiode-array detector were unsuccessful. It was possible to tentatively identify one constituent of this peak by verifying the increase in relative peak area when 2-amino-4,6dinitrotoluene was co-injected with the methanol extract of Cinebar soil aged with 20 ppm TNT for 18 days. Chromatograms illustrating the co-injection experiment are shown in Figure 3.16.

Characterizing the ubiquitous component observed in soils centered on GC/MS studies. Figure 3.17 shows the resulting chromatograms and mass spectra of standards containing TNT and 2-amino-4,6-dinitrotoluene. To collect sufficient material from soil extracts for GC/MS studies, an extract from Burbank soil ( $t=7$ days) was concentrated tenfold and repetitively chromatographed while the HPLC-peak of interest was collected. The pooled material from 10 collections was reduced to dryness with a stream of dry nitrogen and taken up in $20-\mu \mathrm{l} \mathrm{MeCl}$. The gas chromatogram of this material (Figure 3.18) shows two major components. A match in both retention time and mass-spectral fragmentation patterns unambiguously identified one component as 2-amino-4,6-dinitrotoluene. The second and more-abundant component showed a mass spectrum clearly indicative of a structural isomer of 2-amino-4,6-dinitrotoluene. Although a standard of 4-amino-2, 6-dinitrotoluene was not available, this compound is aimost certainly the additional isomer. It is of interest that 4-amino-2,6-dinitrotoluene was present at about twice the concentration of 2-amino-4,6-dinitrotoluene.

Throughout the entire analysis, 2- and 4-aminodinitrotoluene were found to be the principal transformation products in all three soils. These components appeared almost immediately in the soil and increased dramatically by 10 days post-amendment. Between 10 and 61 days post-amendment, concentrations increased only slightly. The chromatographic profiles of the Burbank-soil extracts continued to show the presence of a unique transformation product. Figure 3.19 plots for Burbank soil the peak areas of TNT aminodinitrotoluene isomers and the unique transformation product as functions of time throughout the 61-day study. 
The peak area of TNT in the methanol extracts dramaticaily decreases over the 10 day period as the concentration of the aminodinitrotoluene isomers increase. Interestingly, the peak area of the unique component was maximal immediately after amendment and decreased somewhat in concentration with time. This temporal profile suggests that this unique component may be a short-lived intermediate in the pathway leading to the formation of the aminodinitrotoluene isomers. A principal candidate was hydroxylaminodinitrotoluene, a known intermediate in the formation of the aminodinitrotoluene isomers (McCormick et al.

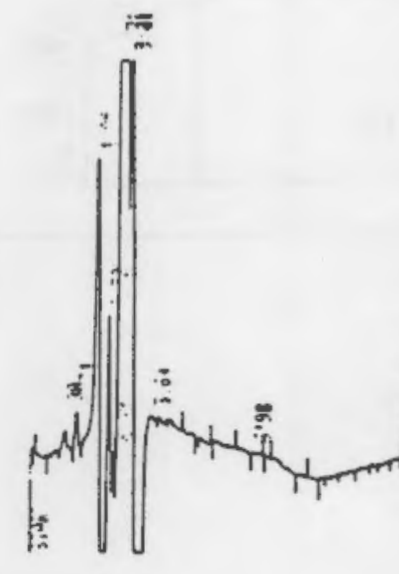

\section{CINEBAR SOIL}

20 PPM TNT

$t=18$ days

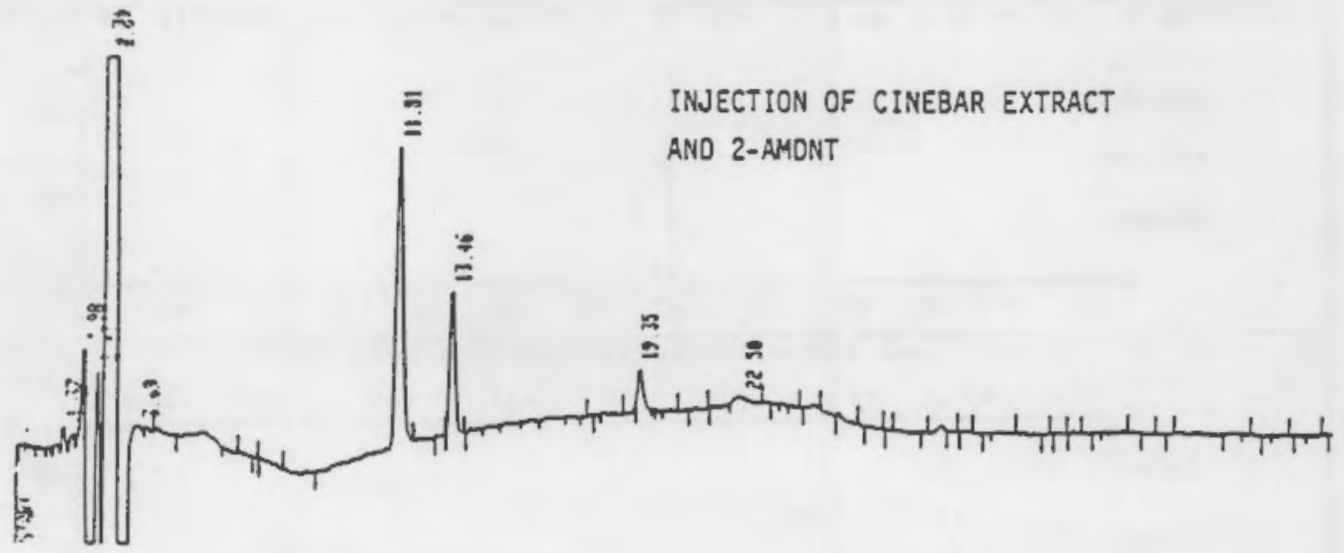

FIGURE 3,16. HPLC CHROMATOGRAM OF TNT RESIDUES IN CINEBAR SOILS INCUBATED FOR 18 DAYS (UPPER), AND COCHROMATOGRAPHY OF ADDED 2-AMINO-4,6-DINITROTOLUENE (LOWER) 

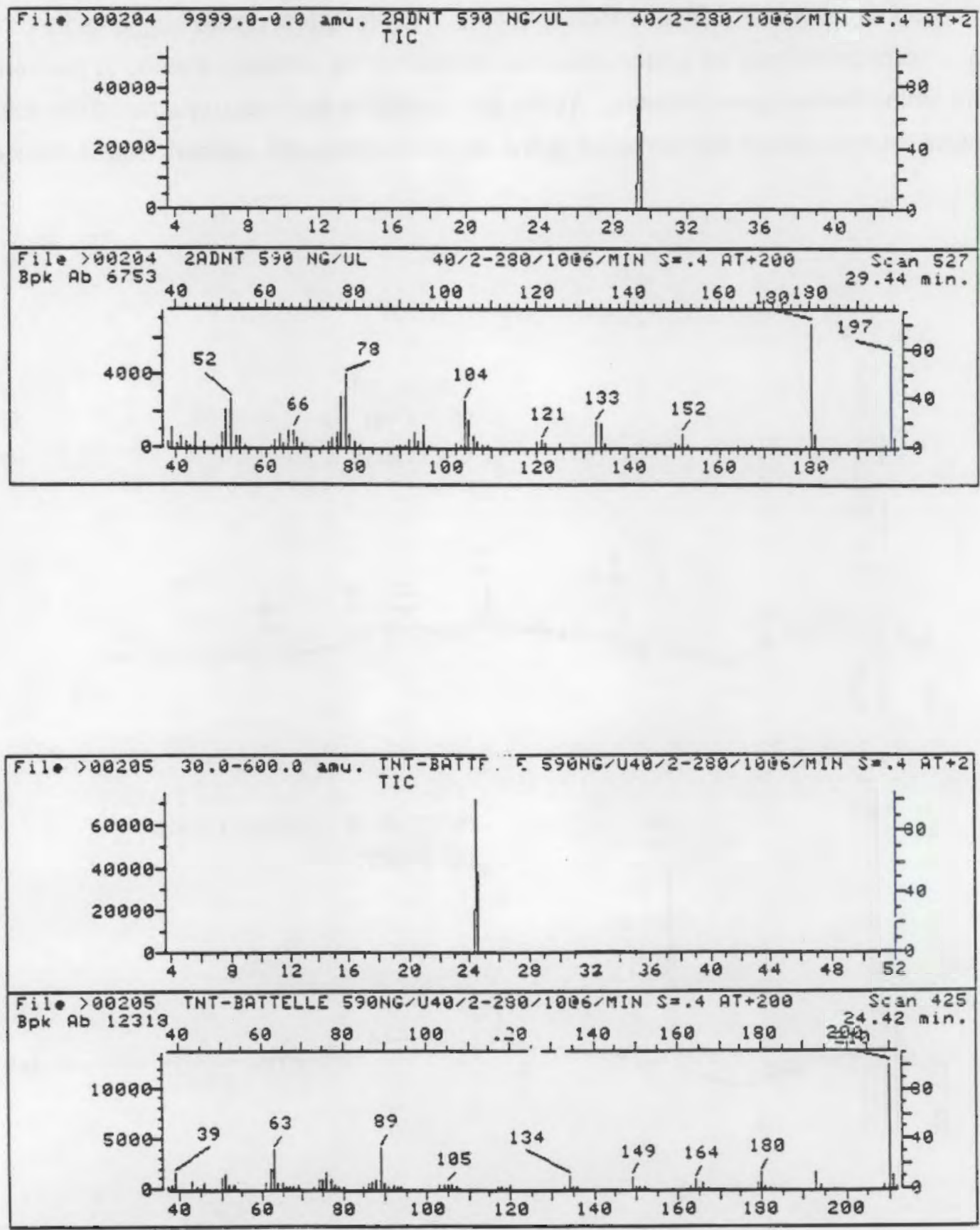

EIGURE 3.17. CHROMATOGRAMS AND MASS SPECTRA OF TNT AND 2-AMINO4,6-DINITROTOLUENE STANDARDS 

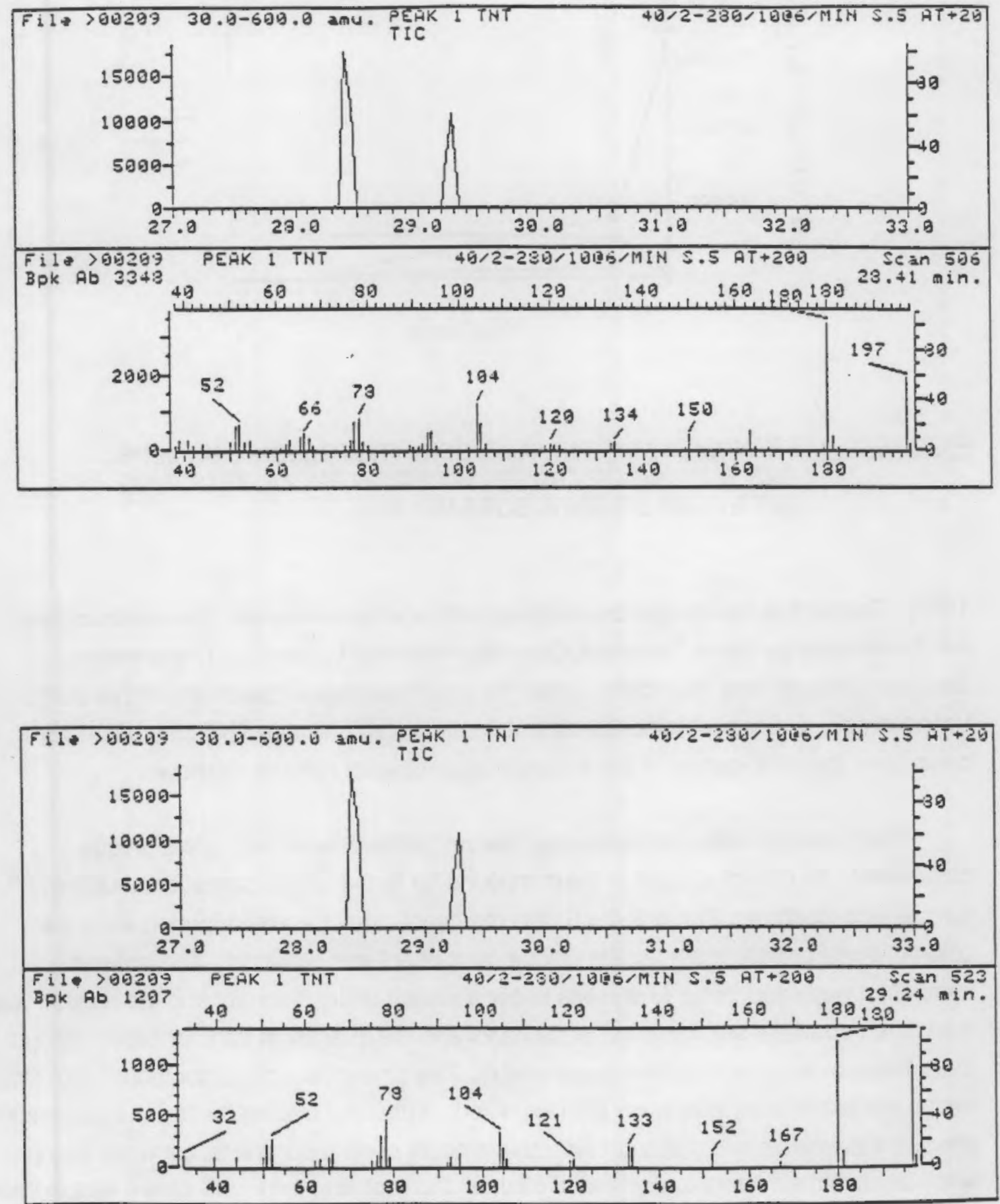

FIGURE 3.18. TOTAL ION-CURRENT CHROMATOGRAM AND MASS SPECTRA OF TNT RESIDUES EXTRACTED FROM BURBANK SOIL 


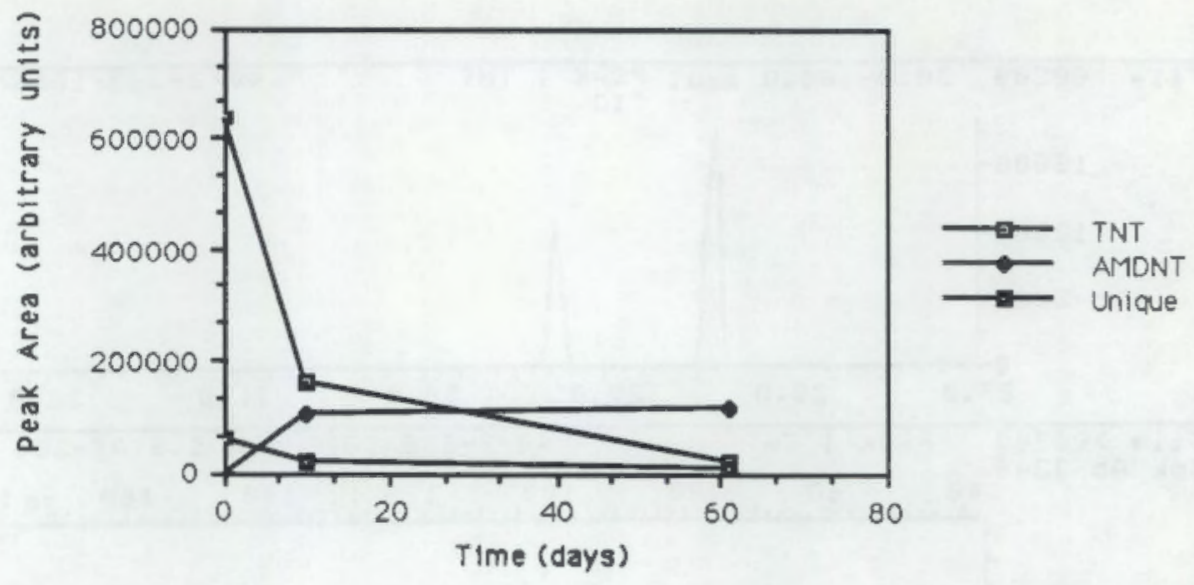

EIGURE 3.19. PEAK AREAS OF TNT, AMINODINITROTOLUENE ISOMERS, AND THE UNIQUE TRANSFORMATION PRODUCT DURING THE 61-DAY STUDY IN BURBANK SOIL

1976). To test this hypothesis, the retention time of 4-hydroxylamino-2,6- dinitrotoluene (kindly provided by Bruce Tompkins, Oak Ridge National Laboratory, Environmental Sciences Division) was determined under the chromatographic conditions of this study. Unfortunately, 4-hydroxylamino-2,6-dinitrotoluene eluted between TNT and the unique compound, thus the identity of this transformation product remains unknown.

Considerable effort was expended toward further characterizing this unique component. To collect enough of the compound for further characterization, multiple HPLC runs of a concentrated Burbank ( $\mathrm{t}=0$ day) methanol extract were performed while the column eluate corresponding to the unique component was collected. The isolated compound was evaporated to dryness under a stream of dry nitrogen, and the residue was then taken up with a small volume of methanol and the quantity of transformation product determined by liquid scintillation spectrometry. The amount of unique component collected during this experiment was lower than expected. It became evident that the transformation product was volatile and that a considerable amount of compound was lost while taking the water/acetonitrile mixture to dryness. To curtail this problem, the HPLC eluate was extracted with diethyl ether. The ether phase was stored at $-80^{\circ} \mathrm{C}$ until immediately before analysis by $\mathrm{GC} / \mathrm{MS}$ when it was thawed and evaporated just to dryness. The residue was then taken up in a small aliquot of toluene. Injections were made (2- $\mu$ l splitless) onto a 15-m SE-54 fused silica capillary column. The components were separated by programming the column from 
50 to $280^{\circ} \mathrm{C}$ at $8^{\circ} \mathrm{C} / \mathrm{min}$. Nominal-resolution mass spectra were collected by scanning the Hewlett-Packard model 5985 quadrupole mass spectrometer from 40 to 400 amu.

The GC/MS data revealed a compound with an apparent molecular weight of 212 eluting with a retention time of $14.98 \mathrm{~min}$. The mass spectrum of this compound is shown in Figure 3.20. The loss of 17 amu to give the base fragment of 195 is diagnostic

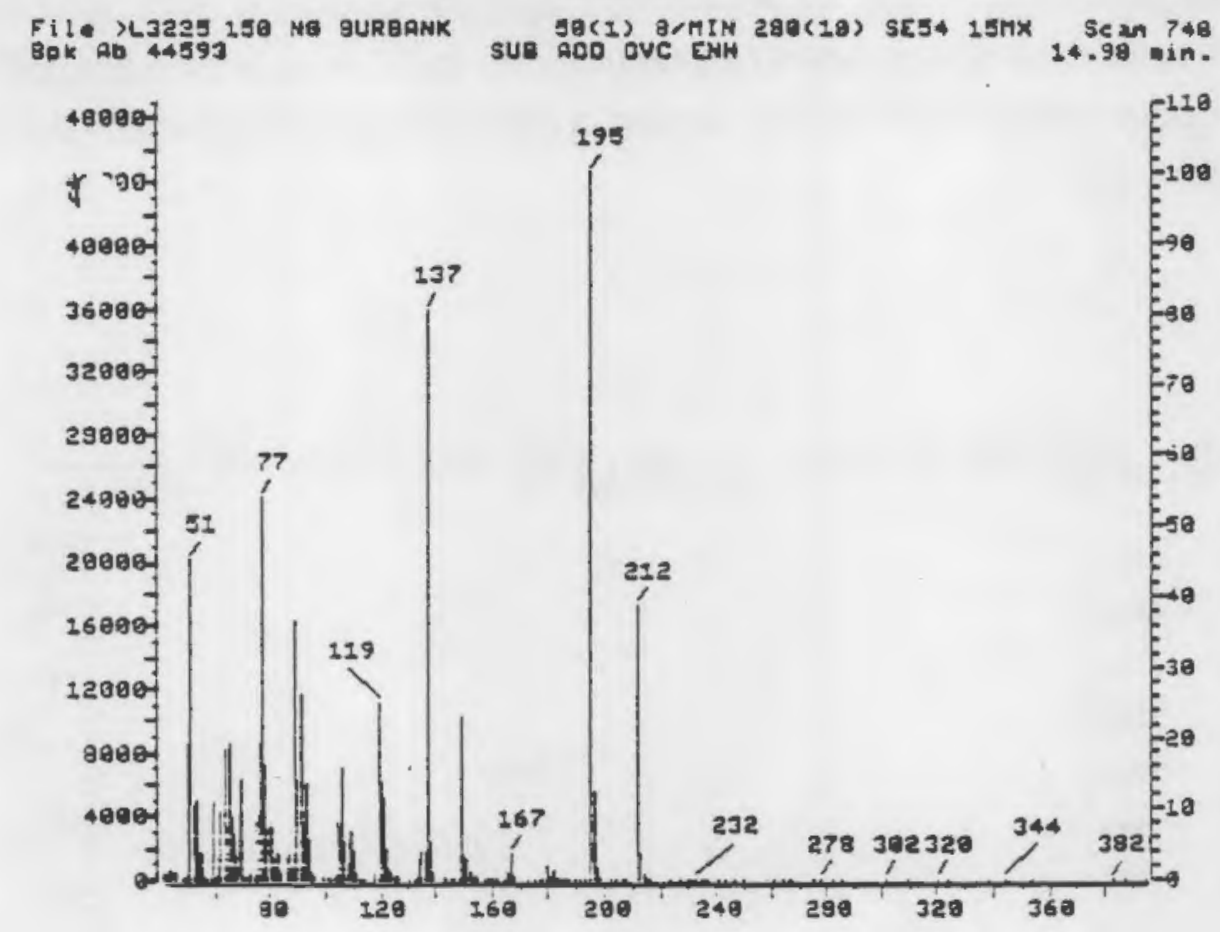

\section{EIGURE 3.20. MASS SPECTRA OF THE UNIQUE TRANSFORMATION PRODUCT ISOLATED FROM BURBANK SOIL CONTAINING TNT}

of a nitro group positioned ortho to the methyl functionality of toluene. Assuming that the 212 fragment represents the molecular ion, this analyte has an even number of nitrogens, indicating a loss or gain of a nitrogen atom by the parent TNT molecule. Further scrutiny of the GC/MS data revealed the presence of a second isomer of the unknown compound eluting with a retention time of $14.00 \mathrm{~min}$. The concentration of the first eluting isomer was much less than that of the second. The mass spectrum of the trace component is presented in Figure 3.21. 
Although the exact identity of the unknown transformation products remain a mystery, several interesting properties of these compounds are evident. The undeniable evidence for the volatility of the transformation products suggests that analysis by GC/MS is appropriate and that the mass spectra shown in Figures 3.20 and 3.21 correspond to the transformation products rather than thermal-decomposition products produced in the gas-chromatographic injection port. Because the spectra presented in Figures 3.20 and 3.21 do not correspond to any published spectra of TNT-derived transformation products (Yinon 1989; Yinon and Hwang 1984; Spanggord et al. 1980), we believe the unique transiormation products isolated from TNT-spiked Burbank soil represent hitherto unknown transformation products of TNT. The volatile nature of these products may explain in part the larger mass-balance deficit observed in the Burbank soil.

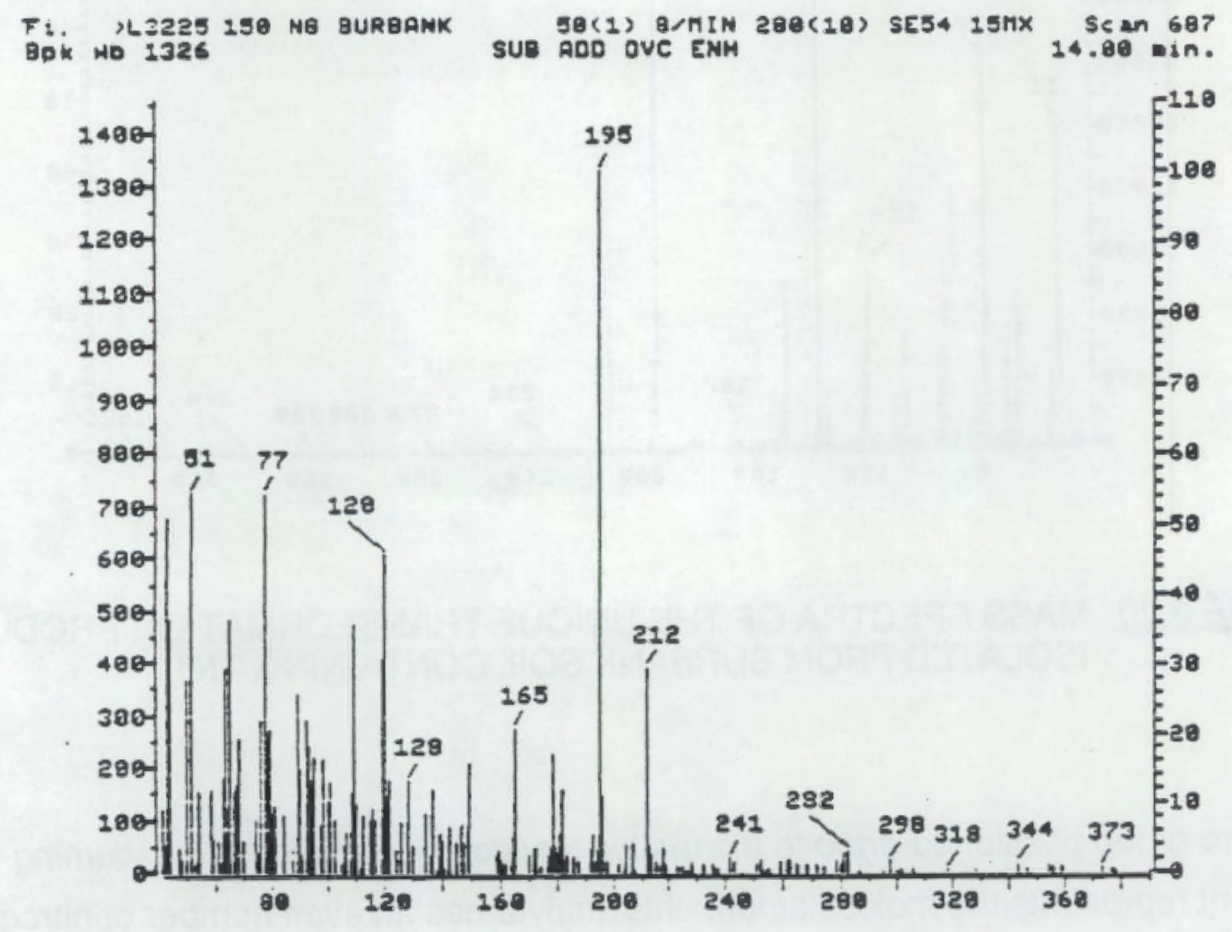

FIGURE 3.21. MASS SPECTRUM OF AN ADDITIONAL ISOMER OF THE UNIOUE TRANSFORMATION PRODUCT WHICH CO-ELUTES IN THE SAME HPLC PEAK AS THE COMPOUND IN FIGURE 3.20 


\section{INT Transformations in Sterile Soils}

The data from Table 3.2 indicate that transformation of TNT in soil was extensive, with the major extractable transformation products being both 2-and 4-aminodinitrotoluene. The question arises of whether these transformations are a result of microbial metabolism, soil catalytic transformation, or a combination of both. To directly address this question, we conducted experiments with sterile soils. Soils were sterilized by exposing them to $60 \mathrm{Krad}(0.6$ KGy) of gamma radiation from a ${ }^{60} \mathrm{Co}$ source. Such an exposure adequately assures that the soils are devoid of microbial activity, and additionally, it is highly improbable that enzymes originally present in bacterial cells would remain as functioning free enzymes under these high radiation fields.

Since radiation sterilization can significantly alter the organic composition of the soil and can expose active catalytic sites, it was especially important to perform extraction blanks of the radiation-sterilized soils. HPLC analyses of the methanol extracts of sterilized soils were virtually identical to those of the nonsterilized soils (Figure 3.22). No additional peaks were observed in sterile soils, indicating that the sterilization process produced no UV-absorbing compounds that could interfere with the TNT analysis procedures.

Sterile soils were amended with filter-sterilized solutions of TNT in a laminar-flow germfree hood. Soils were subsequently always handled using standard sterile techniques. One extraction was performed for each soil immediately after amendment and at 3 days and 10 days post-amendment. The length of the study was limited to 10 days to assure that sterile integrity of the soil samples was maintained. The samples were Soxhlet extracted and analyzed by HPLC as previously described. The results of this study are summarized in Table 3.5. Comparing the data in Table 3.5 with those nonsterile soils in Table 3.2 provides some insight into the transformation process. TNT was transformed in the sterilized soils more slowly than the nonsterile soils. Several trends are consistent throughout the comparison between sterile and nonsterile soils. The percentage of extractable radiolabel was higher at $\mathrm{t}=$ 10 days in the sterile soils. Additionally, the percentage of radiolabel bound to the soils in nonextractable forms at $t=10$ days and at $t=3$ days was considerably less than the amount in the corresponding nonsterile soils. Finally, the percentage of unaltered TNT recovered from the extraction of sterile soils was consistently higher than the recovery from nonsterile soils. These data indicate that transformations still occur in sterile soils but that transformation is much slower than in nonsterile soils. As previously mentioned, the sterilization technique empioyed 
would be expected to destroy any free enzymes in the soils, so transformations in sterile soils would be exclusively due to catalytic mechanisms. The overall results indicate that transformations observed in nonsterile soils were the result of both catalytic and microbial activity. No attempt has been made to delineate between these transformation mechanisms because radiation-sterilized soils may significantly differ from their nonsterilized counterparts with respect to available catalytic sites. Hence, the catalytic activity of radiation-sterilized soils may be far greater than that of the corresponding nonsterilized soil.

IABLE 3.5. MASS BALANCE OF STERILE SOIL SYSTEMS CONTAINING TNT

\begin{tabular}{lccccc}
\hline Soil & $\begin{array}{c}\text { Time } \\
\text { (days) }\end{array}$ & $\begin{array}{c}\text { \% Radiolabel } \\
\text { in Methanol } \\
\text { Extract }\end{array}$ & $\begin{array}{c}\text { \% Unaltered } \\
\text { TNT }\end{array}$ & $\begin{array}{c}\text { \% Radiolabel } \\
\text { in Soil After } \\
\text { Extraction }\end{array}$ & $\begin{array}{c}\text { Mass Balance } \\
\text { Deficit } \\
\text { (\%) }\end{array}$ \\
\hline Burbank & 0 & 103 & 71.8 & 2 & -5 \\
& 3 & 96 & 62.0 & 5 & -1 \\
& 10 & 95 & 59.5 & 10 & -5 \\
Palouse & & & & & \\
& 0 & 101 & 82.9 & 2 & -3 \\
& 3 & 107 & 82.7 & 6 & -13 \\
& 10 & 98 & 73.8 & 10 & -8 \\
Cinebar & & & & & \\
& 0 & 96 & 87.1 & 3 & 1 \\
& 3 & 77 & 63.9 & 13 & 10 \\
& 10 & 74 & 60.8 & 22 & 4 \\
\hline
\end{tabular}

The transformation products observed in the sterile soils were the same as those observed in the nonsterile soils. The appearance of the aminodinitrotoluene isomers was evident in sterile soils aged with TNT for 3 days. Interestingly, the unique transformation product previously found in Burbank soil was observed in sterile Burbank soil during all three sampling periods. Chromatograms of the methanol extract of sterile Burbank soil containing 60 ppm of TNT are shown for extractions performed immediately after amendment and 10 days post-amendment in Figures 3.23A and 3.23B, respectively. 

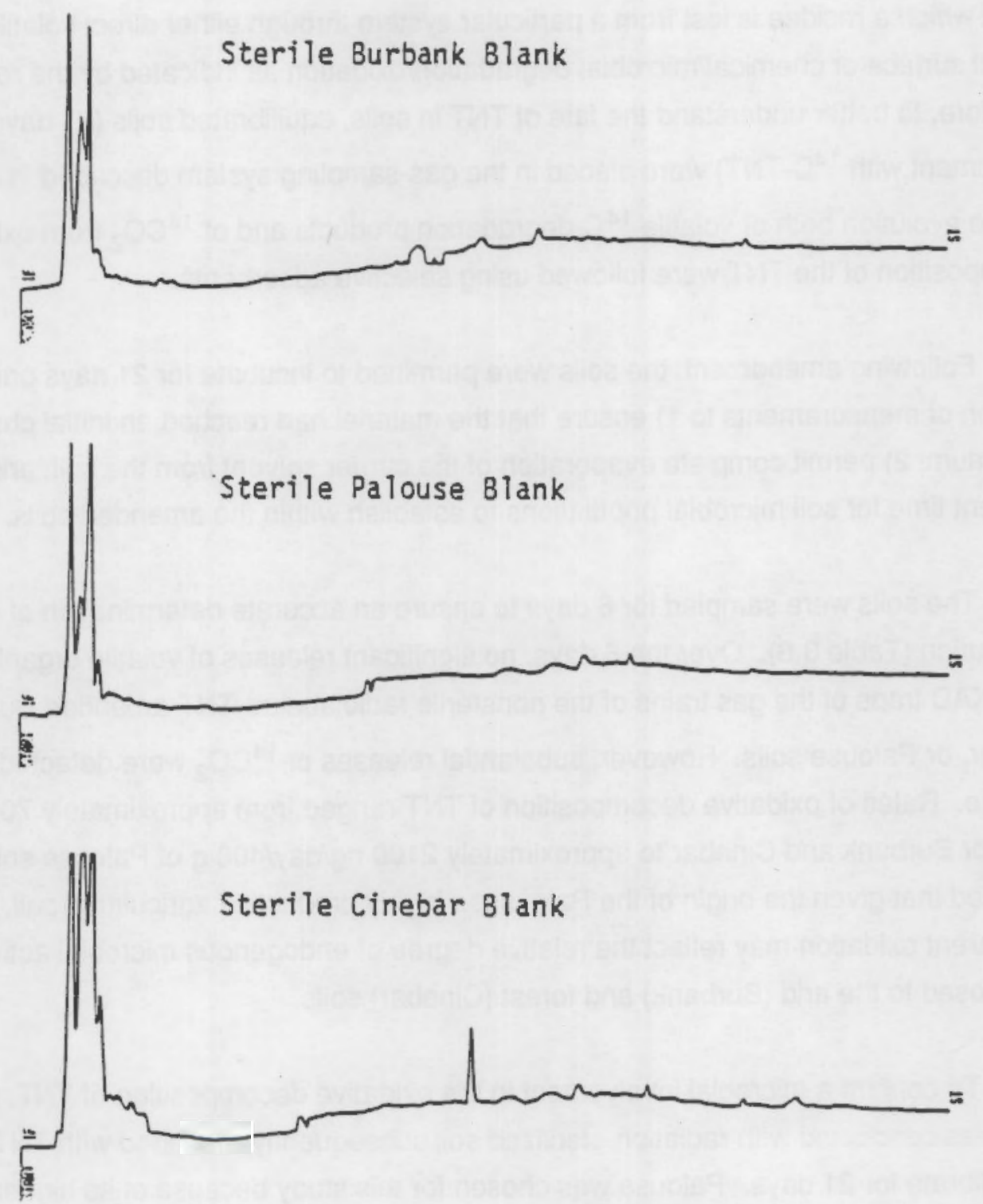

FIGURE 3.22. CHROMATOGRAMS OF STERILE BURBANK, PALOUSE AND CINEBAR SOILS 


\subsubsection{Oxidative Decomposition in Soils}

One important aspect of organic-contaminant behavior and fate in the environment is the rate at which a residue is lost from a particular system through either direct volatilization from the soil surface or chemical/microbial degradation/oxidation as indicated by the release of $\mathrm{CO}_{2}$. Therefore, to better understand the fate of TNT in soils, equilibrated soils (21 days postamendment with ${ }^{14} \mathrm{C}$-TNT) were placed in the gas-sampling system described in Section 2.4.4 and the evolution both of volatile ${ }^{14} \mathrm{C}$-degradation products and of ${ }^{14} \mathrm{CO}_{2}$ from oxidative decomposition of the TNT were followed using selective adsorbents.

Following amendment, the soils were permitted to incubate for 21 days prior to the initiation of measurements to 1) ensure that the materiel had reached an initial chemical equilibrium; 2) permit complete evaporation of the carrier solvent from the soil; and 3) allow sufficient time for soil microbial populations to establish within the amended soils.

The soils were sampled for 6 days to ensure an accurate determination of the daily rate of evolution (Table 3.6). Over the 6 days, no significant releases of volatile organics were noted in the XAD traps of the gas trains of the nonsterile radiolabeled-TNT-amended Burbank, Cinebar, or Palouse soils. However, substantial releases of ${ }^{14} \mathrm{CO}_{2}$ were detected from each soil type. Rates of oxidative decomposition of TNT ranged from approximately $700 \mathrm{ng} / \mathrm{day} / 400$ $\mathrm{g}$ soil for Burbank and Cinebar to approximately $2100 \mathrm{ng} /$ day $/ 400 \mathrm{~g}$ of Palouse soil. It was proposed that given the origin of the Palouse, a highly productive agricultural soil, this difference in apparent oxidation may reflect the relative degree of endogenous microbial activity in this soil as opposed to the arid (Burbank) and forest (Cinebar) soils.

To confirm a microbial involvement in the oxidative decomposition of TNT, a similar study was conducted with radiation-sterilized soil subsequently amended with TNT and allowed to equilibrate for 21 days. Palouse was chosen for this study because of its higher rate of oxidative decomposition. Amendment levels for this soil treatment were $10 \mu \mathrm{Ci}$, as opposed to $20 \mu \mathrm{Ci}$ used in the nonsterile study, and six times the TNT mass concentration (60 ppm), based on the assumption that microbial oxidation of TNT would be lower than for nonsterile soil. The results, also shown in Table 3.6, demonstrated that even at a higher rate of oxidative decomposition. Amendment levels for this soil treatment were $10 \mu \mathrm{Ci}$, as opposed to $20 \mu \mathrm{Ci}$ used in the nonsterile study, and six times the TNT mass concentration (60 ppm), based on the assumption that microbial oxidation of TNT would be lower than for nonsterile soil. The results, also shown in Table 3.6, demonstrated that even at a higher soil-concentration of TNT $(6 \mathrm{X})$ 
A)

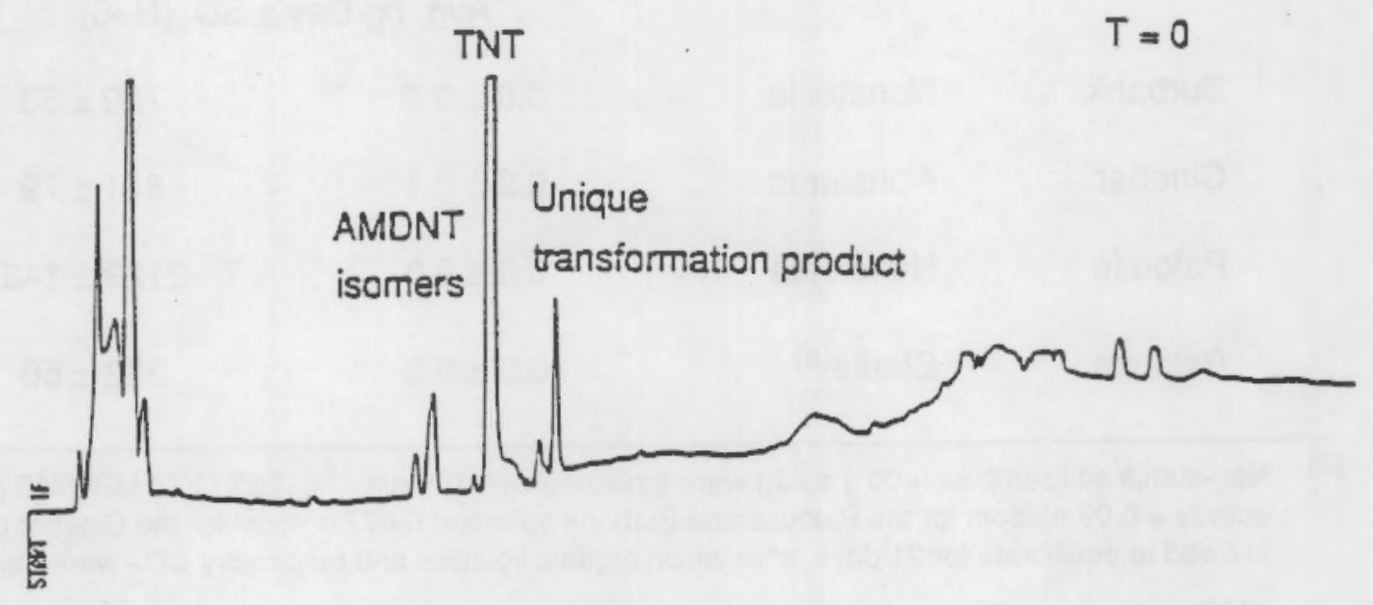

B)

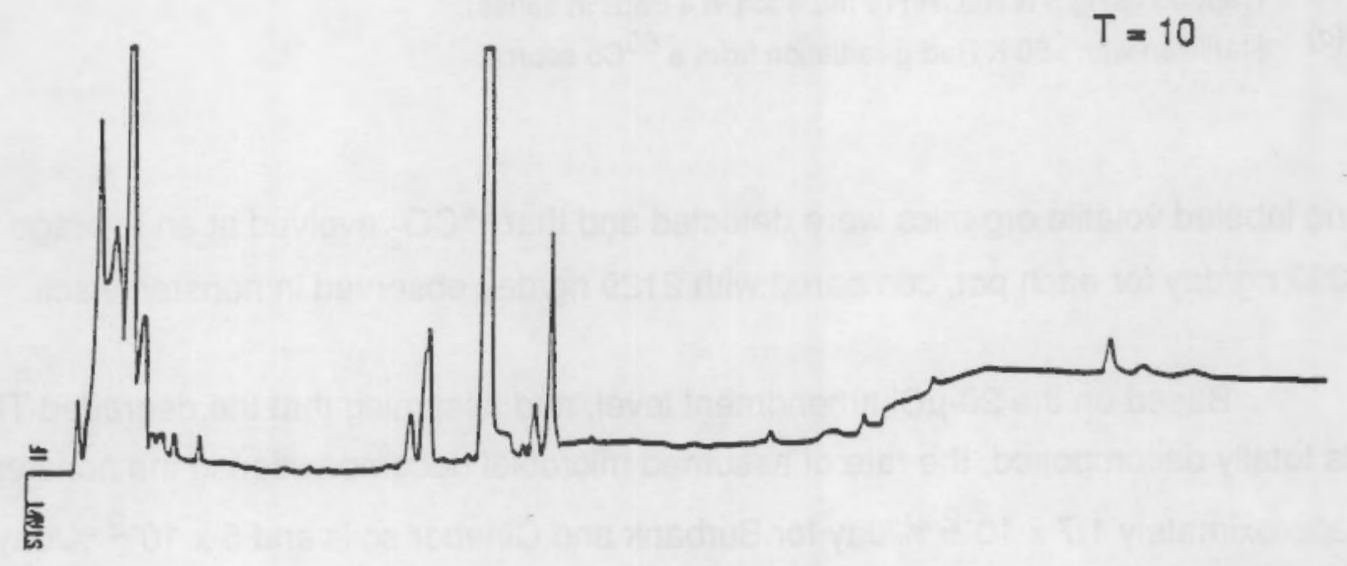

FIGURE 3.23. COMPARISON OF THE METHANOL-EXTRACTABLE COMPONENTS FROM STERILE BURBANK SOIL AT T=0 (A) AND AT T=10 DAYS (B) 
IABLE 3.6. VOLATILITY AND RESPIRATION OF SOIL AMENDED WITH RADIOLABELED-TNT (a)

\begin{tabular}{|c|c|c|c|c|}
\hline & Soil & Condition & Organic Volatiles(b) & Respiration(c) \\
\hline & & & \multicolumn{2}{|c|}{ Avg. $n g / D a y \pm S D .(N=6)$} \\
\hline & Burbank & Nonsterile & $0.0 \pm 0.0$ & $729 \pm 53$ \\
\hline & Cinebar & Nonsterile & $0.2 \pm 0.1$ & $641 \pm 79$ \\
\hline & Palouse & Nonsterile & $0.0 \pm 0.0$ & $2129 \pm 143$ \\
\hline & Palouse & Sterile $^{(d)}$ & $0.0 \pm 0.0$ & $362 \pm 50$ \\
\hline (a) & \multicolumn{4}{|c|}{$\begin{array}{l}\text { Non-sterile soil samples ( } 400 \mathrm{~g} \text { each) were amended with } 10 \mathrm{ppm}{ }^{14} \mathrm{C}-\mathrm{TNT}(0.74 \mathrm{MBq} / 400 \mathrm{~g} \text { soil; specific } \\
\text { activity }=0.09 \mathrm{ng} / \mathrm{dpm} \text { for the Palouse and Burbank soils and } 0.077 \mathrm{ng} / \mathrm{dpm} \text { for the Cinebar pots) and } \\
\text { allowed to equilibrate for } 21 \text { days, after which organic volatiles and respiratory } \mathrm{CO}_{2} \text { were trapped daily }\end{array}$} \\
\hline & \multirow{2}{*}{\multicolumn{4}{|c|}{$\begin{array}{l}\text { (XAD resin and } \mathrm{NaOH} \text { traps) and counted. Data are averages } \pm \mathrm{SD}(\mathrm{N}=6) \text { of daily }{ }^{14} \mathrm{C} \text { releases for each } \\
\text { soil type plus a sterile control (Palouse) amended with } 60 \mathrm{ppm}{ }^{14} \mathrm{C} \text {-TNT }(0.37 \mathrm{MBq} / 400 \mathrm{~g} \text { soil; } 0.93 \\
\mathrm{ng} / \mathrm{dpm}) \text { and also equilibrated for } 21 \text { days. }\end{array}$}} \\
\hline & & & & \\
\hline (b) & \multicolumn{4}{|c|}{ Trapped with two tandem $1 \times 15 \mathrm{~cm}$ XAD resin columns and eluted with $100 \% \mathrm{MeOH}$. } \\
\hline (c) & \multicolumn{4}{|c|}{ Trapped using $3 \mathrm{~N} \mathrm{NaOH}$ (10 mL each in 4 traps in series). } \\
\hline (d) & \multicolumn{4}{|c|}{ Sterilized with $>60 \mathrm{~K}$ Rad g-radiation from a ${ }^{60} \mathrm{Co}$ source. } \\
\hline
\end{tabular}

no labeled volatile organics were detected and that ${ }^{14} \mathrm{CO}_{2}$ evolved at an average rate of only $362 \mathrm{ng} /$ day for each pot, compared with $2129 \mathrm{ng} /$ day observed in nonsterile soil.

Based on the $20-\mu \mathrm{Ci}$ amendment level, and assuming that the degraded TNT residue is totally decomposed, the rate of assumed microbial decomposition in the nonsterile soils is approximately $1.7 \times 10^{-2} \%$ dday for Burbank and Cinebar soils and $5 \times 10^{-2} \% /$ day for Palouse. On a yearly basis, $6 \%$ of the TNT in Burbank and Cinebar is oxidized to $\mathrm{CO}_{2}$, while in Palouse $19 \%$ is oxidized. This yields an estimated soil half-life of 10 years for Burbank and Cinebar and 4 years for Palouse. When the differing specific activities used are taken into account (see Table 3.6), the release rate for the sterilized Palouse soil is only $17 \%$ of the nonsterile rates. This strongly suggests that the observed oxidative decomposition in the nonsterile soils was microbial in origin. The release in the sterilized samples likely resulted both from oxidative reactions of nonmicrobial origin and a concomitant slow build-up of a new microbial population over the 21-day post-sterilization incubation period when the soil was exposed to a nonsterile atmosphere. 
Throughout these studies, XAD traps failed to indicate evolution of volatile transformation products from the soils (Table 3.6). This result is especially interesting since a unique volatile TNT-transformation product was isolated from TNT-amended Burbank soil. These results seem to indicate that this unique transformation product may represent a short-lived intermediate in the formation of further nonvolatile transformation products.

\subsection{SHORT-TERM PLANT AVAILABILITY FROM HYDROPONICS, AND CHEMICAL FATE OF TNT}

Hydroponic studies sought to address two basic needs. The first was to establish the physiological capacity of plants to absorb and transport TNT in the absence of soils and their sorptive components. In other words, How does the soluble concentration of TNT affect its biological availability? The second need was to elucidate the chemical fate of TNT in the absence of the major secondary residues observed to rapidly appear in soils. The latter is essential in interpreting the source and fate of residues identified from the soil/plant uptake experiments and in separating soil/microbial and plant metabolic transformations.

Plants were grown in hydroponic solutions containing a total of 10- and 60-ppm TNT, with a total of $5 \mu \mathrm{Ci} /$ plant of radiolabeled TNT available for uptake. Plant tissue harvested from these experiments were fractionated and analyzed for radioactivity, TNT, and TNT metabolites. The TNT concentrations were selected to provide a range below that which had previously been determined to produce visible phytotoxic effects in soil-grown wheat and grasses $(50 \mathrm{ppm})$. Data are provided below.

\subsubsection{Plant Availability of TNT from Solution Culture}

To determine the uptake rate and the relative bioavailability of TNT to the three plant species, a series of experiments were perlormed in which the roots of plants grown in solution culture were exposed to increasing concentrations of TNT, ranging from 1 to $25 \mathrm{ppm}$. The average uptake rates ( $\mu \mathrm{g} \mathrm{TNT/h} / \mathrm{g}$ fresh weight root) by the plants as a function of solution concentration $(\mathrm{ppm})$ for each of the three species \pm 1 SD are presented in Figure 3.24. Differences between the dicot (bean) and the monocot (wheat and grass) species in uptake rates of ${ }^{14} \mathrm{C}$-TNT by the roots from the amended nutrient solutions were observed. Although it was less evident at the lowest ( $1 \mathrm{ppm}$ ) concentration, the bean consistently exhibited a greater rate of ${ }^{14} \mathrm{C}$-TNT uptake compared with the blando brome and wheat. For example, absorption 


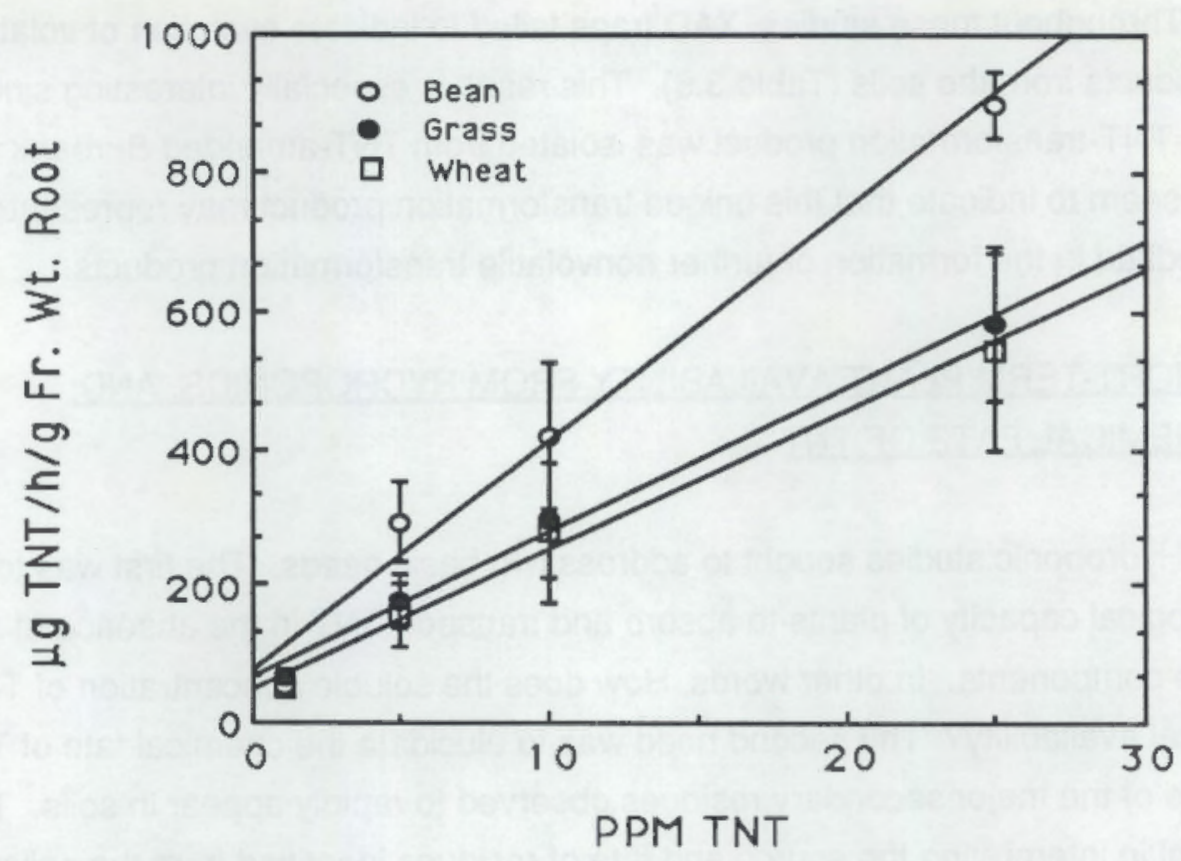

FIGURE 3.24. UPTAKE RATES OF RADIOLABELED-TNT BY ROOTS OF BUSH BEAN, WHEAT, AND BLANDO BROME FROM 1, 5, 10, AND 25 PPM TNTAMENDED NUTRIENT SOLUTIONS. DATA ARE AVERAGES \pm STANDARD DEVIATION ( $\mathrm{N}=3$ ). LINEAR REGRESSION $\left(\mathrm{r}^{2}\right.$ Values) FOR THE THREE SPECIES WERE 0.985, 0.990, AND 0.994 FOR BEAN, WHEAT, AND GRASS, RESPECTIVELY

rates of the ${ }^{14} \mathrm{C}$-TNT at solution concentrations of $25 \mathrm{ppm}$ were $450 \mu \mathrm{g} / \mathrm{g}$ rooth for the grasses and $900 \mu \mathrm{g} / \mathrm{g}$ root/h for the bean. Uptake rates for the three species appeared to be linear over the concentrations tested, with no indication of saturation in absorption potential by the plants for soluble, available TNT.

To ascertain differences in specific uptake between the plant species, the uptake data for TNT was subjected to analysis by Lineweaver-Burke double-reciprocal plots (Figure 3.25) so that a $\mathrm{K}_{s}$, analogous to the Michaelis-Menten $\mathrm{K}_{\mathrm{m}}$, and a root absorption rate $\left(\mathrm{V}_{\max }\right)$ could be calculated for each species under the exposure conditions (Table 3.7). Because $\mathrm{K}_{\mathrm{s}}$ is analogous to $\mathrm{K}_{\mathrm{m}}$, it would be expected that the lower the $\mathrm{K}_{\mathrm{s}}$ value, the greater the affinity of transport sites for TNT. 
For bush bean, the average $\mathrm{K}_{\mathrm{s}}$ was calculated to be $280 \mu \mathrm{M}$, with a $\mathrm{V}_{\max }$ (uptake rate at saturating concentration) of approximately $15 \mu$ moles TNT/g fresh wt root/h (Table 3.7). The wheat and the grass were markedly different from the bean but were similar to each other. The wheat and grass exhibited absorption isotherms with average $K_{s}$ values of 133 and $138 \mu \mathrm{M}$, respectively, and $V_{\max }$ values of 6.4 and $5.6 \mu$ moles TNT/g fresh wt root/h. These kinetic constants indicate that the monocots (blando brome and wheat) may have approximately twice the affinity of the dicot (bean) for the TNT. The bean however, possessed the larger $V_{\max }$ and would therefore be capable of accumulating more of the material over time, on a per-unit massroot basis. It should also be noted that both of the monocot isotherms varied from the more linear one of the dicot (bean) (Figure 3.25), particularly at the lowest substrate concentration $(0.227 \mu \mathrm{M})$, indicating a biphasic absorption isotherm characteristic of plant root absorption.

The differing absorption kinetics indicate that the two plant families may have different mechanisms of metabolism or storage of TNT. The soybean, a dicot similar in physiology to the bush bean, has been reported to accumulate dinitroaniline herbicides, chemically similar to TNT, at a much greater rate than corn (a monocot from the grass family), while exhibiting fewer phytotoxic symptoms (Marquis et al. 1979). The root structures of the wheat and grass are much more fibrous, with a smaller root diameters and volume per unit-length than that of the bean. This may limit their holding capacity (metabolism or sequestering) of the xenobiotic TNT.

IABLE 3.7. CALCULATED $K_{S}$ AND $V_{\text {max }}$ VALUES FROM APPARENT ISOTHERMS FROM FIGURE 3.25

\begin{tabular}{ccc}
\hline Species & Component & Value \\
\hline Bean & $\mathrm{K}_{\mathrm{s}}$ & $280 \pm 48$ \\
& $\mathrm{~V}_{\max }$ & $15.4 \pm 2.6$ \\
Wheat & $\mathrm{K}_{\mathrm{s}}$ & $133 \pm 35$ \\
& $\mathrm{~V}_{\max }$ & $6.4 \pm 1.6$ \\
& $\mathrm{~K}_{\mathrm{s}}$ & $138 \pm 37$ \\
& $\mathrm{~V}_{\max }$ & $5.6 \pm 1.5$ \\
\hline
\end{tabular}

(a) $K_{s}$ expressed in $\mu M$, and $V_{\max }$ expressed in $\mu$ moles TNT/g fresh wt root/h 

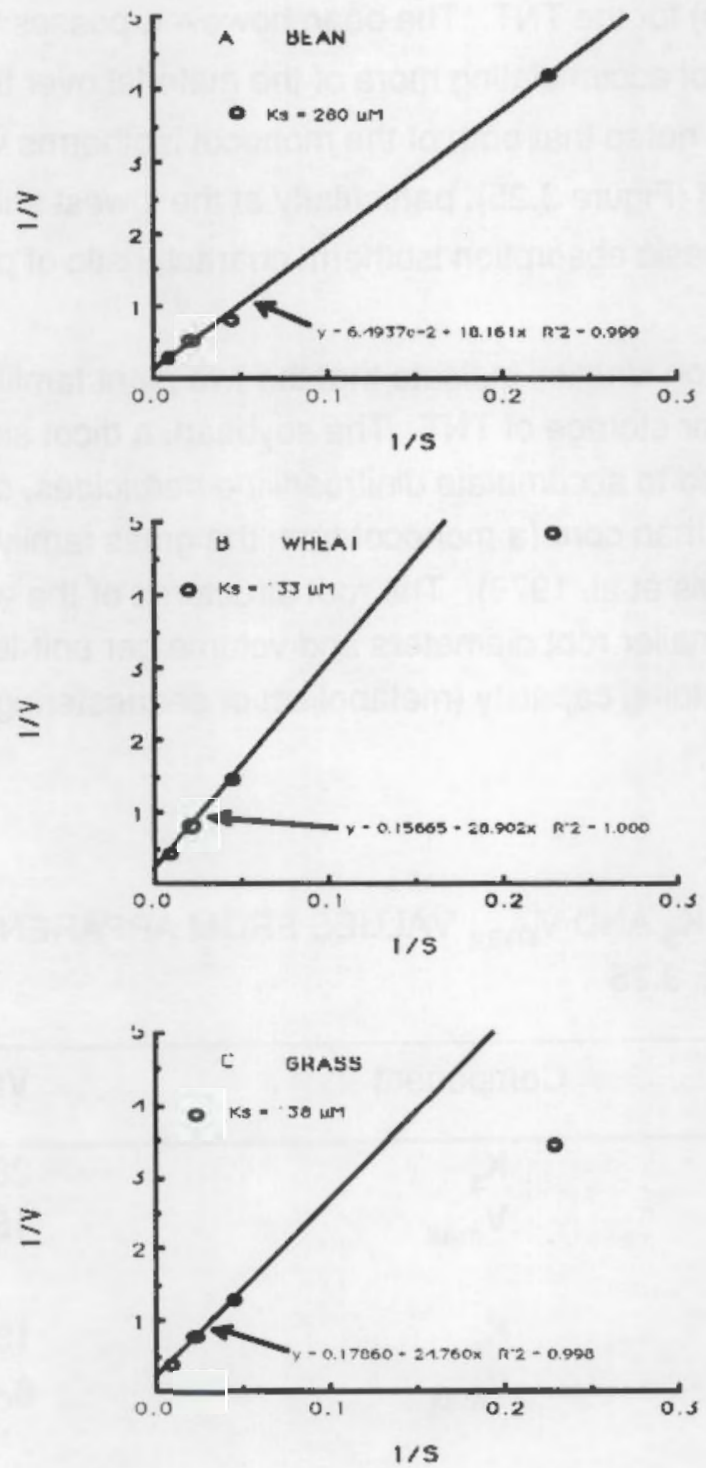

FIGURE 3.25. DOUBLE RECIPROCAL PLOTS OF $1 / N$ VERSUS $1 / S$ FOR BUSH BEAN (A), WHEAT (B), AND BLANDO BROME (C) 


\subsubsection{Short-Term Partitioning of TNT Within the Plant}

Species differences, including the rate at which TNT may be absorbed by a plant's roots, could also affect partitioning of the absorbed TNT between tissues and organs and the subsequent chemical fate or metabolism of the partitioned TNT. The description of the metabolic fate of plant-absorbed TNT involved in analysis of tissues derived from the shortterm hydroponic studies is reported in Section 3.2.3. The partitioning patterns and effects of elevated ${ }^{14} \mathrm{C}$-TNT concentrations (1 to $25 \mathrm{ppm}$ ) are provided in Table 3.8 .

From these data, it appears that the majority ( $\geq 83 \%$ ) of the label taken up from the nutrient solution after $2 \mathrm{~h}$ of direct exposure was retained by the roots, in all the plants tested. In the bean, only 3 to $5 \%$ of the absorbed TNT was transported to the shoot during these shortterm studies. Slightly more, 3 to $8 \%$, was transported in blando brome. The wheat, with 7 to $17 \%$ transported to the shoots, had the highest transport rate, particularly at the higher concentrations of TNT, while no significant $(P \geq 0.1)$ concentration effects were evident in either blando brome or bush bean. This is interesting, because the wheat had the lowest overall uptake rate per mass of root (Figure 3.24). This may indicate that there is less storage capacity in the root of the wheat plant and that there is a higher tendency to accumulate the TNT in the aerial portions of the plant when the TNT is made available hydroponically. Conversely, the higher overall rate of accumulation by the bean and the lower rate of transport to the shoot may again indicate a greater storage (or metabolism)

IABLE 3.8. DISTRIBUTION OF RADIOCARBON IN PLANTS FOLLOWING 2-h EXPOSURE IN SOLUTION CULTURE AT VARIOUS TNT CONCENTRATIONS

\begin{tabular}{|c|c|}
\hline Species & Exposure Solution Concentration (pom) ${ }^{\text {(a) }}$ \\
\hline Tissue & $\begin{array}{llll}1 & 5 & 10\end{array}$ \\
\hline
\end{tabular}

\begin{tabular}{|c|c|c|c|c|c|c|c|c|}
\hline \multirow{3}{*}{ Bean } & & \multicolumn{7}{|c|}{ Avg. $\%$ Total Label \pm SD $(n=3)$} \\
\hline & Root & 97.23 & \pm 1.28 & 97.09 & \pm 1.21 & $96.12 \pm 0.79$ & $95.36 \pm$ & \pm 0.95 \\
\hline & Shoo(b) & 2.77 & \pm 1.25 & 2.91 & \pm 1.37 & $3.88 \pm 0.88$ & $4.64 \pm$ & \pm 0.98 \\
\hline \multicolumn{9}{|c|}{ Wheat } \\
\hline & Root & 93.90 & \pm 0.65 & 90.73 & \pm 1.24 & $86.97 \pm 7.30$ & $83.52 \pm$ & \pm 5.72 \\
\hline & Shoot ${ }^{(b)}$ & 6.10 & \pm 0.57 & 9.27 & \pm 1.52 & $13.03 \pm 7.31$ & $16.48 \pm$ & \pm 5.72 \\
\hline \multicolumn{9}{|l|}{ Grass } \\
\hline & Poot & 98.19 & \pm 0.63 & 92.88 & \pm 5.21 & $92.24 \pm 3.73$ & $93.28 \pm$ & \pm 4.45 \\
\hline & Shoot ${ }^{(b)}$ & 1.81 & \pm 1.12 & 7.12 & \pm 5.21 & $7.76 \pm 3.73$ & $6.72 \pm$ & \pm 4.46 \\
\hline
\end{tabular}

(a) Expressed as average \pm SD percent of total label found in plants $(n=3)$ as determined by oxidation.

(b) Includes stem plus leaves. 
capacity by these larger-diameter roots over the exposure period. The observed differences between these important agronomic plants indicate that TNT and its residues may enter the human food chain through differing ways.

\subsubsection{Chemical Fate of TNT in Hydroponically Grown Plants}

Hydroponically grown plants were used to establish analytical procedures needed to resolve the relative availability and fate of TNT and associated residues and their chemical fates once accumulated. This experimental system permits close control of source term in solution and eliminates those processes occurring in soil that are likely to confuse intial steps in elucidating ENT fate, namely sorption and soil-based chemical transformation of the parent compound.

Plants were grown in $500 \mathrm{~mL}$ of hydroponic solution and individual $600-\mathrm{mL}$ beakers. The hydroponic solutions contained $10-\mu \mathrm{Ci}$ TNT/L and a total TNT concentration of $10 \mathrm{ppm}$. the solutions were filter-sterilized and placed in autoclaved beakers to minimize microbial contamination. Solution samples were collected for liquid scintillation spectrometry and HPLC analysis at the beginning of the study and at each harvest. Control solutions maintained in the growth chamber represent different conditions with respect to light and aeration. The first two control beakers were exposed to the high-intensity growth-chamber lights. The first of these beakers was aerated, whereas the second beaker was not. The third control beaker was aerated and jacketed with an opaque cover to exclude light. These controls allowed the examination of TNT loss through photolytic reactions, volatilization, and oxidation. Hydroponic solutions containing plants were also analyzed at the time of harvest for comparison to the controls. The quantity of TNT and the total activity in each beaker is shown in Table 3.9. 
IABLE 3.9. QUANTITY OF TNT AND RADIOLABEL IN HYDROPONIC SQLUTIONS AT THE BEGINNING OF THE STUDY AND AT THE TWO HARVEST TIMES

\begin{tabular}{|c|c|c|c|c|c|c|}
\hline \multirow[b]{2}{*}{$\begin{array}{l}\text { Species/ } \\
\text { Treatment }\end{array}$} & \multicolumn{2}{|c|}{0 day } & \multicolumn{2}{|c|}{1 day } & \multicolumn{2}{|l|}{7 day } \\
\hline & $\begin{array}{ll}\mu \mathrm{Ci} & \mathrm{mg} \\
\text { Beaker }\end{array}$ & $\begin{array}{l}\text { mg TNT/ } \\
\text { Beaker }\end{array}$ & $\begin{array}{c}\mu \mathrm{Ci} / \\
\text { Beaker }\end{array}$ & $\begin{array}{l}\text { mg TNT/ } \\
\text { Beaker }\end{array}$ & $\begin{array}{lr}\mathrm{Ci} / & \mathrm{mg} \\
\text { Beaker } & \mathrm{B}\end{array}$ & $\begin{array}{l}\text { mg TNT/ } \\
\text { Beaker }\end{array}$ \\
\hline \multicolumn{7}{|l|}{ Bean } \\
\hline $\begin{array}{l}\text { Control, light, } \\
\text { bubbled }\end{array}$ & 4.55 & 5.09 & 4.88 & 4.43 & 4.15 & -- \\
\hline $\begin{array}{l}\text { Control, light, } \\
\text { not bubbled }\end{array}$ & 4.96 & 4.74 & 5.00 & 4.87 & 4.763. & 26 \\
\hline $\begin{array}{l}\text { Control, dark, } \\
\text { bubbled }\end{array}$ & 5.62 & 5.68 & 5.12 & 5.15 & 4.86 & 4.54 \\
\hline Plants 1-3 & $5.20 \pm 0.31$ & $5.00 \pm 0.60$ & $3.52 \pm 0.60$ & $0.96 \pm 0.87$ & - & - \\
\hline Plants 7-9 & $5.01 \pm 0.13$ & $4.44 \pm 0.11$ & - & $\cdots$ & $0.59 \pm 0.39$ & B.D.L. (a) \\
\hline \multicolumn{7}{|l|}{ Grass } \\
\hline $\begin{array}{l}\text { Control, light, } \\
\text { bubbled }\end{array}$ & 4.92 & 4.94 & 5.00 & 4.87 & 4.69 & 2.96 \\
\hline $\begin{array}{l}\text { Control, light, } \\
\text { not bubbled }\end{array}$ & 5.07 & 5.01 & 5.06 & 4.87 & 4.66 & 3.33 \\
\hline $\begin{array}{l}\text { Control, dark, } \\
\text { bubbled }\end{array}$ & 4.96 & 5.02 & 5.10 & 4.98 & 4.95 & 4.63 \\
\hline Plants $1-3$ & $4.95 \pm 0.05$ & $4.96 \pm 0.07$ & $3.75 \pm 0.12$ & $2.48 \pm 1.4$ & $\ldots$ & $\ldots$ \\
\hline Plants $7-9$ & $4.93 \pm 0.09$ & $4.80 \pm 0.02$ & -.. & - & $0.33 \pm .27$ & B.D.L. \\
\hline \multicolumn{7}{|l|}{ Wheat } \\
\hline $\begin{array}{l}\text { Control, light, } \\
\text { bubbled }\end{array}$ & 5.10 & 5.25 & 5.21 & 4.61 & 4.89 & 2.73 \\
\hline $\begin{array}{l}\text { Control, light, } \\
\text { not bubbled }\end{array}$ & 5.33 & 5.42 & 5.17 & -4.95 & 4.78 & 2.56 \\
\hline $\begin{array}{l}\text { Control, dark, } \\
\text { bubbled }\end{array}$ & 5.09 & 5.49 & 5.29 & 4.86 & 4.88 & 4.38 \\
\hline Plants $1-3$ & $5.36 \pm 0.20$ & $5.49 \pm 0.12$ & $1.83 \pm 1.0$ & $0.05 \pm 0.03$ & $\ldots$ & - \\
\hline Plants 7-9 & $5.30 \pm 0.10$ & $5.32 \pm 0.06$ & $\ldots$ & - & $0.13 \pm 0.15$ & B.D.L. \\
\hline
\end{tabular}

(a) B.D.L. = below detection limit 
Several trends in the data are worthy of mention. As can be seen, the control beakers maintained in the dark (without plants) exhibited a fairly stable concentration of TNT and radiolabel, with only a minimal loss throughout the 7-day exposure. The control beakers exposed to the growth-chamber lights also show a reasonably stable amount of radiolabel in solution, but the concentration of TNT (as determined by HPLC) shows a distinct decrease in concentration during the study. This decrease in TNT coincided with the appearance of a pink hue in the hydroponic solution. Exposure to the growth chamber lights evidently caused photolysis of TNT, with the concomitant production of a pink product. The pink product was not observed in the dark control beakers. Solutions in plant-containing beakers were shielded from light to protect the roots and there was no evidence for the appearance of any pink coloration in these beakers. Preliminary analysis of the colored product indicated that it is highly polar and is similar to the product described earlier by Spanggord and coworkers (Spanggord et al. 1980). The lack of appreciable differences between aerated and nonaerated controls exposed to light indicates that oxidation or volatilization of TNT from the beakers was not a major process.

Hydroponic solutions containing plants showed rapid chemical transformation and uptake of the available TNT. After 7 days, the hydroponic solutions containing plants had very low amounts of radiolabel and no detectable TNT. Transformations of the parent TNT, which also occurred rapidly, can be visualized as a discrepancy between the radioactivity contained in each beaker and the quantity of unaltered TNT (Table 3.9). The hydroponic solutions from plants harvested at $24 \mathrm{~h}$ all show a large disparity between TNT concentration and radiolabel content, indicating that the root tissue has transformed the TNT. This may represent a rootsurface catalytic effect, common with organic residues. Differences in the chromatographic profiles between control beakers and plant-containing beakers are due both to plant uptake and to transformation of TNT by the root tissue. Chromatograms comparing hydroponic solutions used to support bush bean growth for 0, 1, and 7 days are shown in Figure 3.26. 

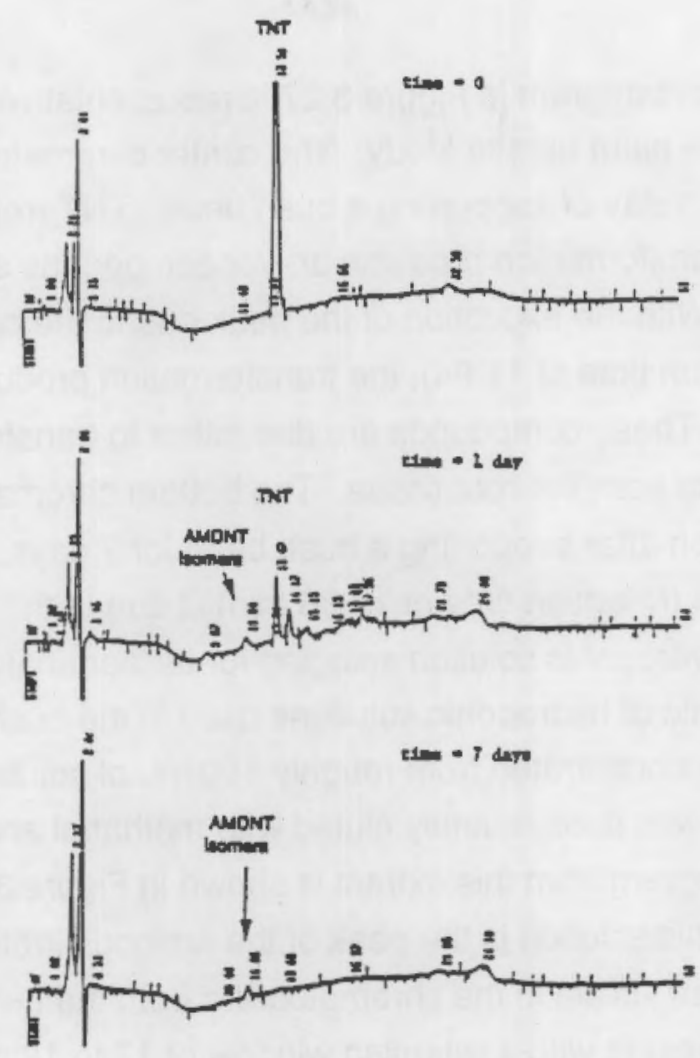

FIGURE 3.26. CHROMATOGRAPHIC PROFILES OF HYDROPONIC SOLUTIONS PRIOR TO THE UPTAKE STUDY (TOP), AFTER 1 DAY (CENTER) AND AFTER 7 DAYS (BOTTOM) OF SUPPORTING GROWTH OF BUSH BEAN

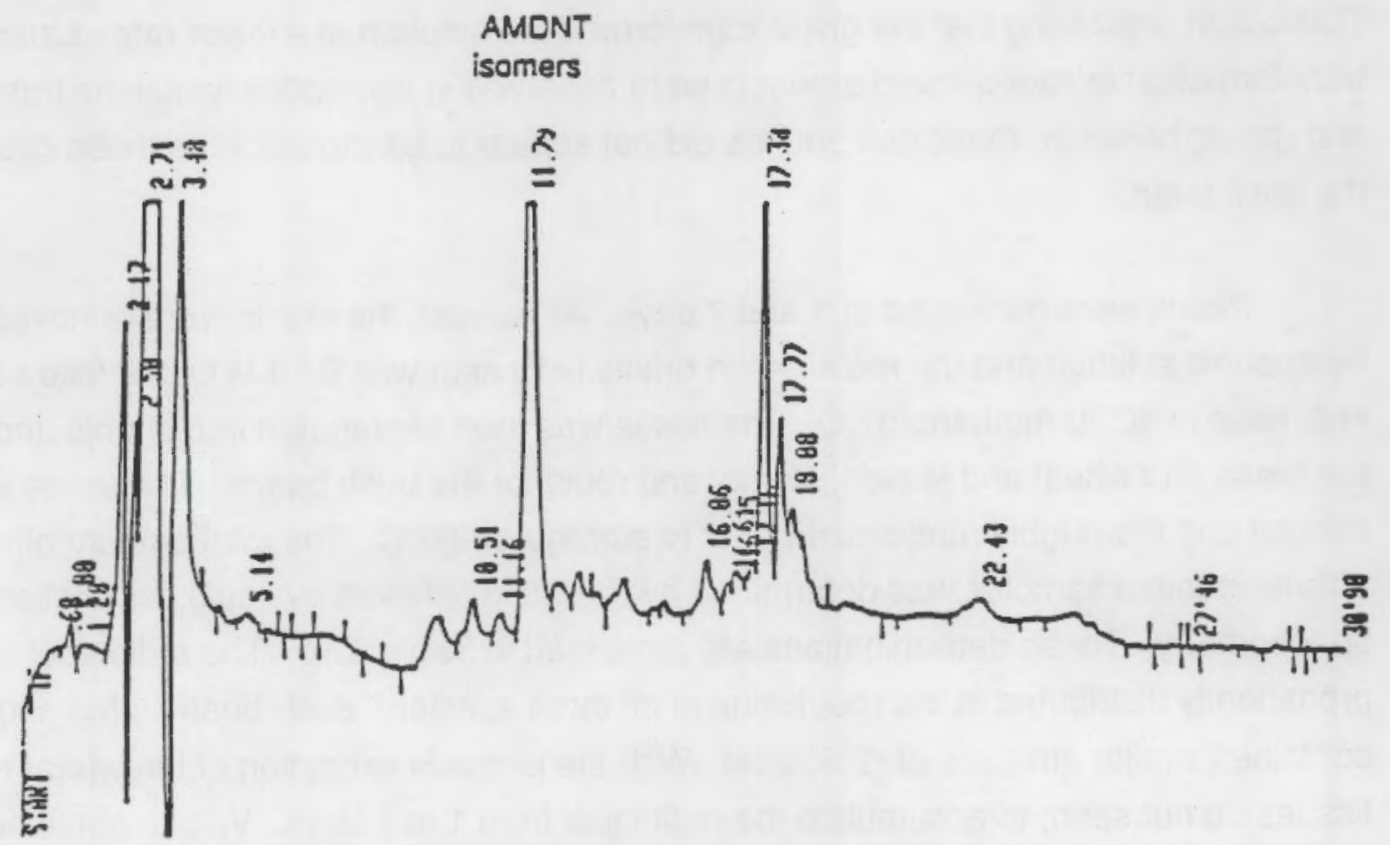

FIGURE 3.27. CHROMATOGRAPHIC PROFILE OF COMPONENTS CONCENTRATED FROM A BUSH BEAN HYDROPONIC SOLUTION 
The upper chromatogram in Figure 3.27 is representative of the hydroponic solutions prior to initiation of the plant-uptake study. The center chromatogram is representative of the solution profiles after 1 day of supporting a bush bean. TNT (retention time of $13.47 \mathrm{~min}$ ) as well as a variety of transformation products and/or compounds of root origin are observed in this chromatogram. With the exception of the peak due to the co-elution of 2-and 4-aminodinitrotoluene (retention time of 11.84), the transformation products have retention times greater than $14 \mathrm{~min}$. These compounds are due either to transformation of TNT or to compounds originating from the root tissue. The bottom chromatogram in Figure 3.27 shows the hydroponic solution after supporting a bush bean for 7 days. The only observable component in this solution (retention time of $11.86 \mathrm{~min}$ ) is due to the aminodinitrotoluene isomers. A 4-day bush bean hydroponic solution selected for further analysis had a yellow-orange coloration characteristic of hydroponic solutions used in the bush bean studies. The yelloworange color was preconcentrated from roughly $100 \mathrm{~mL}$ of solution on a C-18 Sep-Pak cartridge. The cartridge was subsequently eluted with methanol and the solution examined by HPLC. The chromatogram from this extract is shown in Figure 3.27. It is evident that the major component of this solution is the peak of the aminodinitrotoluene isomers. Several other components, also visible in the chromatogram from the $t=1$ day chromatogram (center of Figure 3.26), are present with a retention window of 17 to $18 \mathrm{~min}$.

Hydroponic solutions used to support the growth of grass and wheat plants showed transformations similar to the bush bean solutions. A peak corresponding to the aminodinitrotoluene isomers was observed in both the grass and wheat solutions. The TNT peak was more prominent in the grass than in the bush bean or wheat solutions at $t=1$ day (Table 3.9), indicating that the grass transformed the solution at a lower rate. Later-eluting transformation or root-derived products were observed in hydroponic solutions from wheat and grass; however, these compounds did not appear to be the same as those observed in the bush bean.

Plants were harvested at 1 and 7 days. At harvest, the plants were removed from hydroponic solution and the roots rinsed briefly ( $<15 \mathrm{sec}$ ) with $0.10 \mathrm{M} \mathrm{CaCl}_{2}$ followed by a final rinse in 80:20 methanol: $\mathrm{H}_{2} \mathrm{O}$. The tissue was then segregated into shoots and roots for the grass and wheat and leaves, stems, and roots for the bush beans. The tissue was then minced and thoroughly randomized prior to storage at $-80^{\circ} \mathrm{C}$. The total amount of radioactivity in these samples was determined by oxidation followed by liquid scintillation spectrometry. These determinations are presented in Table 3.10. The radiolabel was prominently distributed in the root tissue of all three species. Bush bean stems and leaves contained similar amounts of radiolabel. With the possible exception of the wheat roots, the tissues do not seem to accumulate the radiolabel from 1 to 7 days. Values obtained during this study were used to calculate the percentage of total radioactivity in various chemical fractions during subsequent chemical analysis of individual plants. 
IABLE 3.10. RADIOLABEL CONTAINED IN TISSUES OF BUSH BEAN, WHEAT, AND BLANDO BROME

\begin{tabular}{|c|c|c|c|c|}
\hline & \multirow{2}{*}{$\begin{array}{c}\text { Species } \\
\text { Tissue }\end{array}$} & & \multicolumn{2}{|c|}{ Radioactivity Distribution (a) } \\
\hline & & & $T=1$ day & $\mathrm{T}=\overline{7 \text { days }}$ \\
\hline \multicolumn{5}{|l|}{ Bean } \\
\hline & Leaves & & $47069 \pm 38 \%$ & $58612 \pm 30 \%$ \\
\hline & Stem & & 64442 & 4384 \\
\hline & Roots & & $419734 \pm 3 \%$ & $613582 \pm 46 \%$ \\
\hline \multicolumn{5}{|l|}{ Grass } \\
\hline & Shoots & & $52450 \pm 21 \%$ & $84666 \pm 15 \%$ \\
\hline & Roots & & $272216 \pm 7 \%$ & $625268 \pm 20 \%$ \\
\hline \multicolumn{5}{|l|}{ Wheat } \\
\hline & Shoots & & $13758 \pm 77 \%$ & $13235 \pm 41 \%$ \\
\hline & Roots & . & $271594 \pm 27 \%$ & $284062 \pm 16 \%$ \\
\hline
\end{tabular}

(a) $\mathrm{dpm} \pm \mathrm{SD}, \mathrm{n}=3$ except for bush bean stems, which are based on 1 plant.

Chemical analysis utilized $1.00 \mathrm{~g}$ of tissue. Initial studies examined the amount of radiolabel extractable into organic solvents. Leaf tissue from a 7-day bush bean was homogenized with water and subsequently extracted with diethyl ether. Only $4 \%$ of the total label was found to partition into the ether layer, while $57 \%$ of the label remained in the water layer. This indicated that the TNT was metabolized to very polar, and perhaps conjugated, forms. In an attempt to free possible conjugates, an acid hydrolysis was implemented immediately after homogenization. A subsample of the above leaf tissue was hydrolyzed with 1 $\mathrm{N} \mathrm{HCl}$ for $1 \mathrm{~h}$ prior to extraction with diethyl ether. It was found that $23 \%$ of the radiolabel was now ether extractable, with $41 \%$ remaining in the $\mathrm{HCl}$ layer. This experiment clearly illustrated that approximately $19 \%$ of TNT was metabolized to $\mathrm{HCl}$-hydrolyzable conjugates. Interestingly, acid hydrolysis did not increase the amount of radiolabel solubilized. In both the acid hydrolysis and the water experimental conditions, slightly over $60 \%$ of the total radiolabel was found to be solubilized in the aqueous or ether layers. In all subsequent experiments, acid hydrolysis of the plant tissue followed homogenization. The fractions resulting from the partitioning between the $1 \mathrm{~N} \mathrm{HCl}$ and $\mathrm{Et}_{2} \mathrm{O}$ layers are referred to as the $\mathrm{HCl}$ and $\mathrm{Et}_{2} \mathrm{O}$ AN fractions, respectively.

In the next step of the fractionation sequence, the $1 \mathrm{~N} \mathrm{HCl}$ layer was made basic by the addition of $4 \mathrm{M} \mathrm{NH}_{4} \mathrm{OH}$. The basic aqueous layer was then extracted with diethyl ether. The resulting organic and aqueous layers are referred to as the $\mathrm{Et}_{2} \mathrm{O}$ base fraction and the Aq-base layer, respectively. Only a small amount of the radiolabel was extracted into ether from the basic aqueous solution. The remainder of the chemical fractionation of the plant tissues closely follow the scheme outlined in Materials and Methods (Figure 2.1). The ether extracts were then 
pooled and further fractionated by chromatography on a Florisil Sep-Pak. Four fractions were collected from this column as the mobile phase increased in strength from methylene chloride to methanol. In order of increasing elution, these four fractions are referred to as the F1, F2, F3, and F4 fractions. Standards of TNT and 2-arnino-4,6-dinitrotoluene were found to partition from $1 \mathrm{~N} \mathrm{HCl}$ into diethyl ether and to elute in the second Florisil fraction (designated F2).

During the fractionation and analysis of plant materials, all fractions were counted by liquid scintillation spectrometry. Of particular interest was the efficiency of the analytical scheme in extracting radiolabeled components from the plant matrix. This was determined by comparing the radiolabel left in the pellet to the original activity contained in the plant tissue (both values determined by oxidation). Calculations from these extractions indicate that an average of $28 \pm 10 \%(N=38)$ of the original radiolabel remains in the pellet after extraction. This extraction efficiency did not seem to depend on species or tissue type or on the period of TNT uptake from the hydroponic solution.

The percentage of total radioactivity in the various fractions of the bush bean is tabulated in Table 3.11. Several trends are evident. A substantial portion of TNT was metabolized to very polar forms that were not extractable into ether (Aq-base fraction). This trend was particularly pronounced in leaf tissue. As such, this may represent the progressive formation of polar compounds as TNT metabolites were transported from the root tissue to the leaves. Also indicative of the formation of polar metabolites was the appearance of substantial amounts of radiolabel in fraction F4. Avery grout solvent strength (100\% methol) was used to elute this fraction in an attempt to strip the Florisil adsorbent of all components. The polar etherextractable compounds contained in fraction F4 are strongly adsorbed by the Florisil column. Further analysis of fraction F4 poses a number of serious analytical problems, since this fraction also contains the majority of the plant pigments. Further separations and characterization centered on the HPLC analysis of fraction F2.

Representative chromatograms of the F2 fraction of bush bean leaves, stems, and roots are presented in Figure 3.28. The upper chromatogram from leaf tissue shows both TNT and the primary metabolites, the aminodinitrotoluene isomers, at concentrations slightly above the detection limit $(0.10 \mathrm{ppm})$ of the analytical scheme. The chromatogram in the bottom of Figure 3.28 , from bush bean root tissue, shows copious amounts of aminodinitrotoluene isomers and TNT. The center chromatogram, the analysis of the F2 fraction from bush bean stems, shows concentrations of TNT and the aminodinitrotoluene isomers intermediate between those contained in root and leaf samples. 

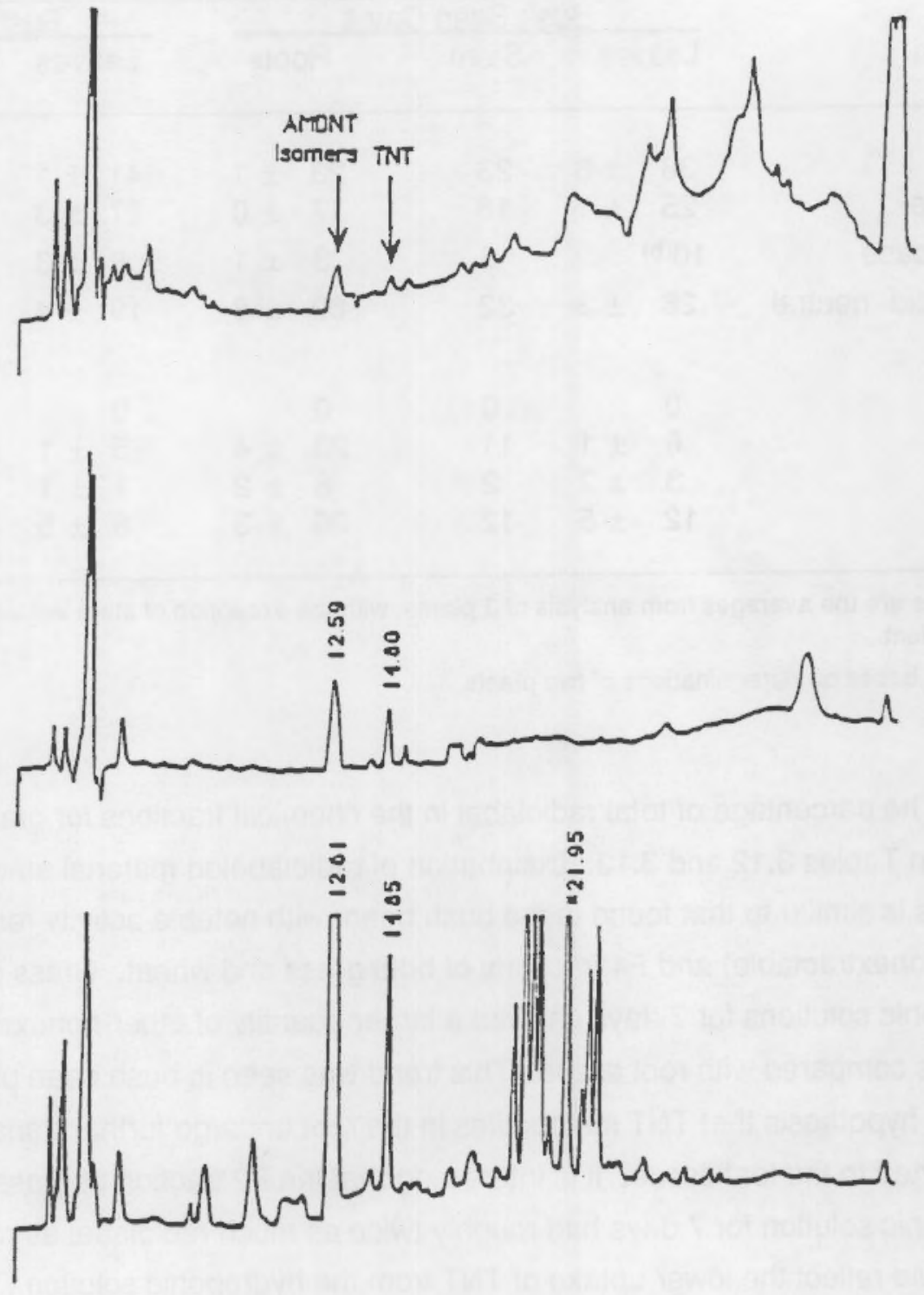

FIGURE 3.28. REPRESENTATIVE CHROMATOGRAMS OF THE F2 FRACTION OF BUSH BEAN LEAVES (TOP), STEMS (CENTER), AND ROOTS (BOTTOM) 
IABLE 3.11. PERCENTAGE OF TOTAL RADIOACTIVITY, BASED ON OXIDATION, IN CHEMICAL FRACTIONS OF BUSH BEAN(a)

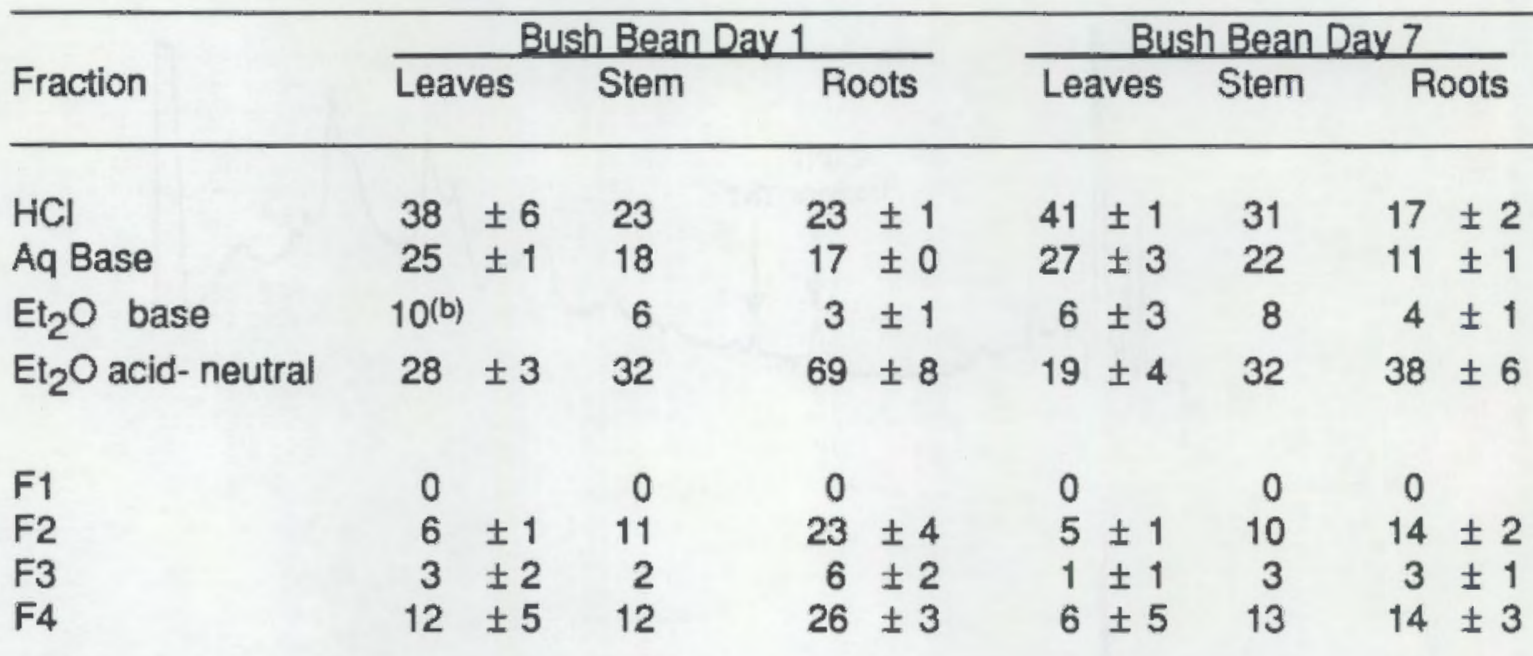

\footnotetext{
(a) Values are the averages from analysis of 3 plants, with the exception of stem values, which are based on one plant.

(b) Value based on determinations of two plants.
}

The percentage of total radiolabel in the chemical fractions for grass and wheat are shown in Tables 3.12 and 3.13. Distribution of radiolabeled material among the chemical fractions is similar to that found in the bush bean, with notable activity residing in the Aq-base (ether nonextractable) and F4 fractions of both grass and wheat. Grass plants grown in hydroponic solutions for 7 days showed a larger quantity of ether-nonextractable metabolites in shoot as compared with root tissue. This trend was seen in bush bean plants and is consistent with the hypothesis that TNT metabolites in the root undergo further transformation once transported to the leaf tissue. It is interesting that the F2 fraction of grass roots exposed to hydroponic solution for 7 days had roughly twice as much radiolabel as roots exposed for 1 day. This could reflect the lower uptake of TNT from the hydroponic solution (Table 3.9). The distribution of radiolabel in wheat was similar to that observed in grass. Representative chromatograms of the F2 fraction of grass roots and shoots are shown in Figure 3.29. The concentration of the aminodinitrotoluene isomers was much higher in the grass shoots compared with the bush bean leaves.

The concentrations of TNT and the aminodinitrotoluene isomers observed in the bush bean and wheat plants are summarized in Table 3.14. TNT and AMDNT concentrations represent measured values, while the polar and nonpolar concentrations are estimated based on the distribution of radioactivity following fractionation. The concentration of TNT is near the detection limit in bush bean, wheat, and grass leaves $(<0.1 \mu \mathrm{g} / \mathrm{g})$. Concentrations of the 
IABLE 3.12. PERCENTAGE OF TOTAL RADIOACTIVITY, BASED ON OXIDATION, IN CHEMICAL FRACTIONS OF BLANDO BROME (a)

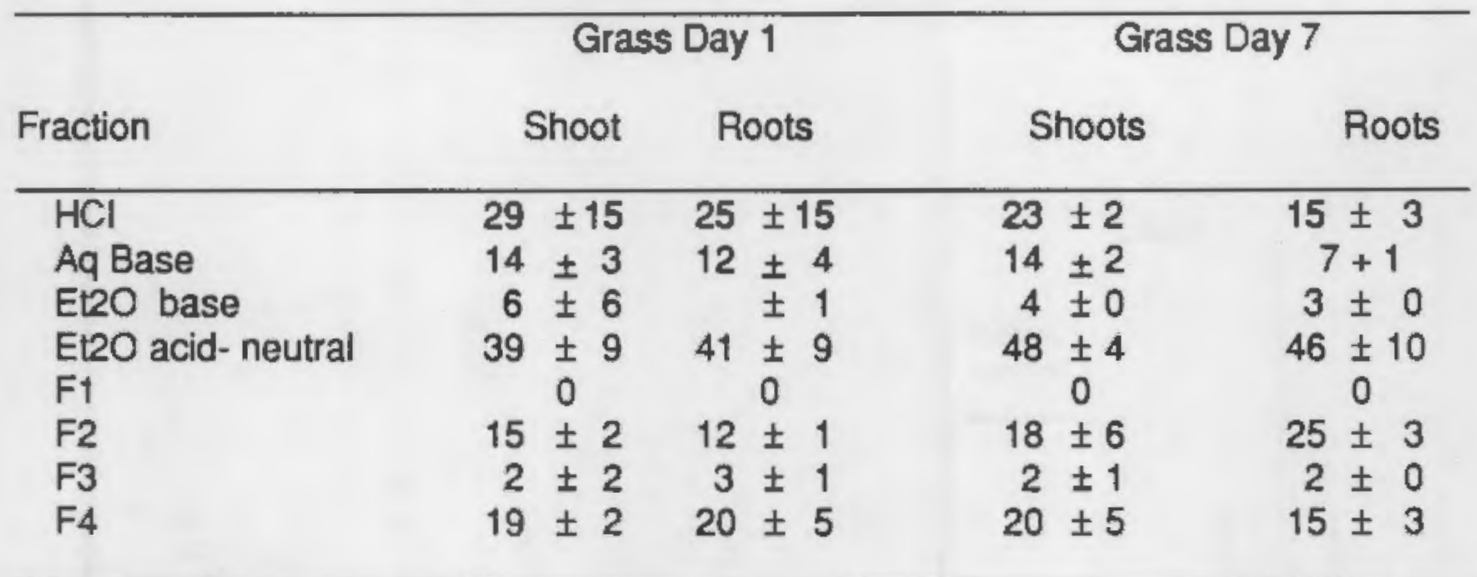

(a) Values are the average of 3 plants.

IABLE 3.13. PERCENTAGE OF TOTAL RADIOACTIVITY, BASED ON OXIDATION IN CHEMICAL FRACTIONS OF WHEAT (a)

\begin{tabular}{lcc}
\hline & \multicolumn{2}{c}{ Wheat Day 1 } \\
\cline { 2 - 3 } Fraction & Shoots & Roots \\
\hline $\mathrm{HCl}$ & 22 & $15 \pm 7$ \\
$\mathrm{Aq}$ base & 19 & $9 \pm 5$ \\
$\mathrm{Et}$ O base & 4 & $4 \pm 3$ \\
$\mathrm{Et} \mathrm{t}_{2} \mathrm{O}$ acid- neutral & 48 & $50 \pm 4$ \\
$\mathrm{~F} 1$ & 0 & 0 \\
$\mathrm{~F} 2$ & 19 & $22 \pm 6$ \\
$\mathrm{F3}$ & 3 & $3 \pm 1$ \\
$\mathrm{~F} 4$ & 22 & $18 \pm 3$ \\
\hline
\end{tabular}

(a) Shoot values are based on determinations of 2 plants, while root values are based on analysis of 3 plants.

aminodinitrotoluene isomers are either similar to or slightly higher than TNT in all tissues, ranging from $0.2 \mu \mathrm{g} / \mathrm{g}$ for bush bean leaves to $3.7 \mu \mathrm{g} / \mathrm{g}$ for shoots of blando brome. The concentrations both of TNT and the aminodinitrotoluene isomers are higher in root than in leaf or shoot tissue. Interestingly, roots of blando brome accumulate substantial amounts of the aminodinitrotoluene isomers, as evidenced by an increase in concentration from $5.0 \mathrm{ppm}$ in the 1-day plants to $22.0 \mathrm{ppm}$ in the 7-day plants. 

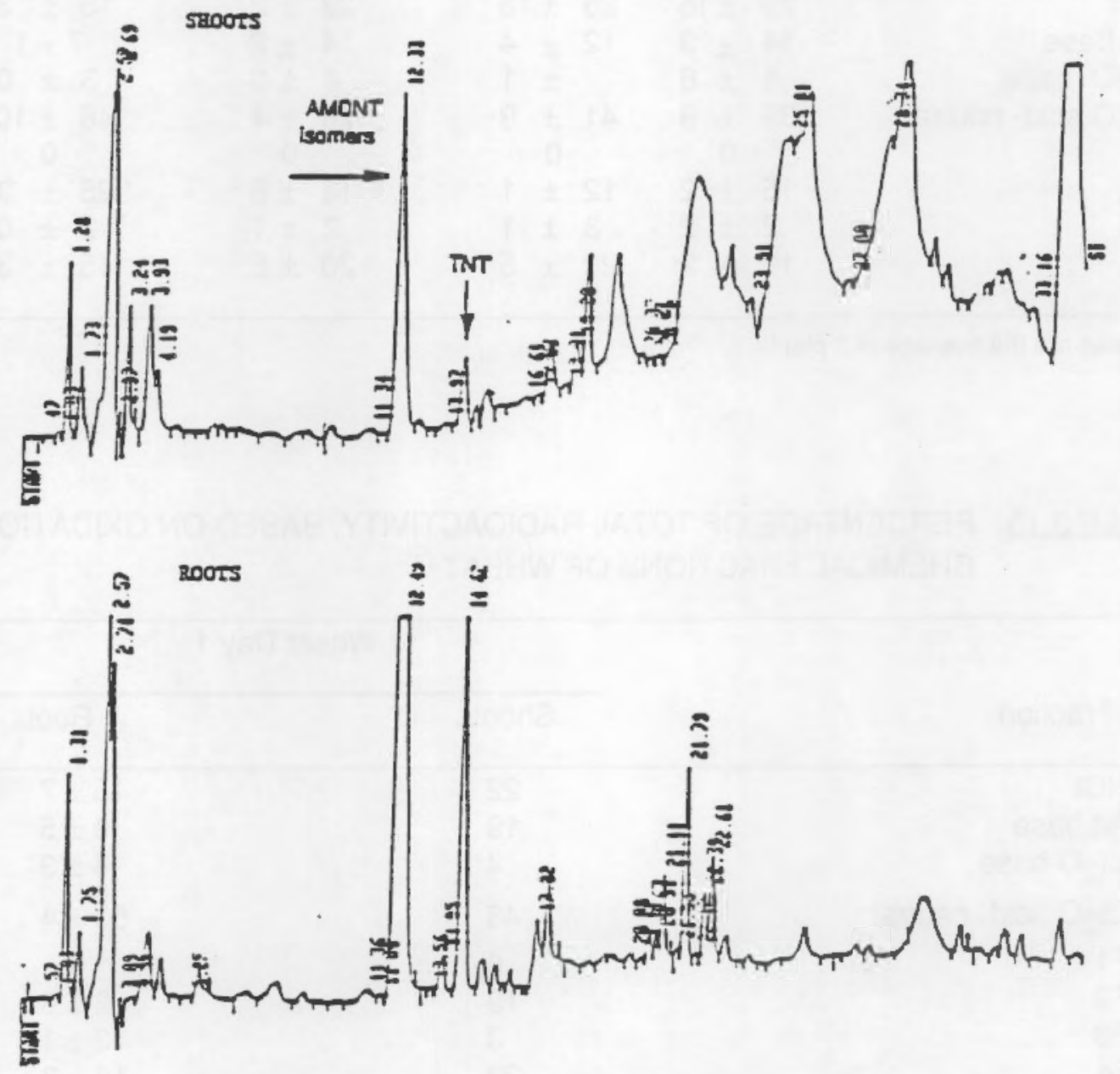

EIGURE 3.29. CHROMATOGRAMS OF THE F2 FRACTIONS OF BLANDO BROME SHOOT (TOP) AND ROOTS (BOTTOM) 
IABLE 3.14. CONCENTRATIONS OF TNT, AMDNT ISOMERS, AND UNIDENTIFIED POLAR AND NONPOLAR COMPONENTS IN PLANT TISSUES

FOLLOWING 1 AND 7 DAYS OF ABSORPTION FROM HYDROPONIC SOLUTIONS

\begin{tabular}{|c|c|c|c|c|c|c|c|c|}
\hline \multirow{3}{*}{$\begin{array}{l}\text { Species/ } \\
\text { Tissue }\end{array}$} & \multicolumn{8}{|c|}{ Concentration } \\
\hline & \multicolumn{4}{|c|}{ Day 1} & \multicolumn{4}{|c|}{ Day 7} \\
\hline & TNT & AMDNT & Nonpolar & Polar & TNT & AMDNT & Nonpolar & Polar \\
\hline
\end{tabular}

\begin{tabular}{|c|c|c|c|c|c|c|c|c|}
\hline Wheat & \multicolumn{8}{|c|}{$\mu g$ (asTNT or Residue)/g Fresh Wh Tissue ${ }^{(a)}$} \\
\hline Shoot & & & & & & & & \\
\hline Roots & $1.6 \pm 1.1$ & $8.3 \pm 5.9$ & $\begin{array}{r}0.4 \\
16.9 \pm 7.3\end{array}$ & $36.6 \pm 7.2$ & $1.0 \pm 0.9$ & $0.27 \pm 0.02$ & $2.6 \pm 1.6$ & $29.4 \pm 6.4$ \\
\hline \multicolumn{9}{|c|}{ Blando Brome } \\
\hline Shoots & $0.3 \pm 0.2$ & $1.5 \pm 0.2$ & $1.7 \pm 0.4$ & $8.3 \pm 0.5$ & $0.3 \pm 0.1$ & $3.7 \pm 1.8$ & $2.9 \pm 1.0$ & $13.7 \pm 1.9$ \\
\hline Roots & $1.7 \pm 0.1$ & $4.8 \pm 1.2$ & $8.2 \pm 3.6$ & $42.9 \pm 6.1$ & $1.5 \pm 0.6$ & $22.0 \pm 3.7$ & $46.9 \pm 8.4$ & $67.6 \pm 7.6$ \\
\hline \multicolumn{9}{|c|}{ Bush Beans } \\
\hline Leaves & $0.2 \pm 0.1$ & $0.4 \pm 0.3$ & $0.7 \pm 0.2$ & $6.4 \pm 2.4$ & $0.2 \pm 0.1$ & $0.2 \pm 0.2$ & $0.9 \pm 0.2$ & $9.0 \pm 2.7$ \\
\hline Stem & 0.35 & 0.63 & 2.2 & 9.3 & 0.12 & 1.25 & 0.7 & 8.0 \\
\hline Roots & $4.1 \pm 1$ & $6.1 \pm 2$ & $33.2 \pm 1.4$ & $92.6 \pm 2.8$ & $1.5 \pm 0.6$ & $7.4 \pm 3$ & $29.8 \pm 3.2$ & $77.3 \pm 35.5$ \\
\hline
\end{tabular}

(a) Concentrations are given in ppm on a fresh-weight basis. Values reported are the average of 3 plants, with the exception of the values reported for the bush bean stems, which are based on 1 plant.

It should be noted that the concentrations of unidentified nonpolar constituents are as high as or higher than the contentrations of TNT or AMDNT. More importantly, the concentrations of unidentified polar constituents are substantially higher than those of TNT or AMDNT. This change in chemical form and polarity could dramatically affect food chain transfer.

\subsubsection{Transport Forms of TNT in Hydroponically Grown Bush Bean}

Aminodinitrotoluene isomers and TNT were identified in acid-hydrolyzed tissues of plants grown in hydroponic solutions containing TNT. A larger proportion of acid-hydrolyzed metabolites in the aerial tissues were not ether extractable compared with metabolites contained in root tissue. Stem tissue from bush beans contained concentrations of TNT and the aminodinitrotoluene isomers intermediate between the large quantities in the roots and the small concentrations in the leaf tissue.

To characterize the chemical speciation of TNT metabolic-transport products, the roots of an intact 27-day-old bush bean were immersed in a 25-ppm TNT solution containing $10 \mu \mathrm{Ci}$ of radiolabeled TNT (total volume of $400 \mathrm{~mL}$ ). The stem was severed approximately $3 \mathrm{~cm}$ above 
the roots and $1.30 \mathrm{~mL}$ of exudate was collected over $5 \mathrm{~h}$. Analysis of stem exudate offers several inherent advantages over the analysis of stem tissue. Paramount among these is that stem exudate contains only xylem transport products, or those metabolites being transported from root to shoot tissues, whereas stem tissue contains both transport products and storage forms of xenobiotics. Additional advantages include the nonviscous nature of exudates, the absence of pigments, and the relatively simple chemical composition of exudates.

The composite exudate was divided into two equal aliquots. The first of these was lyophilized and reconstituted with $100 \mu \mathrm{L}$ of $50: 50 \mathrm{MeOH}: \mathrm{H}_{2} \mathrm{O}$. A radiochromatogram of this sample is presented in Figure 3.30. The overwhelming majority of radiolabel eluted in the dead volume of the reverse-phase column, indicating the highly polar nature of the transport products. A very small amount of radiolabeled compound elutes with a retention time of $13 \mathrm{~min}$. This peak, also observed on the UV absorption trace $(254 \mathrm{~nm})$, corresponds to the retention time of the aminodinitrotoluene isomers.

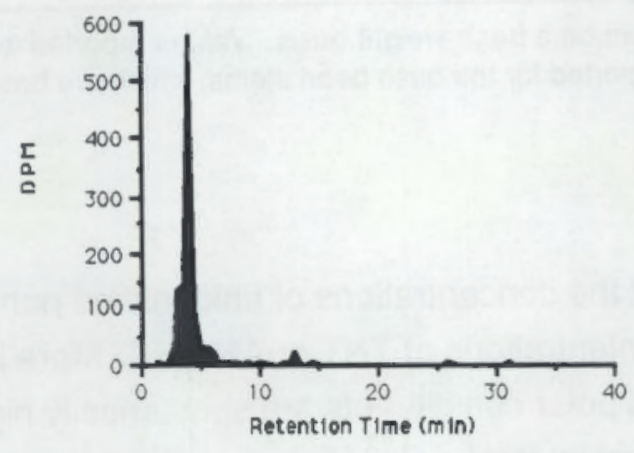

FIGURE 3,30. RADIOCHROMATOGRAM OF BUSH BEAN EXUDATE

The second $0.65-\mathrm{mL}$ aliquot of exudate was acid hydrolyzed with $5.0 \mathrm{~mL}$ of $1.0 \mathrm{M} \mathrm{HCl}$ at $100^{\circ} \mathrm{C}$ for $1 \mathrm{~h}$ and then extracted with $10.0 \mathrm{~mL}$ of diethyl ether. The aqueous layer was made basic by adding $4.0 \mathrm{~mL}$ of $4 \mathrm{M} \mathrm{NH}_{4} \mathrm{OH}$ and again was extracted with $10.0 \mathrm{~mL}$ of diethyl ether. The ether layers were pooled, evaporated to dryness, and brought up to a final volume of 100 $\mu \mathrm{L}$ with $50: 50 \mathrm{MeOH}: \mathrm{H}_{2} \mathrm{O}$. The radiochromatogram obtained on the acid-hydrolyzed material (Figure 3.31) represents a surprisingly simple chromatographic profile, containing only two major constituents. The most abundant peak (retention time of $13 \mathrm{~min}$ ) is due to the aminodinitrotoluene isomers, whereas the second peak (retention time of $22 \mathrm{~min}$ ) is a 
compound of unknown composition. This experiment clearly demonstrates that TNT is transported from the root to leaf tissue almost exclusively as conjugates of the aminodinitrotoluene isomers.

For comparison with the acid-hydrolyzed exudate, radiochromatography of the F2 fraction of acid-hydrolyzed bush bean root tissue was performed (the fractionation scheme was described previously). The resulting radiochromatogram is shown in Figure 3.32. This profile contains three major components. In order of increasing retention time, these peaks are due to the aminodinitrotoluene isomers, TNT, and the same unknown metabolite observed in the hydrolyzed xylem exudate. The column eluate was collected during the elution of the unknown compound, and a UV spectrum was obtained (Figure 3.33). Because the absorption maximum of $262 \mathrm{~nm}$ indicates the lack of any extended conjugation, the possibility of an azo-type compound may be eliminated from the myriad possibilities. Further characterization of this TNT-derived plant metabolite should be the focus of future investigations.

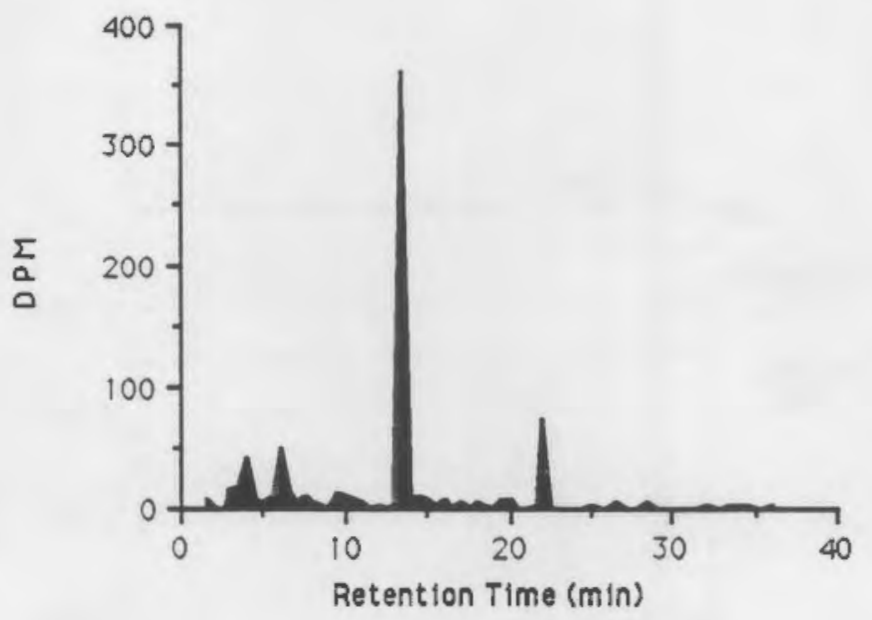

FIGURE 3.31. RADIOCHROMATOGRAM OF ACID-HYDROLYZED BUSH BEAN EXUDATE 


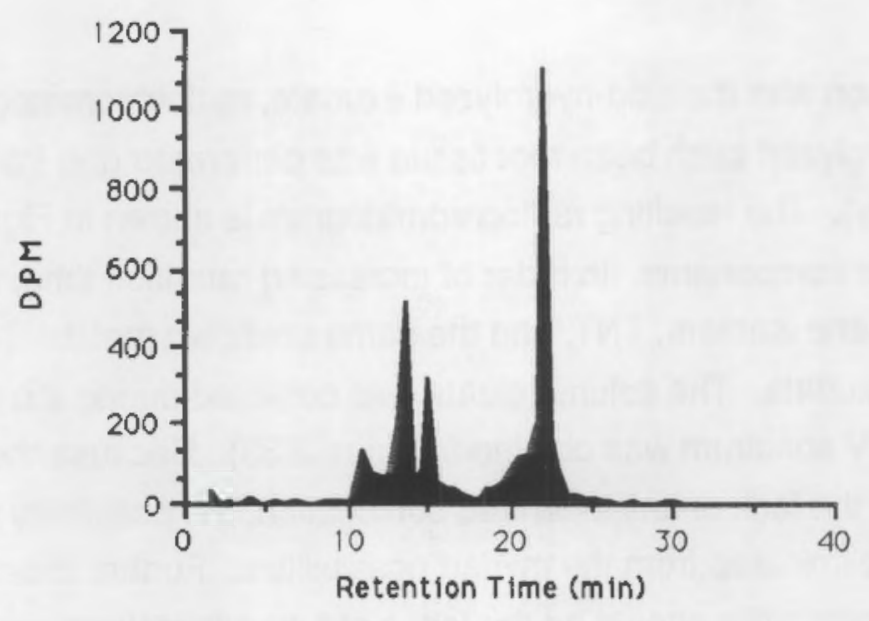

FIGURE 3.32. RADIOCHROMATOGRAM OF THE F2 FRACTION OF ACID-HYDROLYZED BUSH BEAN ROOT TISSUE

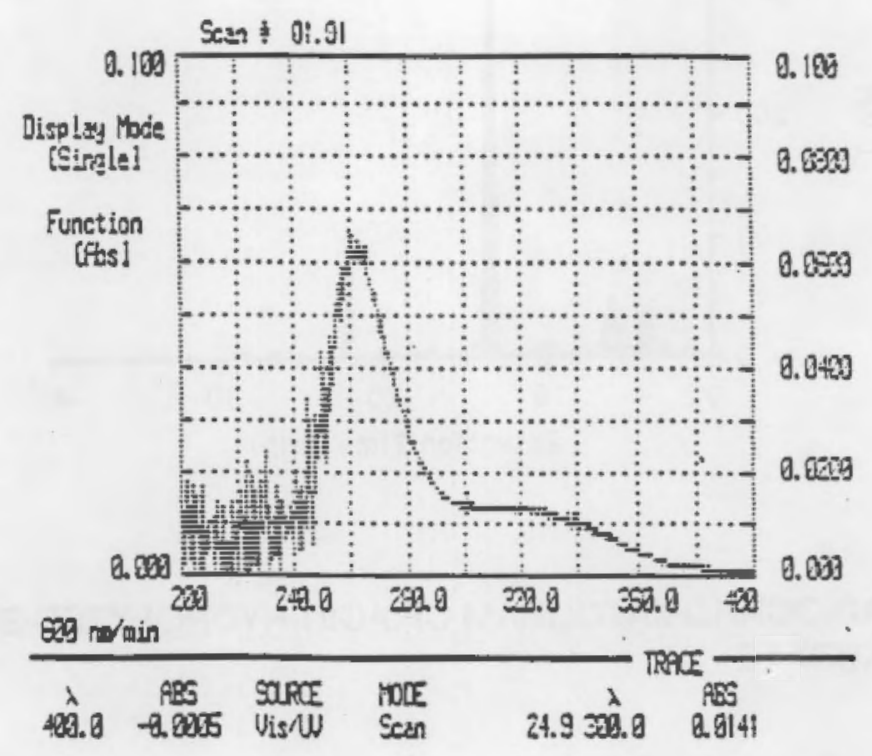

FIGURE 3.33. UV SPECTRUM OF THE UNKNOWN TNT METABOLITE (RETENTION TIME OF 22 MIN) 


\subsubsection{Respiration and/or Volatization of TNT by Plants Grown in Solution Culture}

TNT and other related residues which are absorbed by plant roots and exported to the stem and leaves may 1) be further metabolized to a form innocuous to the plant; 2) be sequestered and/or stored; 3 ) undergo further metabolic conversions achieving a final form of $\mathrm{CO}_{2}$; and/or 4) pass through the plant through the transpiration stream, to be released to the atmosphere essentially unchanged. To determine the potential for these latter two processes, a 28-day-old hydroponically grown soybean in a beaker containing ${ }^{14} \mathrm{C}$-TNT-amended nutrient solution was placed into the $\mathrm{CO}_{2}$ /volatiles trapping chamber. Over $72 \mathrm{~h}$, volatile organic compounds and $\mathrm{CO}_{2}$ emissions were assayed from the shoot portion of the plant. From the collected data, a ${ }^{14} \mathrm{C}$ mass balance was constructed between the initial and remaining label in the nutrient solution and the plant.

The results, given in Table 3.15, demonstrate a mass-balance recovery of approximately $104 \%$. More importantly, they show that over a $72-h$ period, while the majority of the label ( $>60 \%$ ) had been accumulated by the plant from the nutrient solution, no detectable loss of label in either an organic form or as $\mathrm{CO}_{2}$ from the foliage of the bean plant occurred. Of the label within the plant, greater than $91 \%$ remained within the root, and only $\sim 3 \%$ was transported to the leaves.

These results indicate that TNT or transformed residues are not directly volatilized from foliage to the atmosphere. Furthermore, oxidative metabolism of the TNT or its transport products is slight or nonexistent over this period. It appears that the majority of the residues are stored within the plant, particularly in the root. 
IABLE3.15 DISTRIBUTION OF RADIO-LABELED TNT IN A HYDROPONICALLY GROWN BUSH BEAN FOLLOWING 72-h EXPOSURE TO A 20-ppm SOLUTION. PLANT WAS MAINTAINED UNDER NORMAL GROWTH CONDITIONS AND IN A SPLIT CHAMBER.

\begin{tabular}{|c|c|c|}
\hline \multicolumn{3}{|l|}{ Tissue/ } \\
\hline Fraction & TNT (mg) & $\%$ Total Initial ${ }^{14} \mathrm{C}$ \\
\hline Original ${ }^{14} \mathrm{C}$-TNT Solution & $7.254^{(a)}$ & 100.00 \\
\hline Plant Tissue & $4.915^{(b)}$ & 67.75 \\
\hline Shoot $\mathrm{CO}_{2}{ }^{(c)}$ & n.d. (d) & 0.00 \\
\hline Shoot $\mathrm{XAD}^{(\theta)}$ & n.d. & 0.00 \\
\hline Transpired Water(f) & 0.001 & 0.01 \\
\hline Sum & $\overline{4.916}$ & 67.76 \\
\hline $\mathrm{CaCl}_{2}$ Root Wash & 0.080 & 1.10 \\
\hline MeOH Root Wash & 0.314 & 4.32 \\
\hline $\begin{array}{l}\text { Final }{ }^{14} \mathrm{C} \text {-TNT Solution } \\
\text { Sum }\end{array}$ & $\frac{2.260^{(f)}}{7.570}$ & $\frac{31.15}{104.33}$ \\
\hline \multicolumn{3}{|c|}{ (a) Based on HPLC analysis of the $350-\mathrm{mL}$ starting solution. } \\
\hline \multicolumn{3}{|l|}{ (b) Determined by tissue oxidation } \\
\hline \multicolumn{3}{|l|}{ (c) Based on ${ }^{14} \mathrm{C}$-TNT starting-s } \\
\hline \multicolumn{3}{|c|}{ (d) Not detected. } \\
\hline \multicolumn{3}{|c|}{ (e) Based on ${ }^{14} \mathrm{C}$-TNT starting-solution equivalents from XAD resin columns. } \\
\hline \multicolumn{3}{|c|}{$\begin{array}{l}\text { (i) Based on }{ }^{14} \mathrm{C} \text {-TNT starting-solution equivalents in condensed transpired water in upper (shoot) chamber. } \\
\text { (g) Based on }{ }^{14} \mathrm{C} \text {-TNT starting-solution equivalents in remaining TNT nutrient solution at end of exposure }\end{array}$} \\
\hline \multicolumn{3}{|c|}{$\begin{array}{l}\text { Based on }{ }^{14} \mathrm{C} \text {-TNT starting-solution equivalents in remaining TNT nutrient solution at end of exposure } \\
\text { period. }\end{array}$} \\
\hline
\end{tabular}

\subsection{ABSORPTION AND CHEMICAL FATE OF TNT IN MATURE PLANTS GROWN IN SOIL}

A major objective of these studies was to assess to what extent and in what form TNT and/or its principal residues are accumulated, stored, and/or metabolized in soil-grown mature plants (bush bean, blando brome and wheat). Preliminary studies were conducted to determine the maximum range of soil-TNT concentration that could be used in both hydroponic and longterm soil studies without inducing adverse plant effects. The plant-maturity studies relate to the accumulation and tissue partitioning of ${ }^{14} \mathrm{C}$ derived from soil-amended TNT. Plants were grown to physiological maturity, subsampled, and analyzed for total ${ }^{14} \mathrm{C}$ and fractionated for detailed chemical analyses. It should be noted that the following data sets contain treatments referred to as "chamber controls," which are plants maintained in the same growth chambers as 
treatments. This is a standard procedure when dealing with ${ }^{14} \mathrm{C}$-labeled organics having the potential for either volatilization or oxidative decomposition. Actual treatment controls were maintained in a separate growth chamber.

\subsubsection{Short-Term Soil/Plant Toxicity Studies}

To evaluate potential phytotoxicity of the TNT for both soil and hydroponic experiments, 400-g pots of Palouse and Cinebar soils were amended with TNT to final concentrations of 0 , 10,30 ,and $60 \mathrm{ppm}$ TNT. Pots of each soil type with each concentration were then planted with either bean, wheat, or blando brome and the plants were allowed to grow for 60 days, or until maturity. During this period, the plants were monitored for visible phytotoxic symptoms such as chlorosis, leaf curl or burn, or reduced growth. Results indicated a reduction in plant height of greater than $50 \%$ in all species at the $60 \mathrm{ppm}$ concentration and a reduction of $\sim 25 \%$ in the wheat and grass at the $30-\mathrm{ppm}$ concentration. In addition to the stunting, the grasses exhibited marked chlorosis at the 60-ppm level and tip burn at both the 30 -and 60-ppm concentrations. No phytotoxic symptoms were visible in the $10-\mathrm{ppm}$ plants, so this concentration was chosen for the future long-term soil-uptake studies. Short-term hydroponic studies were conducted at solution concentrations of 25 ppm or less.

\subsubsection{Long-Term Partitioning of TNT Within the Plant}

The following data for tissue activity were originally determined on a dpm/g fresh wttissue basis by liquid scintillation analysis following fresh-frozen harvested tissue and were converted to $\mu \mathrm{g}$ TNT/g fresh-wt tissue for comparative purposes. These calculated concentrations are based on the ${ }^{14} \mathrm{C}$-TNT- or TNT-derivative specific activity of the soils, which was $0.09 \times 10^{-3} \mu \mathrm{g} / \mathrm{dpm}$ for the Palouse and Burbank and $0.077 \times 10^{-3} \mu \mathrm{g} / \mathrm{dpm}$ for the Cinebar soils, at the start of the experiment.

Table 3.16 provides summary data for bush bean grown to maturity on TNT-amended soils and for chamber controls. It should be noted that the chamber-control plants contain from 100 to $700 \mathrm{dpm}{ }^{14} \mathrm{C} / \mathrm{g}$ fresh-wt tissue. This activity results from the release of radiolabeled $\mathrm{CO}_{2}$ from the oxidative decomposition of ${ }^{14} \mathrm{C}$-TNT in the treated soils and subsequent foliar absorption and photosynthetic fixation by both treatment plants and chamber-control plants. Since both the chamber-control and treated plants will absorb similar quantities of gaseous ${ }^{14} \mathrm{CO}_{2}$ from adjacent plant canopies, and because the derived ${ }^{14} \mathrm{CO}_{2}$ specific activity was impossible to determine as to soil origin and amount, ${ }^{14} \mathrm{C}$ contents of treated plants were adjusted appropriately. Only in the Cinebar TNT treatment are the calculated TNT-tissue 
concentrations, particularly for pod and seed, significantly altered by this refixation, because of their low initial levels. These data have been subsequently corrected below. Controls maintained in a separate chamber had no detectable ${ }^{14} \mathrm{C}$ activity.

The total concentration of ${ }^{14} \mathrm{C}$ in tissues, derived from soil-amended TNT (10 ppm), varied with soil type. For roots, which were the major organ accumulating ${ }^{14} \mathrm{C}$, concentrations of TNT-derived residues were 4.8, 35.4, and $104 \mu \mathrm{g} / \mathrm{g}$ for Cinebar-, Palouse-, and Burbankgrown plants, respectively (Table 3.16). Stem concentrations ranged from 0.9 to $34 \mu \mathrm{g} / \mathrm{g}$, while leaf concentrations ranged from 0.3 to $9 \mu \mathrm{g} / \mathrm{g}$. Pod and seed concentrations were calculated to be less than $0.7 \mu \mathrm{g} / \mathrm{g}$. This would indicate for bush bean exposed to soil contaminated with TNT that the TNT and/or related degradation products root-absorbed from the soil are primarily

TABLE 3.16. CONCENTRATION OF TISSUE TNT-DERIVED RESIDUES FROM RADIOLABELED TNT IN TISSUES OF BUSH BEAN GROWN IN SOILS CONTAINING 10-ppm TNT OR IN CONTROL SOILS ${ }^{(a)}$

Condition/

Soil

TNT-Amended(b)

Cinebar

Palouse

Burbank
$0.88 \pm 0.13$

$9.07 \pm 1.77$

$23.99 \pm 1.23$
Plant Secment

Pod

Seed

Root

Chamber Control(c)

$\begin{array}{llllrr}\text { Cinebar } & 0.04 \pm 0.002 & 0.05 \pm 0.003 & 0.04 \pm 0.003 & 0.05 \pm 0.006 & 0.02 \pm 0.002 \\ \text { Palouse } & 0.04 \pm 0.013 & 0.04 \pm 0.013 & 0.01 \pm 0.003 & 0.009 \pm 0.005 & 0.02 \pm 0.005 \\ \text { Burbank } & 0.06 \pm 0.002 & 0.07 \pm 0.014 & 0.03 \pm 0.009 & 0.02 \pm 0.005 & 0.04 \pm 0.023\end{array}$

\footnotetext{
(a) Plants grown in soils amended with $10 \mathrm{ppm}{ }^{14} \mathrm{C}-\mathrm{TNT}(0.74 \mathrm{MBq} / 400 \mathrm{~g}$ pot), and from plants grown in nonamended chamber-control soils maintained in the same growth chamber. Data are averages \pm SD ( $n=9$ for TNT amended plants and $n=6$ for controls).
}

(b) $n=9$.

(c) $n=6$.

sequestered in the root, a lesser fraction being partitioned between leaves and stem, followed by pods and seed (Table 3.17). The partitioning results for TNT-treated plants are similar to those seen in the short-term hydroponic experiments. The partitioning of radiolabel is clearly different for chamber controls. Except for the root tissues, the label is uniformly distributed 
between aerial tissues. This indicates that the observed activity distributions result from fixation of radiolabeled $\mathrm{CO}_{2}$ released from TNT treatment and are likely root off-gases.

Tissue TNT concentration and percent total-label partitioning for wheat and blando brome are provided in Table 3.18. The data for the monocots are presented as root and shoot, given the close anatomical association of the culm (stem) and leaves in these species. Again, as seen above in the short-term hydroponic studies, 48 to $89 \%$ of the label absorbed by the plants was retained in the roots. This again shows the relative immobility of the TNT-derived material within the plants, even after extended absorption periods. Uptake and transport of TNT was comparable for both grass species, while total uptake and root accumulation was approximately $50 \%$ higher in wheat. However, unlike the short-term experiments, only in the Cinebar-soil grown plants was the percentage of export to the shoot of the wheat higher than that for all three soil types in the bean.

An interesting aspect of the results presented in Tables 3.16 and 3.18 is the variation in relative plant availability of TNT in the three soil types. In the case of bush bean, TNT and TNTderived activity sources appeared to be most available from Burbank, followed by Palouse, with Cinebar exhibiting the lowest bioavailability (Table 3.16). The data given in Table 3.16 show relative uptake ( $\mu \mathrm{g}$ TNT/g tissue) to be roughly 1:7:20 for Cinebar, Palouse, and Burbank,

\section{TABLE 3.17. DISTRIBUTION OF RADIOCARBON IN BUSH BEAN PLANTS GROWN FOR 60 DAYS IN TNT-AMENDED OR IN CONTROL SOILS ${ }^{(a)}$. Radioactivity associated with TNT-derived residues.}

Condition
Soil

Soil

\begin{tabular}{lcc} 
& & Plant Seament \\
\hline Leaf & Stem & Pod
\end{tabular}

Seed

Root

TNT-Amended(b)

Average $\%$ Total ${ }^{14} \mathrm{C} \pm \mathrm{SD}$

$\begin{array}{cccccc}\text { Cinebar } & 5.60 \pm 0.64 & 14.08 \pm 8.32 & 1.76 \pm 0.48 & 1.60 \pm 0.016 & 76.96 \pm 6.08 \\ \text { Palouse } & 12.90 \pm 2.39 & 17.23 \pm 5.03 & 1.41 \pm 0.21 & 0.34 \pm 0.21 & 67.34 \pm 16.45 \\ \begin{array}{c}\text { Burbank } \\ \text { Chamber Control(c) }\end{array} & 6.50 \pm 2.22 & 17.38 \pm 0.89 & 0.41 \pm 0.15 & 0.0 \pm 0.01 & 75.30 \pm 5.91 \\ \begin{array}{c}\text { Cinebar } \\ \text { Palouse }\end{array} & 24.02 \pm 1.04 & 20.67 \pm 1.51 & 20.06 \pm 1.50 & 25.06 \pm 3.23 & 10.19 \pm 1.11 \\ \text { Burbank } & 27.27 \pm 0.91 & 31.82 \pm 6.36 & 13.64 \pm 4.10 & 9.09 \pm 2.27 & 18.18 \pm 7.56\end{array}$

(a) Plants grown in soils amended with $10 \mathrm{ppm}{ }^{14} \mathrm{C}-\mathrm{TNT}(0.74 \mathrm{MBq} / 400 \mathrm{~g}$ pot), and from plants grown in nonamended chamber-control soils maintained in the same growth chamber. Data are averages \pm SD (n=9 for TNT amended plants and $n=6$ for controls).

(b) $n=9$.

(c) $n=6$. 
respectively. This trend is roughly similar for the monocots, with the exception of the wheat roots from Burbank soil, where the value was more than 40 times that for Cinebar (218 vs. 5 $\mu \mathrm{g}$ TNT/g fresh. wt) (Table 3.18). This may suggest additional species differences in the mode of uptake, sequestering, and transport of TNT and related residues.

IABLE 3.18. CONCENTRATION OF TISSUE TNT-DERIVED RADIOCARBON AND DISTRIBUTION OF RADIOCARBON IN WHEAT AND BLANDO BROME TISSUES FROM PLANTS GROWN ON TNT-AMENDED SOILS OR CONTROL SOILS(a)

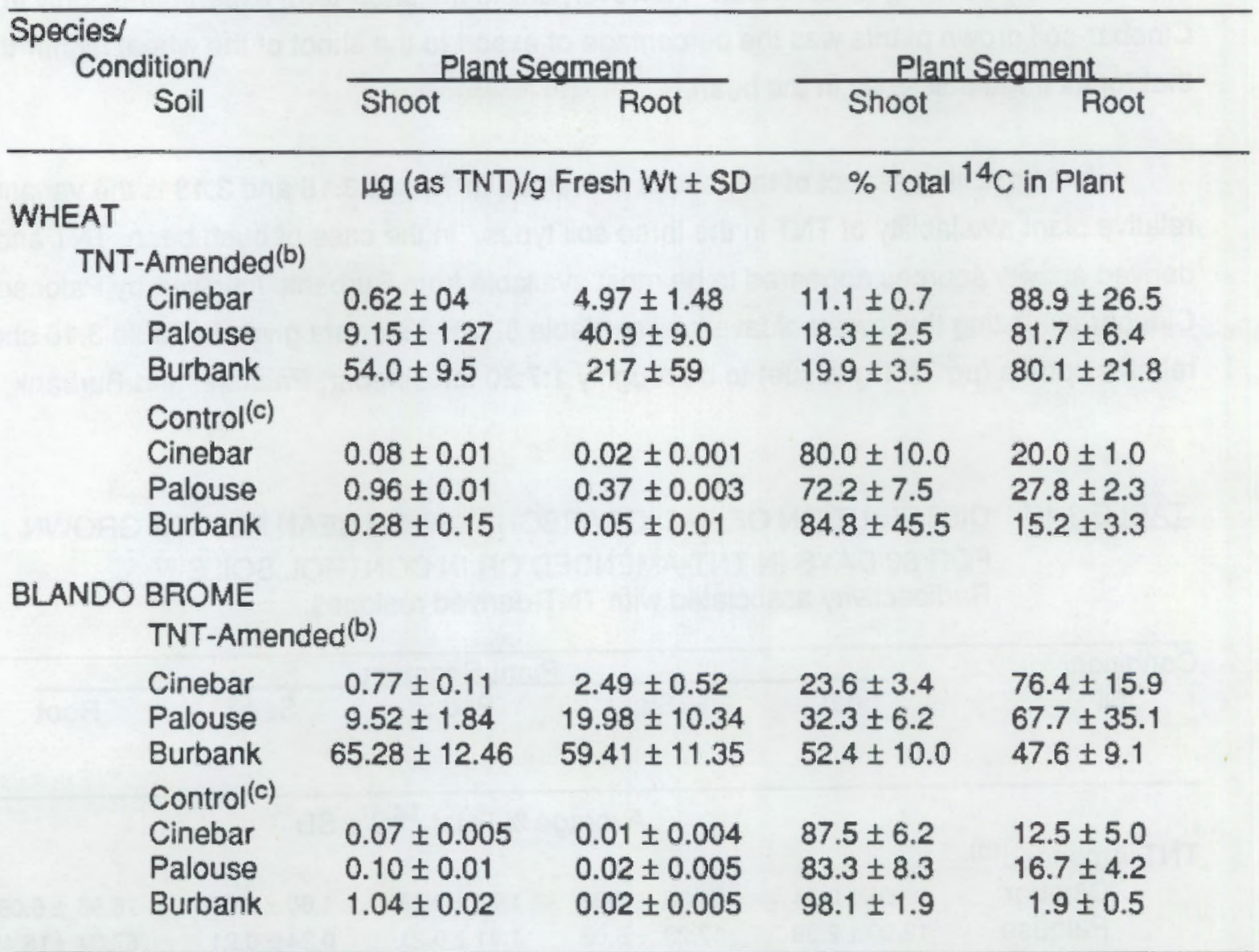

\footnotetext{
(a) Plants grown in soils amended with $10 \mathrm{ppm}{ }^{14} \mathrm{C}-\mathrm{TNT}(0.74 \mathrm{MBq} / 400 \mathrm{~g}$ pot), and plants grown in nonamended chamber control soils maintained in the same growth chamber. Data are averages \pm SD $(n=9$ for TNT amended plants and $n=6$ for controls)

(b) $n=9$.

(c) $n=6$.
} 
It is also important to note that these uptake/accumulation values are based on fresh weights. Because fresh tissues are typical $90 \%$ water by weight, all values for TNT should be multiplied by a factor of approximately 10 to convert them to a dry-weight basis. On this basis, it can be seen that the uptake and ingestion of crops such as wheat grown in areas of TNT contamination could provide a source term for herbivores.

Direct phytotoxicity could not explain the differences observed in uptake from the different soils, since range-finding studies (Section 3.3.1) indicated that a $10 \mathrm{ppm}$ concentration of TNT in the soil was not visibly toxic to bush beans and was only slightly so to the monocot species. Another possibility is the capability of the soil to support plant growth, or soil fertility. There are significant nutritional differences (i.e., mineral content, CEC, OM content, etc.) between the soil types used. It was therefore important to investigate whether these differences (i.e., relative deficiencies) and their subsequent effects on plant growth and metabolism might be partially responsible for the variability in specific uptake. Thus, the potential TNT toxicity, based on the fresh weights of the exposed and control plants, were determined. They are given in Table 3.19 for the bean and in Table 3.20 for the wheat and blando brome.

IABLE 3.19. AVERAGE FRESH WEIGHT (g) OF BUSH BEAN PLANTS GROWN FOR 60 DAYS IN SOILS AMENDED WITH RADIOLABELED-TNT OR IN CONTROL SOILS

\begin{tabular}{cllllll}
\hline $\begin{array}{c}\text { Condition/ } \\
\text { Soil }\end{array}$ & Leaf & Stem & Pod & Seed & Root & Total
\end{tabular}

TNT-Amended(a)

Average Fresh $W_{t} \pm \mathrm{SD}^{(a)}$ or Variance ${ }^{(b)}$

$\begin{array}{ccccccc}\text { Cinebar } & 7.33 \pm 0.78^{(d)} & 3.43 \pm 0.45^{(d)} & 7.48 \pm 1.93^{(d)} & 1.71 \pm 0.27^{(d)} & 9.80 \pm 1.22^{(d)} & 29.75 \pm 2.86^{(d)} \\ \text { Palouse } & 2.86 \pm 1.18^{(c)} & 1.58 \pm 0.12^{(c)} & 3.41 \pm 0.60^{(d)} & 1.19 \pm 0.81^{(c)} & 4.97 \pm 1.71^{(d)} & 14.01 \pm 3.54^{(d)} \\ \text { Burbank } & 3.44 \pm 0.96^{(c)} & 1.37 \pm 0.16^{(c)} & 3.28 \pm 1.52^{(d)} & 0.54 \pm 0.42^{(c)} & 5.04 \pm 0.32^{(c)} & 13.65 \pm 1.15^{(c)} \\ & & & & & & \\ \text { Control(b) } & & & & & & \\ \text { Cinebar } & 7.63 \pm 0.78 & 3.56 \pm 0.21 & 6.29 \pm 0.01 & 2.44 \pm 0.47 & 11.53 \pm 0.16 & 31.45 \pm 0.90 \\ \text { Palouse } & 2.32 \pm 0.83 & 1.94 \pm 0.21 & 3.21 \pm 2.44 & 0.78 \pm 0.24 & 5.25 \pm 1.16 & 13.49 \pm 0.42 \\ \text { Burbank } & 5.43 \pm 2.82 & 2.79 \pm 1.03 & 2.82 \pm 0.91 & 0.70 \pm 0.60 & 8.07 \pm 2.46 & 19.80 \pm 4.41\end{array}$
(a) $n=5$.
(b) $\mathrm{n}=2$.
(c) Significant ( $P \leq 0.2)$ according to one-tailed t-Test.
(d) Not significant ( $P \geq 0.2)$ according to one-tailed $t$-Test. 
The results in Table 3.19 indicate that significant differences $(P \leq 0.01)$ exist in the total weights of bush bean plants grown in the Cinebar $(29.8 \pm 3.0 \mathrm{~g})$ verses those grown in either the Palouse or Burbank soils (i.e., $14.0 \pm 3.5 \mathrm{~g}$ for the Palouse plants versus $13.7 \pm 1.2 \mathrm{~g}$ for the Burbank). Total absorption (roots and shoots) (Table 3.16) for the plants grown on these soils were 52 and $138 \mu \mathrm{g} \mathrm{TNT/g}$ fresh wt, respectively, for Palouse and Burbank compared with 6.2 $\mu \mathrm{g} \mathrm{TNT/g}$ fresh wt for Cinebar. Because there were no detectable fresh-weight differences $(P \geq 0.1)$ between either the TNT-amended Palouse, Burbank, or Cinebar soils and their controls (Table 3.19), it can be assumed that toxic effects of TNT on uptake or growth can be ruled out. The fresh weights of chamber-control bush beans were only slightly effected $(P \leq 0.2)$ in the Burbank soils (13.6 $\pm 1.2 \mathrm{~g}$ versus $19.8 \pm 4.4 \mathrm{~g}$ amended versus nonamended, respectively). Thus, the TNT content of the plants grown in the Cinebar, Palouse, and Burbank $(6.2,52$, and $138 \mu \mathrm{g} \mathrm{TNT} / \mathrm{g}$ fresh wt. respectively) is likely due to soil factors (i.e. sorption, binding) rather than to any toxicity from TNT.

The grasses, blando brome and wheat were more sensitive to soil-amended TNT (Table 3.20) than was bush bean (Table 3.19). In wheat, shoot biomass was significantly affected $(P<0.1)$ for plants grown on all three soils compared to their controls. Shoot fresh weights decreased by 15 to $40 \%$, while root fresh weights and total-plant dry weights were unaffected. Overall biomass production was least for the low-fertility Burbank soil and highest for Cinebar. TNT accumulation for wheat was approximately 5,50 , and $250 \mu \mathrm{g} / \mathrm{g}$ (Table 3.18), inversely proportional to biomass production. In blando brome, both shoot and root biomass were significantly affected $(P<0.1)$ for plants grown on all three soils amended with TNT. Shoot fresh weights, compared with controls, decreased by 15 to $60 \%$, while root fresh weights were depressed by approximately $50 \%$. Overall biomass production was generally comparable for Burbank and Palouse soils and was substantially higher for Cinebar. TNT accumulation for these plants was approximately 3,25, and $120 \mu \mathrm{g} / \mathrm{g}$ for Cinebar, Palouse, and Burbank soil, respectively (Table 3.18); as with wheat, uptake was inversely proportional to biomass production.

While gross toxicity effects can be ruled out as influencing TNT uptake in bush bean and wheat, the reduced biomass production in blando brome may be affected. However, all three plant species show a distinct soil effect on uptake of TNT, with Cinebar yielding the lowest uptake and Burbank the highest. This pattern of plant availability for TNT is inversely related to soil organic-matter content (Table 2.1) and soil solubility of TNT (Table 3.2). Biomass studies clearly show that tissue dilution does not account for differences in plant species uptake of TNT. For bush bean, the maximum difference in plant fresh weight is twofold for the three soils while TNT concentrations vary by a factor of 20 . In wheat, biomass varies with soil type by a factor of 7, while TNT levels vary by 40 -fold. In blando brome, biomass varies by a factor of 5 , TNT by a factor of 25 . 
IABLE3.20. AVERAGE FRESH WEIGHTS OF WHEAT AND BLANDO BROME PLANTS GROWN FOR 60 DAYS ON 10-PPM TNT-AMENDED OR CONTROL SOILS

\begin{tabular}{|c|c|c|c|}
\hline \multirow{3}{*}{$\begin{array}{c}\text { Species/ } \\
\text { Condition/ } \\
\text { Soil }\end{array}$} & \multirow{2}{*}{\multicolumn{2}{|c|}{ Plant Segment }} & \multirow[b]{3}{*}{ Total } \\
\hline & & & \\
\hline & Shoot & Root & \\
\hline & \multicolumn{3}{|c|}{ Average Fresh Weight $\mathrm{SD}^{(\mathrm{a})}$ or variance ${ }^{(\mathrm{b})}$} \\
\hline \multicolumn{2}{|c|}{ TNT-Amended(a) } & \multicolumn{2}{|c|}{ 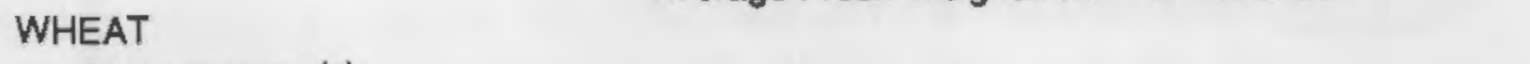 } \\
\hline Cinebar & $6.59 \pm 0.30(c)$ & $17.20 \pm 5.43^{(\theta)}$ & $23.98 \pm 5.60^{(\theta)}$ \\
\hline Palouse & $1.95 \pm 0.18^{(c)}$ & $5.29 \pm 1.14^{(\theta)}$ & $7.35 \pm 1.21^{(\theta)}$ \\
\hline Burbank & $0.70 \pm 0.04^{(c)}$ & $2.87 \pm 0.51^{(\theta)}$ & $3.59 \pm 0.54^{(\theta)}$ \\
\hline \multicolumn{4}{|l|}{ Control(b) } \\
\hline Cinebar & $7.53 \pm 0.10$ & $18.57 \pm 4.77$ & $26.10 \pm 4.67$ \\
\hline Palouse & $3.08 \pm 0.53$ & $5.59 \pm 1.45$ & $8.66 \pm 0.92$ \\
\hline Burbank & $1.20 \pm 0.30$ & $4.57 \pm 2.88$ & $5.76 \pm 3.18$ \\
\hline \multirow{2}{*}{\multicolumn{4}{|c|}{$\begin{array}{l}\text { BLANDO BROME } \\
\text { TNT-Amended (a) }\end{array}$}} \\
\hline & & & \\
\hline Cinebar & $6.18 \pm 0.38^{(c)}$ & $17.74 \pm 3.01^{(c)}$ & $23.69 \pm 3.30^{(c)}$ \\
\hline Palouse & $2.01 \pm 0.16^{(c)}$ & $4.21 \pm 0.93^{(d)}$ & $6.18 \pm 0.96^{(d)}$ \\
\hline Burbank & $0.56 \pm 0.08(d)$ & $4.58 \pm 0.90(c)$ & $5.14 \pm 0.81^{(d)}$ \\
\hline \multicolumn{4}{|l|}{ Control(b) } \\
\hline Cinebar & $6.86 \pm 0.01$ & $26.63 \pm 0.36$ & $33.48 \pm 0.37$ \\
\hline Palouse & $2.99 \pm 0.11$ & $9.73 \pm 0.06$ & $12.72 \pm 0.05$ \\
\hline Burbank & $1.20 \pm 0.01$ & $9.06 \pm 0.69$ & $10.26 \pm 0.69$ \\
\hline \multirow{2}{*}{\multicolumn{4}{|c|}{$\begin{array}{l}\text { (a) } \mathrm{N}=5 \text {. } \\
\text { (b) } \mathrm{N}=2 \text {. }\end{array}$}} \\
\hline & & & \\
\hline a & & & \\
\hline
\end{tabular}

\subsubsection{Chemistry of TNT in Mature Plants}

Tissues from plants grown to maturity in soil containing $10 \mathrm{ppm}$ TNT $(20 \mu \mathrm{Ci} / 400 \mathrm{~g}$ soil) were fractionated and analyzed as described previously. The results from the chemical fractionation and analyses for mature bush bean, wheat, and blando brome grown in Burbank, Palouse, and Cinebar soils are summarized in Tables 3.21-3.26. In general, the distribution of radiolabel in the different chemical fractions was similar to the results obtained from plants grown in TNT-containing hydroponic solutions for 7 days. The most striking difference between 
plants grown in hydroponic solution and in soils was the lower percentage of radiolabel found in fraction F2 of soil-grown plants. Stems, leaves, and shoots of plants grown in hydroponic culture contained an average of $11 \pm 7 \%(n=20)$ of the total radiolabel in fraction F2. Aerial portions (stems, leaves, and shoots) of plants grown in soils contained a smaller percentage

TABLE 3.21. PERCENTAGE OF TOTAL RADIOACTIVITY, BASED ON OXIDATIONS, IN THE VARIOUS CHEMICAL FRACTIONS OF MATURE BUSH BEAN PLANTS GROWN IN BURBANK SOIL(a)

\begin{tabular}{|c|c|c|c|}
\hline \multirow[b]{2}{*}{ Fraction } & \multicolumn{3}{|c|}{ Tissue } \\
\hline & Seed & Leaves & Stem \\
\hline $\mathrm{HCl}$ & 32 & 27 & 47 \\
\hline Aq base & 22 & 20 & 34 \\
\hline $\mathrm{Et}_{2} \mathrm{O}$ acid-neutral & 0 & 5 & 13 \\
\hline $\mathrm{Et}_{2} \mathrm{O}$ base & 0 & 4 & 10 \\
\hline F1 & 0 & 0 & 0 \\
\hline F2 & 0 & 6 & 6 \\
\hline F3 & 0 & (b) & 1 \\
\hline F4 & 0 & 7 & 5 \\
\hline Pellet & 19 & 15 & 51 \\
\hline
\end{tabular}

(a) Values are based on the fractionation of $1.00 \mathrm{~g}$ samples of tissue.

(b) Sample lost due to container breakage.

a smaller percentage of total radiolabel in fraction F2, an average of $3 \pm 2 \%(n=16)$. This difference between hydroponically and soil-grown plants suggests that further metabolism of TNT occurred during the extended exposure and growth of the mature plants in soil. Although the metabolites produced in the mature plants must appear as more polar compounds (Aq-base or F4 fractions) or be sequestered in the pellet, the data fail to give a clear indication of the chemical nature of these metabolites. With the exception of fraction F2, the percentage of radiolabel among the different fractions is similar in hydroponically and soil-grown plants. The average percentages of radiolabel in fraction $\mathrm{F} 4$ and in the Aq-base fraction for stem, leaf, and shoot tissues of hydroponically grown plants were $14 \pm 7 \%(n=20)$ and $21 \pm 7 \%(n=20)$, respectively. This is approximately the same as the average $(7 \pm 4 \%[n=16])$ of the total radiolabel found among stems, leaves, and shoots in fraction $\mathrm{F} 4$ and that localized in the Aqbase fractions (22 $\pm 10 \%$ ) of soil-grown mature plants. The average percentage of radiolabel in 
IABLE 3.22. PERCENTAGE OF TOTAL RADIOACTIVITY, BASED ON OXIDATIONS, IN THE VARIOUS CHEMICAL FRACTIONS OF MATURE BUSH BEAN PLANTS GROWN IN PALOUSE SOIL(a)

\begin{tabular}{|c|c|c|c|}
\hline \multirow[b]{2}{*}{ Fraction } & \multicolumn{3}{|c|}{ Tissue } \\
\hline & Seed & Leaves & Stem \\
\hline $\mathrm{HCl}$ & 50 & 42 & 45 \\
\hline Aq base & 25 & 32 & 30 \\
\hline $\mathrm{Et}_{2} \mathrm{O}$ acid- neutral & 0 & 11 & 9 \\
\hline $\mathrm{Et}_{2} \mathrm{O}$ base & 0 & 5 & 7 \\
\hline F1 & 0 & 0 & 0 \\
\hline F2 & 0 & 3 & 3 \\
\hline F3 & 0 & 0 & 0 \\
\hline F4 & 0 & 8 & 4 \\
\hline Pellet & 21 & 19 & 39 \\
\hline
\end{tabular}

(a) Values reported for leaf and stem tissues are the average of two determinations \pm range/2. Values reported for pod and seed tissues are based on one determination.

IABLE 3.23. PERCENTAGE OF TOTAL RADIOACTIVITY, BASED ON OXIDATIONS, IN THE VARIOUS CHEMICAL FRACTIONS OF MATURE BUSH BEAN PLANTS GROWN IN CINEBAR SOIL(a)

\begin{tabular}{|c|c|c|c|c|c|c|c|}
\hline \multirow{3}{*}{$\begin{array}{l}\text { Fraction } \\
\mathrm{HCl}\end{array}$} & \multicolumn{7}{|c|}{ Tissue } \\
\hline & \multirow{2}{*}{$\frac{\text { Seed }}{0}$} & \multirow{2}{*}{\begin{tabular}{|l} 
Pod \\
35
\end{tabular}} & \multicolumn{2}{|c|}{ Leaves } & \multicolumn{3}{|c|}{ Stem } \\
\hline & & & 42 & \pm 1 & 36 & \pm & 0.5 \\
\hline Ag base & 0 & 15 & 31 & \pm 8 & 30 & \pm & 7 \\
\hline $\mathrm{Et}_{2} \mathrm{O}$ acid- neutral & 0 & 0 & 9 & \pm 5 & 11 & \pm & 1 \\
\hline $\mathrm{Et}_{2} \mathrm{O}$ base & 0 & 0 & 1 & \pm 1 & 11 & \pm & 4 \\
\hline $\mathrm{F} 1$ & 0 & 0 & & 0 & & 0 & \\
\hline $\mathrm{F} 2$ & 0 & 0 & & 0 & 3 & \pm & 0 \\
\hline $\mathrm{F} 3$ & 0 & 0 & & 0 & & $\overline{0}$ & \\
\hline F4 & 0 & 0 & 6 & \pm 2 & 6 & \pm & 2 \\
\hline Pellet & 17 & 32 & 29 & \pm 5 & 42 & \pm & 1 \\
\hline
\end{tabular}

(a) Values reported for leaf and stem tissues are the average of two determinations \pm range/2. Values reported for pod and seed tissues are based on one determination. 
IABLE 3.24. PERCENTAGE OF TOTAL RADIOACTIVITY, BASED ON OXIDATIONS, IN THE VARIOUS CHEMICAL FRACTIONS OF MATURE WHEAT AND BLANDO BROME PLANTS GROWN IN BURBANK SOIL(a)

\begin{tabular}{lcc}
\hline & \multicolumn{2}{c}{ Tissue } \\
\cline { 2 - 3 } Fraction & Wheat Shoot & Grass Shoot \\
\hline $\mathrm{HCl}$ & 26 & 25 \\
$\mathrm{Aq}$ base & 21 & 15 \\
$\mathrm{Et} \mathrm{2}_{2} \mathrm{O}$ acid- neutral & 11 & 14 \\
$\mathrm{Et} \mathrm{t}_{2} \mathrm{O}$ base & 3 & 4 \\
$\mathrm{~F} 1$ & 0 & 0 \\
F2 & 4 & 6 \\
F3 & 1 & 1 \\
F4 & 6 & 6 \\
Pellet & 31 & 31 \\
\hline
\end{tabular}

(a) Values are based on the fractionation of $1.00 \mathrm{~g}$ samples of tissue.

IABLE 3.25. PERCENTAGE OF TOTAL RADIOACTIVITY, BASED ON OXIDATIONS, IN THE VARIOUS CHEMICAL FRACTIONS OF MATURE WHEAT AND BLANDO BROME PLANTS GROWN IN PALOUSE SOIL(a)

\begin{tabular}{|c|c|c|}
\hline \multirow[b]{2}{*}{ Fraction } & \multicolumn{2}{|c|}{ Tissue } \\
\hline & Wheat Shoot & Grass Shoot \\
\hline $\mathrm{HCl}$ & 31 & 25 \\
\hline Aq base & 22 & 16 \\
\hline $\mathrm{Et}_{2} \mathrm{O}$ acid-neutral & 14 & 19 \\
\hline $\mathrm{Et}_{2} \mathrm{O}$ base & 2 & 3 \\
\hline $\mathrm{F} 1$ & 0 & 0 \\
\hline $\mathrm{F} 2$ & 4 & 6 \\
\hline F3 & 1 & 1 \\
\hline F4 & 9 & 10 \\
\hline Pellet & 29 & 17 \\
\hline
\end{tabular}

(a) Values are based on the fractionation of $1.00 \mathrm{~g}$ samples of tissue. 
IABLE 3.26. PERCENTAGE OF TOTAL RADIOACTIVITY, BASED ON OXIDATIONS, IN THE VARIOUS CHEMICAL FRACTIONS OF MATURE WHEAT AND BLANDO BROME PLANTS GROWN IN CINEBAR SOIL(a)

\begin{tabular}{|c|c|c|c|}
\hline \multirow[b]{2}{*}{ Fraction } & \multicolumn{3}{|c|}{ Tissue } \\
\hline & Wheat Shoot & Grass & Shoot \\
\hline $\mathrm{HCl}$ & $20 \pm 3$ & 19 & \pm 1 \\
\hline Aq base & $19 \pm 7$ & 7 & \pm 1 \\
\hline $\mathrm{Et}_{2} \mathrm{O}$ acid-neutral & $7 \pm 0$ & 13 & \pm 3 \\
\hline $\mathrm{Et}_{2} \mathrm{O}$ base & 0 & & 0 \\
\hline $\mathrm{F} 1$ & 0 & & 0 \\
\hline $\mathrm{F} 2$ & $1 \pm 1$ & & 0 \\
\hline $\mathrm{F3}$ & 0 & & 0 \\
\hline $\mathrm{F} 4$ & $8 \pm 6$ & 13 & \pm 4 \\
\hline Pellet & $37 \pm 2$ & 36 & \pm 3 \\
\hline
\end{tabular}

(a) Values are the average of two determinations \pm range/2.

the pellet was likewise similar in hydroponically and soil-grown plants. The average percentage of total radioactivity in the pellets over all analyses of mature soil-grown plants was $31 \pm 10 \%$ (n $=21)$. This quantity of nonextractable radiolabel is the same as the average $(28 \pm 10[n=38])$ observed for plants grown in hydroponic solutions.

Interestingly, TNT metabolites were found in bush bean seeds (and in the one pod analyzed) from the matured soil-grown plants. These metabolites differ markedly in the distribution of radiolabel among the different chemical fractions, and seem to exemplify the extreme of polarity. In all cases, the metabolites were so polar that none of the radiolabel was extracted into diethyl ether (Tables 3.21 and 3.22).

Chromatographic analysis of the F2 fractions of tissues from mature soil-grown plants failed to indicate the presence of TNT or the aminodinitrotoluene isomers. In nearly all cases, the amounts of these compounds expected, based on calculations using the specific activity of TNT and the amount of radiolabel isolated in fraction F2, were below the detection capability of the HPLC analytical system. In a few instances, particularly for wheat and fescue grown in Burbank soil, the amount of radiolabel isolated in fraction F2 seemed to indicate that TNT and/or the aminodinitrotoluene isomers may be slightly above the detection limit. Inspection of the chromatograms showed several peaks in the vicinity of the expected retention times of these compounds. Chromatograms of the soil-grown plant tissue were found to be more 
complex than those obtained from plants grown in hydroponic solutions. It is possible that matrix interferences arising from the complexity of the F2 fraction of soil-grown plants may present difficulties in the determination of TNT and the aminodinitrotoluene isomers. Should this prove to be the case, further analytical development may be necessary.

By far the most significant finding is the previously unknown presence of an overwhelming abundance of polar TNT metabolites in plants exposed to TNT. It should be emphasized, furthermore, that all chemical fractionations were performed on acid-hydrolyzed tissues, acid hydrolysis being necessary to increase the amount of radiolabel extractable into organic solvents. Thus, the actual TNT metabolites in plants are even more polar than the fractionation of the acid-hydrolyzed material would seem to indicate. It was shown that the bush bean transports TNT from the roots to the aerial portions of the plant as polar conjugates of the aminodinitrotoluene isomers. In the leaves, further metabolism of the aminodinitrotoluene isomers is hypothesized to occur. TNT metabolites were found to be contained within the plant tissue rather than being eliminated as volatile transpiration products. The chemical identity and toxicological properties of the TNT-derived polar metabolites remain to be investigated.

Continued research in this area can be expected to clarify the risks associated with ingestion of plants grown in TNT-contaminated soils and lead to a better understanding of the potential for food chain transfer. 


\subsection{SUMMARY AND CONCLUSIONS}

The goal of these investigations was to elucidate the environmental behavior and fate of 2,4,6-trinitrotoluene (TNT), particularly as related to the transport and chemical form of TNT within the food chain. To meet this goal, it was necessary to adapt and develop suitable analytical methodology to fractionate and characterize both TNT and TNT-derived residues in soil and plant matrices. Using this methodology, the chemical and physical fates of TNT were assessed in soils and plants.

\subsection{SUMMARY OF RESULTS}

\subsubsection{Analytical Methods}

It is clear that our general understanding of the environmental chemistry of organic xenobiotics such as TNT is limited by the depth to which investigations can be scoped. Analytical methods for TNT in waste streams and less-complex matrices have been used for many years, but extension of these methods to soil and plant matrices presents certain problems, particularly with chemical interference and recovery. The procedures developed in this program extend the prior art, through the use of matrix-specific extraction and fractionation schemes followed by classical HPLC separations. For soil matrices, Soxhlet extraction methods and HPLC provide a good basis for mass balance of soil TNT and for identification of reported decomposition and/or transformation products. With plant-tissue matrices, extraction and analyses are severely complicated by endogenous metabolites and pigments. This problem was alleviated through the use of selective solvent extraction and subsequent adsorption and elution chromatography from Florisil. This methodology resolved interference problems, and permitted separation of the less-polar TNT and metabolites from more-polar fractions. Both methods showed good recovery and reproducibility.

\subsubsection{TNT Fate in Soils}

Mass-balance analyses of TNT amended to soils varying in mineralogy, CEC, and organic-matter content were generally good. Soil sorption of TNT, or that fraction not readily removed by exhaustive extraction, increases from less than $6 \%$ at 0 time to 30 to $50 \%$ after 60 days of incubation. Sterile soil systems indicate that the sorption process is nonbiotic in origin, and that mass-balance deficits can be partially accounted for by microbial oxidation of 
TNT to $\mathrm{CO}_{2}$. The latter process, by calculation, indicates a half-life of 4 to 10 years for TNT in soils, depending on soil type.

Of the extractable TNT-derived fraction, the content of 2,4,6-trinitrotoluene decreases to 2 to $36 \%$ after 60 days of incubation. Several TNT-derived residues isolated from soil make up the balance of the extractable material amended. Mass spectrometry showed TNTderived transformation products to include two aminodinitrotoluene isomers (AMDNT) (2amino-4,6-dinitrotoluene and 4-amino-2,6-dinitrotoluene) and one unidentified product, unique to Burbank soil. In addition, radiochromatograms of TNT-containing Burbank soil showed several unidentified polar transformation products. After 60 days of incubation, the two aminodinitrotoluene compounds were prominent features of the chromatographic profiles. In extracts from both Cinebar and Burbank soils, the concentrations of these isomers were higher than TNT after 60 days of aging. In contrast, TNT concentrations were higher than those of the aminodinitrotoluene isomers in the 60-day extracts from Palouse soil. Similar transformation patterns were observed for the sterile soils, indicating that these transformations are nonbiotic.

\subsubsection{Plant Availability and Chemical Fate of TNI}

Hydroponic systems clearly indicated that the absorption capacity for plants is high. Uptake of TNT was highest in the bush bean dicot model and was lower in the monocots blando brome and wheat. Absorption was concentration dependent. Thus, soil sorption will control the concentration of soil-solution TNT and/or TNT-derived residues available for root uptake. Hydroponic systems were used to calibrate subsequent soil studies and to ascertain what chemical transformations may occur within the rhizosphere (in the absence of soil), and thus the chemistry peculiar to plant metabolism. Results showed that in the presence of roots, solution TNT rapidly declines, with the appearance of aminodinitrotoluene isomers and unidentified metabolites, while the mass balance is retained. Results indicate that both TNT and the aminodinitrotoluene isomers are root absorbed.

Following root absorption, greater than $75 \%$ of the accumulated residues are retained within the root. Of the total TNT residues recovered from the root, less than $20 \%$ were recovered within the TNT and TNT-residue fraction. The remainder represent highly polar or nonextractable components. A similar trend was seen for shoot tissues, although their total TNT-derived activity was substantially lower. The principal identified components were the AMDNT isomers, and substantially less TNT. Analysis of stem residues indicated that nearly all TNT-derived activity transported from the root to shoot of bush bean was an unidentified 
highly polar component which on acid hydrolysis releases principally the aminodinitrotoluene isomers and an unidentified metabolite. Similar studies with root-tissue extracts containing similar but substantially more of the high molecular-weight metabolite showed acid hydrolysis to yield substantial amounts of aminodinitrotoluene isomers. These results indicate that TNT-derived and plant-accumulated products are stored and transported as conjugates. These conjugates are not normally recovered or assayed using current analytical methods.

Studies with plants grown to maturity on TNT amended soils show TNT-derived metabolites to accumulate in all tissues. The relative order of concentration was root >stemsleaves >>seed and pod. Total plant concentration was highly dependent on soil type or on soil available-TNT concentrations. In all cases, plant uptake was inversely proportional to soil organic-matter content. The chemistry of accumulated residues shows patterns similar to hydroponic studies, the principal components being TNT and the aminodinitrotoluene isomers.

\subsection{RESEARCH NEEDS}

It is clear that the environmental chemistry of TNT is unrelated to classical chemical pathways identified for waste streams. The analytical methods developed for this project have provided only a basis for understanding the environmental behavior and fate of TNT and its residues, namely AMDNT and polar residues believed to be conjugated. Extending this information to assess food chain and/or health implications of munitions released to the environment will require the expansion of our understanding of soil catalytic reactions and of the plant availability and further metabolism of these materials.

An interesting result obtained during the course of this study was the isolation in Burbank soil of a unique transformation product of TNT. This component is thought to be an intermediate in the formation of nonvolatile residues. Structural elucidation of this catalytically formed intermediate, based on furthering the studies contained in this report, could lead to a better understanding of the nature of the irreversibly bound residues and could lay the foundation for understanding the catalytic transformation of TNT in contaminated soils. Semipreparative HPLC isolation and further characterization by isobutane chemicalionization mass spectrometry, $300-\mathrm{MHz}$ proton nuclear magnetic resonance, and IR studies would be used to determine the structure of this unknown. Since the extent of TNT degradation and/or decomposition was not resolved previously to these studies, the latter methodologies were beyond the original scope of the present work. 
These results strongly indicate that greater than $80 \%$ of the activity derived from TNT is either conjugated and/or chemically modified in plant tissues. Current analytical methods, including those described in this report, are inadequate to characterize these metabolites. Several key issues related to plant metabolism raised by the present study need to be addressed by future research. Foremost among these is the identification of the unknown metabolite in the F2 fraction of hydrolyzed xylem exudates and root tissues. An approach similar to the one outlined above for the structural elucidation of the soil transformation product would be brought to bear on the unknown plant metabolite. Since both the aminodinitrotoluene isomers and the unknown plant metabolite are involved in the transport of TNT, a related issue would be to determine the chemical nature of these polar conjugates. Studies utilizing specific enzyme hydrolysis of xylem exudate followed by radiochromatography could clarify the nature of the conjugated transport forms. Similarly, successive enzyme digests of the pellet could yield insight into the types of TNT metabolic products sequestered for long-term storage.

Since the majority of TNT-derived radiolabel resides in the Aq-base and F4 fractions described in this report, further characterization of these metabolites is fundamental to a better understanding of TNT metabolism in plants. The approach would be to characterize the material by exclusion chromatography and to follow this with studies of the low molecular-weight metabolites ( $M W<1000$ ). Further structural elucidation would require additional chromatographic fractionations and extensive characterization by liquid chromatography/ mass spectroscopy and infrared techniques. 


\subsection{LITERATURE CITED}

Bartha, T. S., and D. Pramer. 1967. "Pesticide Transformation to Aniline and Azo Compounds in Soil." Science 156:1617-1618.

Bollag, J. M., P. Blattmann, and T. Laanio. 1978. "Adsorption and Transformation of Four Substituted Anilines in Soil." J.Agric. Food Chem. 26:1302-1306.

Bauer, C. F., C. L. Grant, and T. F. Jenkins. 1986. "Interlaboratory Evaluation of High Performance Liquid Chromatographic Determination of Nitroorganics in Munition Plant Wastewater." Anal. Chem. 58:176-182.

Belkin, F., R. W. Bishop, and M. V. Sheely. 1985. "Analysis of Explosives in Water and Capillary Gas Chromatography." J. Chromatogr. Sci. 24:532-534.

Cataldo, D. A., T. R. Garland, and R. E. Wildung. 1978. "Nickel in Plants 1. Uptake Kinetics Using Intact Soybean Seedlings." Plant Physiol. 62:563-565.

Folsom, B. L. Jr., C. L. Teeter, M. R. Barton, and J. A. Bright. 1986. Plant Uptake of 2.4.6Trinitrotoluene (TNT). Miscellaneous Paper, EL-86- U. S. Army Corps of Engineer Waterways Experiment Station, Vicksburg, Mississippi.

Hsu, T. S., and R. Bartha. 1974. "Interaction of Pesticide-Derived Chloroaniline Residues with Soil Organic Matter." Soil Science 116:444-452.

Jenkins, F. J. and C. L. Grant. 1987. "Comparison of Extraction Techniques for Munitions Residues in Soil." Anal. Chem. 59: 1326-1331.

Jenkins, T. F., D. C. Leggett, C. L. Grant and C. F. Bauer. 1986. "Reversed-Phase HighPerformance Liquid Chromatographic Determination of Nitroorganics in Munitions Wastewater." Anal, Chem. 58:170-175.

Kearney, P. C., Q. Zeng, and J. M. Ruth. 1983. "Oxidative Pre-Treatment Accelerates 2,4,6Trinitrotoluene Metabolism in Soils." Chemosphere 12:1583-1598.

Kitchens J.F., S. G. Brownlee, W. E. Harward, R. G. Hyde, W. E. Jones, D. A. Price, R. S. Wentsel, and R. S. Valentine. 1978. Preliminary Problem Definition Study on MunitionsRelated Chemicals. DAMD17-77-C-7057. Atlantic Research Corp. Baltimore, Maryland.

Klausmeier, R. E., J. L. Osmon, and D. R. Wells. 1973. "The Effect of Trinitrotoluene on Microorganisms." Dev. Ind. Microbiol. 15:309-317.

Marquis, L. Y., R. H. Shimabukuro, G. E. Stolzenburg, V. J. Feil, and R. G. Zaylskie. 1979. "Metabolism and Selectivity of Fluchloralin in Soybean Roots." J. Agric. Food Chem. 27:1148-1156.

McCormick, N. G., F. E. Feeherry, and H. S. Levinson. 1976. "Microbial Transformation of 2,4,6-Trinitrotoluene and Other Nitroaromatic Compounds." Appl. Environ. Microbiol. 31:949-958. 
Nay, M. W., C. W. Randall, and P. H. King. 1974. "Biological Treatment of Trinitrotoluene Manufacturing Wastewater." J. Water Pollut. Control Fed. 46:485-497.

Palazzo, A. J., and D.C. Leggett. 1986. "Effect and Disposition of TNT in a Terrestrial Plant." J. Environ. Qual. 15:49-52.

Pennington, J. C. 1987. Plant Uptake of 2,4,6-Trinitrotoluene, 4-Amino-2,6-Dinitrotoluene, and 2-Amino-4.6-Dinitrotoluene Using 14C-Labled and Unlabled Comoounds. Technical Report EL-88-, U.S. Army Corps of Engineer Waterways Experiment Station, Vicksburg, Mississippi.

Ryon, M. G., B. C. Pal, S. S. Talamage, and R. H. Ross. 1984. Database Assessment of the Health and Environmental Effects of Munition Production Waste Products. ORNL-6018, Oak Ridge National Laboratory, Oak Ridge, Tennessee.

Schott, C. D., and E. G. Worthley. 1974. The Toxicity of TNT and Related Wastes to an Aquatic Flowering Plant: Lemna perpusilla Torr. Edgewood Arsenal, Technical Report No. EB-TR-74016.

Sikka H. C., S. Banerjee, E. J. Pack, and H. T. Appleton. 1980. Environmental Fate of RDX and TNI. DAMD17-77-C-7026, Syracuse Research Corporation, Syracuse, New York.

Small, M. J., and D. H. Rosenblatt. 1974. Munitions Production Products of Potential Cencern - Phase Il. Technical Report 7404. AD919031, U.S. Army Medical Bioengineering Laboratory, Fort Detrick, Frederick, Maryland.

Smock, L. A., D. L. Stoneburner, and J. R. Clark. 1976. "The Toxic Effects of Trinitrotoluene (TNT) and its Primary Degradation Products on Two Species of Algae and Flathead Minnow." Water Res. 10:534-543.

Spanggord, R. J., T. Mill, T. W. Chou, W. R. Mabey, J. H. Smith, and S. Lee. 1980. Environmental Fate Studies on Certain Munition Wastewater Constituents. Phase II Laboratory Studies. DAMD17-78-C-8081, SRI International, Menlo Park, California.

Spanggord, R. J., B. W. Gibson, R. G. Keck, D. W. Thomas, and J. J. Barkley, Jr. 1982. "Effluent Analysis of Wastewater Generated in the Manufacture of 2,4,6-Trinitrotoluene. 1. Characterization Study." Eviron. Sci. Technol. 16:229-232.

Spanggord, F. J., W. R. Mabey, T. W. Chou, S. Lee, and P. L. Alferness. 1983a. Environmental Fate Studies of HMX. Phase 11 . Detailed Studies. USAMBRDL Report AD-A145122. National Technical Information Service, Springfield, Virginia.

Spanggord, R. J., W. R. Mabey, T. Mill, T. W. Chou, J. H. Smith, S. Lee, and D. Roberts. 1983b. Environmental Fate Studies on Certain Munitions Wastewater Constituents. Phase IV-Lagoon Model Studies. Phase IV. DAMD17 78-C-8081. SRI International, Menlo Park, California.

Spanggord, R. J., T. W. Chou, T. Mill, R.T. Podoll, J.C. Harper, and D. S. Tse. 1985. Environmental Fate of Nitroguanidine. Diethylenealycol Dinitrate, and Hexachloroethane Smoke. Phase I. DAMD17-84-C-4252. SRI International, Menlo Park, California. 
Yang Y., X. Wang, P. Yin, and P. Zhou. 1983. "Three Strains of Corynebacterium Degrading Cyclotrimethylenetrinitroamine." Acta Microbiol. Sin. 23:251-256.

Yinon, J., and D. Hwang. 1984. "Metabolic Studies of Explosives." Biomed. Mass Spectrom. 11:594-600.

Yinon, J. 1989. "Metabolic Studies of Explosives 6. Electron Impact and Chemical Ionization Mass Spectrometry of Metabolites of 2,4-Dinitrotoluene." Biomed. Mass Spectrom. 18:149-156. 
No. of

Copies

OFFSITE

2 DOE/Office of Scientific and Technical Information

25 Commander

U.S. Army Biomedical Research and Development Laboratory

ATTN: SGRD-UBZ-RA

Fort Detrick

Frederick, MD 21707-5010

3 Commander

U. S. Army Medical Research and Development Command

ATTN: SGRD-RMI-S

Fort Detrick

Frederick, MD 21707-5012

1 Dean

School of Medicine

Uniformed Services University of the

Health Sciences

4301 Jones Bridge Road

Bethesda, MD 20814-4799

1 Commandant

Academy of Health Sciences, U.S. Army

ATTN: AHS-CDM

Fort Sam Houston, TX 78234-6100

1 Commander

U.S. Army Material Command

ATTN: AMCEN-A

5001 Eisenhower Avenue

Alexandria, VA 22333-0001
No. of

Copies

ENSITE

DOE Richland Operations Office

41 Pacific Northwest Laboratory

D. A. Cataldo (25)

J.W. Falco

R. J. Fellows

J. M. Hales

P. C. Hays

S. W. Li

M. W. Ligotke

W. T. Pennell

L. E. Rogers

R. L. Skaggs

P. Van Voris

Publishing Coordination

Technical Report Files (5) 
